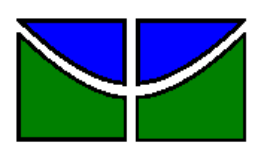

Universidade de Brasília (UnB)

Faculdade de Economia, Administração e Contabilidade (FACE)

Programa de Pós-graduação em Administração (PPGA)

Curso de Mestrado Acadêmico em Administração

\title{
INOVAÇÃO NO SETOR PÚBLICO: Indutores, Capacidades, Tipos e Resultados de Inovação
}

\author{
LEAR VALADARES VIEIRA
}

Brasília - DF

Janeiro de 2016 


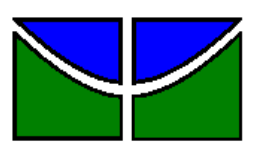

Universidade de Brasília (UnB)

Faculdade de Economia, Administração e Contabilidade (FACE)

Programa de Pós-graduação em Administração (PPGA)

Curso de Mestrado Acadêmico em Administração

INOVAÇÃO NO SETOR PÚBLICO: Indutores, Capacidades, Tipos e Resultados de Inovação

\author{
LEAR VALADARES VIEIRA
}

Orientador: Prof. Dr. Antonio Isidro-Filho

Dissertação de Mestrado

Brasília - DF

Janeiro de 2016 
Vieira, Lear Valadares.

INOVAÇÃO NO SETOR PÚBLICO: Indutores, Capacidades, Tipos e Resultados de Inovação / Lear Valadares Vieira; orientador Antonio IsidroFilho. - Brasília, 2016.

$85 \mathrm{p}$.

Dissertação (Mestrado- Mestrado em Administração) - Universidade de Brasília, 2016.

1. Administração Pública Federal. 2. Inovação em Serviços. 3. Serviços Públicos. 4. Prêmio de Inovação. I. Isidro-Filho, Antonio, orient. II. Título 


\title{
INOVAÇÃO NO SETOR PÚBLICO: Indutores, Capacidades, Tipos e Resultados de Inovação
}

\author{
Dissertação submetida ao Programa de Pós- \\ Graduação em Administração (PPGA) da \\ Universidade de Brasília como requisito à \\ obtenção do grau de Mestre em Administração.
}

Comissão Examinadora:

Prof. Dr. Antonio Isidro-Filho, Universidade de Brasília

Orientador

Prof. Dr. Pedro Luiz Costa Cavalcante, Universidade de Brasília Examinador Interno

Prof. Dr. Cândido Vieira Borges Júnior, Universidade Federal de Goiás Examinador Externo

Prof. Dr. Carlos Denner dos Santos Júnior, Universidade de Brasília Suplente 


\section{RESUMO}

O presente trabalho buscou analisar o efeito de capacidades, indutores e tipos de inovação sobre os resultados de inovação em experiências inovadoras em gestão na Administração Pública Federal. Para tal, foram analisados os relatos dos casos finalistas e premiados no Concurso de Inovação da ENAP entre os anos 1999 e 2014, somando um total de 287 experiências analisadas. Os relatos passaram por uma análise de conteúdo onde as variáveis de interesse do presente estudo - capacidades, indutores, tipos e resultados de inovação - foram codificadas como variáveis binárias representando a presença ou ausência daquela variável no relato. Esta análise de conteúdo se utilizou de uma triangulação de investigadores como ferramenta para aumento da confiabilidade das codificações obtidas. A partir disso, foi possível elaborar modelos de regressão logística para testar as relações entre as variáveis. As relações significativas obtidas demonstram que alguns indutores possuem efeitos positivos sobre a chance de ocorrência de inovações de processo e inovações de comunicação, algumas capacidades aumentam a probabilidade de ocorrência de inovações de produto, inovações organizacionais e inovações de comunicação, mas outras capacidades diminuem a chance de ocorrência de inovações de processo, inovações organizacionais e inovações de comunicação. Também se observou que inovações organizacionais aumentam a chance de presença de melhoria da gestão organizacional, mas diminuem a chance de ocorrência de melhoria na entrega e/ou qualidade dos serviços, assim como inovações de produto diminuem a probabilidade de ocorrência de melhoria do clima organizacional. Esta pesquisa ainda apresenta, a partir dos resultados obtidos e das lacunas teóricas observadas, recomendações para futuros estudos.

Palavras-chave: Administração Pública Federal, Inovação em Serviços, Serviços Públicos, Prêmio de Inovação 


\begin{abstract}
The present research sought to analyse the effect of innovation capabilities, drivers and types on the innovation results in innovative experiences in management on the Federal Public Administration. To do so, the reports of finalists and awarded cases on the ENAP Innovation Contest between 1999 and 2014 were analysed, for a total of 287 analysed experiences. The reports underwent a content analysis in which the variables of interest in this study - innovation capabilities, drivers, types and results - were coded as binary variables representing the presence or absence of that variable on the report. This content analysis used a researcher triangulation as a tool to increase the reliability of the obtained encodings. From this, it was possible to elaborate logistic regression models to test the relationships between variables. The obtained significant relations show that some drivers have positive effects on the chance of occurrence of process innovations and communication innovations, some capabilities raise the probability of occurrence of product innovations, organizational innovations and communication innovations, but other capabilities lower the chance of occurrence of process innovations, organizational innovations and communication innovations. It was also observed that organizational innovations raise the chance of organizational management improvement being present, but lower the chance of occurrence of delivery and/or quality of services improvement, such as product innovation lower the probability of occurrence of organizational climate improvement. This research still presents, from the obtained results and theoretical gaps observed, recommendations for future studies.
\end{abstract}

Keywords: Federal Public Administration, Services Innovation, Public Services, Innovation Prize 


\section{LISTA DE FIGURAS}

Figura 1. Domínios do índice de inovação para o setor público 36

Figura 2. Modelo para inovação em organizações do setor público 37

Figura 3. Modelo para análise da inovação em organizações do setor público 38

Figura 4. Tipologia de coprodução nos níveis individual e organizacional 40

Figura 5. Relações significativas entre capacidades e tipos de inovação 55

Figura 6. Relações significativas entre indutores e tipos de inovação 58

Figura 7. Relações significativas entre capacidades, indutores e inovação de processo 59

Figura 8. Relações significativas entre capacidades, indutores e inovação de comunicação...60

Figura 9. Relações significativas entre tipos e resultados de inovação

Figura 10. Relações significativas entre capacidades, indutores, inovação de produto e melhoria na entrega e/ou qualidade dos serviços.

Figura 11. Relações significativas entre capacidades, indutores, inovação organizacional e melhoria na entrega e/ou qualidade dos serviços

Figura 12. Relações significativas entre capacidades, indutores, inovação de produto e melhoria da gestão organizacional.

Figura 13. Relações significativas entre capacidades, indutores, inovação organizacional e melhoria da gestão organizacional

Figura 14. Relações significativas entre capacidades, indutores, inovação de produto e melhoria do clima organizacional. 


\section{LISTA DE QUADROS}

Quadro 1. Possíveis motivações para inovação nos setores público e privado

Quadro 2. Características dos arquétipos dos setores público e privado e sua possível relação com a propensão e direção das inovações

Quadro 3. Tipologias de inovação para os setores privado e público .26

Quadro 4. Indutores de inovação.

Quadro 5. Capacidades de inovação

Quadro 6. Resultados de inovação 35

Quadro 7. Hipóteses do estudo.... 40

Quadro 8. Frequência de casos por nível de atuação do governo 47

Quadro 9. Frequência de casos por estrutura administrativa. 48

Quadro 10. Frequência de casos por área temática 48

Quadro 11. Frequência de casos por tipo de inovação 49

Quadro 12. Frequência de casos por capacidade de inovação 50

Quadro 13. Frequência de casos por indutor de inovação 51

Quadro 14. Frequência de casos por resultado. 51

Quadro 15. Relações significativas entre capacidades e tipos de inovação 53

Quadro 16. Relações significativas entre indutores e tipos de inovação 56

Quadro 17. Relações significativas entre capacidades, indutores e tipos de inovação 58

Quadro 18. Relações significativas entre tipos e resultados de inovação

Quadro 19. Relações significativas entre capacidades, indutores, tipos e resultados de inovação . .64

Quadro 20. Hipóteses e resultados do estudo. .70-71 


\section{SUMÁRIO}

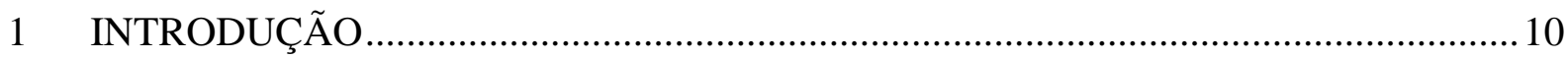

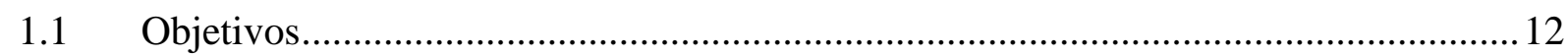

2 REFERENCIAL TEÓRICO .......................................................................................... 14

2.1 Inovação em Serviços Públicos ................................................................................ 14

2.1.1 Tipologias de Inovação em Serviços Públicos …………………………………........24

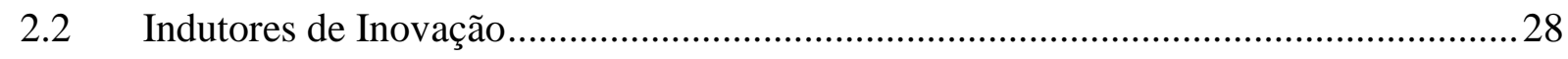

2.3 Capacidades de Inovação …………………………………………………….... 30

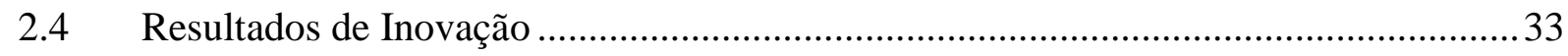

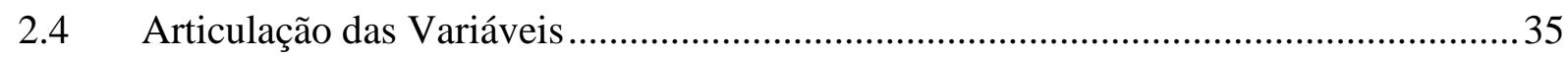

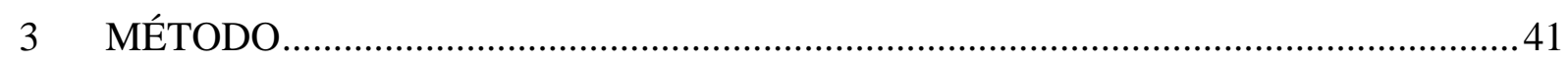

3.1 Caracterização Geral da Pesquisa........................................................................ 41

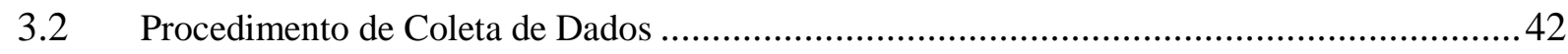

3.2.1 Concurso de Inovação da Escola Nacional de Administração Pública ........................... 44

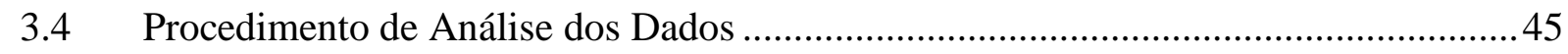

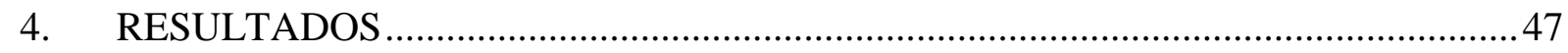

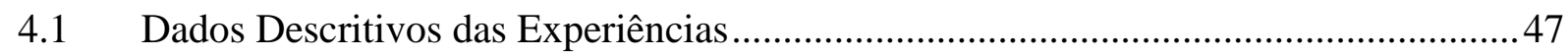

4.2 Dependência em Relação ao Período de Submissão …………………………………...52

4.3 Relações entre Capacidades e Tipos de Inovação ………………………………….....53

4.4 Relações entre Indutores e Tipos de Inovação ……………………………………....56

4.5 Relações entre Capacidades, Indutores e Tipos de Inovação …………………………....58

4.6 Relações entre Tipos e Resultados de Inovação.............................................................61

4.7 Relações entre Capacidades, Indutores, Tipos e Resultados de Inovação ......................63

6. CONCLUSÕES E RECOMENDAÇÕES ................................................................. 70

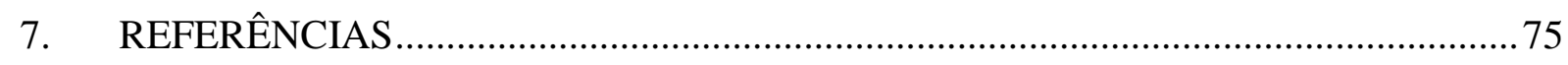

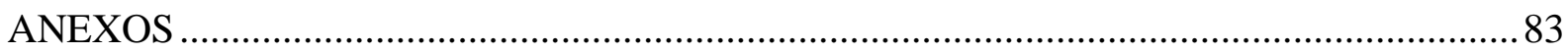

Anexo A - Protocolo para coleta e codificação de informações ................................................ 83

Anexo B - Modelo de tabela para coleta e codificação de informações ......................................85 


\section{INTRODUÇÃO}

Inovação é um tema transversal em pesquisas na área de administração e seu conceito é plural e multifacetado (Resende-Junior \& Guimarães, 2011). No passado, o foco principal dos estudos sobre inovação era sobre os componentes materiais e tecnológicos, tendo em vista a predominância da produção de bens materiais (Gallouj \& Savona, 2009). No entanto, pesquisas recentes começaram a investigar a gestão da inovação em serviços, e, dessa maneira, o tema emergiu como uma importante área de estudo (Menor \& Roth, 2008; Droege, Hildebrand, \& Forcada, 2009; Djellal, Gallouj, \& Miles, 2013). O novo foco se deu em função da crescente importância atribuída aos serviços em função de sua participação na riqueza e emprego nas economias desenvolvidas (Gallouj, 2002), levando a inovação em serviços a se tornar objeto de pesquisas institucionais em diversos países e comunidades internacionais (Bitner \& Brown, 2008; Yen et al., 2012).

Neste contexto, observa-se que a literatura acerca de serviços públicos ainda não está completamente inserida nas principais correntes de pesquisa sobre inovação em serviços (Djellal et al., 2013) e ainda é escassa de estudos empíricos (Resende-Junior \& Guimarães, 2011; Gallouj \& Zanfei, 2013). As atividades do setor público podem ser vistas enquanto serviços, visto que envolvem a prestação de atividades de direito e ordem, transporte, saúde, educação, serviços sociais entre outros (Potts, 2009). Em anos recentes, a inovação no setor público tem sido vista crescentemente como fator central para sustentar um alto nível de serviços para cidadãos e negócios, bem como enfrentar desafios sociais e aprimorar o bem-estar social. A inovação no setor público pode ter um efeito considerável não somente na qualidade e eficiência dos próprios serviços públicos, mas também pode influenciar a habilidade de inovar do setor privado (Bloch, 2011). A efetividade de governos e serviços públicos depende de inovações para aumentar a capacidade de resposta dos serviços para necessidades locais e individuais, e acompanhar necessidades e expectativas públicas (Mulgan \& Albury, 2003). Um setor público inovador que oferece serviços de qualidade age para aprimorar as relações entre o governo e os cidadãos (Bloch, 2011). A inovação no setor público, então, pode aprimorar o entendimento e legitimidade de como os serviços públicos funcionam (Vigoda-Gadot et al, 2008).

Apesar da relevância da inovação para os serviços públicos, há ainda escassez de trabalhos, em especial empíricos, que discutam este tema em profundidade. Além dos serviços públicos funcionarem como monopólios livres de pressão competitiva, devido à sua 
característica de não-mercado (Koch \& Hauknes, 2005), diversas outras razões são colocadas para a dificuldade de tratar da inovação neste setor. Djellal et al. (2013) elencam que estes serviços estão sobre influência política, o que os coloca na margem da racionalidade econômica da inovação e, ainda pior, em algumas circunstâncias essa influência é associada à clientelismo e corrupção, fenômenos geralmente não discutidos na literatura geral de serviços. Os autores também afiram que o setor público sofre uma falta de recursos para serem destinados a projetos de inovação de alto risco, e mesmo para incentivo a inovadores e empreendedores internos. Por fim, Djellal et al. (2013) ainda colocam que há pouca pressão dos consumidores, ou cidadãos, sobre os serviços, ou que esta pressão é dispersa pelas estruturas burocráticas que induzem inércia no setor público. Dadas estas barreiras, entre outros motivos, a literatura teórica que foca especificamente na inovação no setor público ainda é limitada (Mulgan \& Albury, 2003; Bommert, 2010; Bloch \& Bugge, 2013). Adicionalmente, boa parte dos trabalhos existentes não são baseados em pesquisas empíricas (Bloch \& Bugge, 2013).

De forma oposta, alguns argumentos a favor do crescimento do campo de estudos sobre a inovação em serviços públicos podem ser levantados. Djellal et al. (2013) elencam alguns desses argumentos. Primeiramente, é paradoxal acreditar que as administrações públicas são ambivalentes no sentido de querer apoiar a inovação, mas ignorar a inovação para seu próprio benefício. Um exemplo dado pelos autores é a crescente atividade em torno do e-government, as plataformas eletrônicas de acesso a serviços governamentais, que indicam que os regimes governamentais têm uma intenção clara de usar novas tecnologias para aprimorar seus processos internos e suas relações com os cidadãos. Neste ponto, é discutido se uma administração pública que inova para si mesmo consegue melhor suportar a inovação para outros agentes econômicos, numa perspectiva que se aproxima à abordagem de inversão da inovação proposta por Gallouj (2010). Segundo, existem alguns setores específicos dentro dos serviços públicos cuja inovação é indiscutível e bem documentada, mas nem sempre em estudos científicos sobre inovação, entre eles as universidades públicas e os serviços de saúde (Rosenberg \& Nelson, 1994; Djellal \& Gallouj, 2007). O terceiro argumento refere-se à diminuição da clareza das fronteiras entre serviços públicos e privados, havendo, em alguns casos, competição entre serviços dos dois setores. Isso poderia, por exemplo, limitar a falta de competitividade do setor público enquanto barreira para a inovação. Por fim, as crises econômicas e demográficas são colocadas como fatores importantes para a inovação nos serviços públicos, dado que levam a pressões por parte da sociedade.

Mulgan e Albury (2003) também levantam alguns motivos pelos quais é importante inovar no setor público e, consequentemente, porque este é um campo frutífero para pesquisas. 
Inicialmente, os autores afirmam que a inovação deve ser vista como uma atividade central para aumentar a capacidade de resposta dos serviços para necessidades locais e individuais e para acompanhar necessidades e expectativas públicas. A inovação nos serviços públicos também é importante para conter pressões de custo e aumentar a eficiência dos serviços, dado que, sem inovação, os custos dos serviços públicos tendem a crescer mais rápido do que no restante da economia e, sem inovação, a única maneira de conter custos é forçar os funcionários públicos a produzirem mais.

De modo a aprimorar o conhecimento e entendimento da inovação em serviços públicos, assim como seus incentivos, processos e impactos, existe uma atenção crescente à necessidade de informações mais sistemáticas sobre a inovação no setor público (Koch, Cunningham, Schwabsky, \& Hauknes, 2006; Bloch, 2011). Para entender e apoiar a inovação em serviços públicos, um conhecimento preciso dos fatores que influenciam o desempenho de inovação em organizações públicas se torna um requisito (Bloch, Jorgensen, Norn, \& Vad, 2009). Neste sentido, diversas iniciativas internacionais têm buscado desenvolver um entendimento mais holístico da inovação no setor público (Innovation Unit, 2009; APSII, 2011; Bloch, 2011; Hughes et al., 2011), discutindo aspectos referentes à própria inovação, tais como tipos, atividades e práticas de inovação, mas também características sistêmicas, ambientais e contextuais que afetam a inovação, tais como capacidades, indutores, barreiras e facilitadores de inovações. O presente trabalho reflete este esforço de investigação acerca da inovação nos serviços públicos, buscando explorar lacunas de pesquisa nos seguintes temas: a) capacidades de inovação; b) indutores de inovação; c) tipos de inovação; e d) resultados de inovação.

Portanto, a presente pesquisa fundamenta-se ao redor da seguinte pergunta de pesquisa: qual o efeito da presença de capacidades, indutores e tipos de inovação sobre a probabilidade de ocorrência de resultados de inovação em experiências inovadoras em gestão na Administração Pública Federal?

\subsection{Objetivos}

O objetivo geral desta pesquisa é analisar o efeito da presença de capacidades, indutores e tipos de inovação sobre a probabilidade de ocorrência de resultados de inovação em experiências inovadoras em gestão na Administração Pública Federal. Para tal, são delineados os seguintes objetivos específicos: 
a. Detectar a ocorrência de capacidades, indutores, tipos e resultados de inovação nas experiências selecionadas;

b. Identificar capacidades e indutores de inovação que afetam a probabilidade de ocorrência de tipos de inovação;

c. Identificar os tipos de inovação que afetam a probabilidade de ocorrência de resultados de inovação;

d. Investigar a relação entre capacidades, indutores, tipos e resultados de inovação. 


\section{REFERENCIAL TEÓRICO}

\subsection{Inovação em Serviços Públicos}

A inovação no setor público tem como uma de suas definições a criação e implementação de novos processos, produtos, serviços e métodos de entrega de serviços que resultem em uma melhoria significativa de eficiência, efetividade e eficácia de resultados (Mulgan \& Albury, 2003). A inovação é uma ferramenta para atingir os propósitos do serviço público, e, para que a inovação ocorra efetivamente, uma relação sinérgica entre liderança, gestão, recursos humanos e tecnologia deve existir (Anggadwita \& Dhewanto, 2013). Neste sentido, a implementação de inovações no setor público oferece oportunidades consideráveis para o crescimento econômico e para atrair investidores (Avlonitis, Papastathopoulou, \& Gounaris, 2001).

Em um esforço inicial para definir a inovação em organizações de serviços públicos, Koch e Hauknes (2005) sugerem o conceito de inovação enquanto implementação e desempenho, por uma entidade social, de uma nova forma ou repertório específico de ações sociais que é implementado deliberadamente no contexto dos objetivos e funcionalidades desta entidade. Para os autores, a inovação no setor público está relacionada aos produtos gerados por este setor. Estes produtos, ou bens públicos, são bens socioeconômicos não-exclusivos e não-rivais. Nesta definição, exclusividade refere-se à oportunidade de expressar direitos de propriedade sobre um bem. Deste modo, um proprietário com um item perfeitamente exclusivo poderia excluir, sem qualquer custo, outros usuários de terem acesso ao bem. Rivalidade define que o bem só pode ser utilizado um por vez, ou quando é consumido por um grupo de consumidores não pode ser consumido por outro. Dada a ausência dessas duas características nos bens públicos, implica-se que é impossível configurar um mercado competitivo para bens públicos, sendo esta uma das principais barreiras para a inovação no setor público.

Dada a escassez de trabalhos específicos nesta área, alguns conceitos derivados de outras correntes da teoria da inovação podem ser úteis para o entendimento da inovação no setor público (Koch \& Hauknes, 2005). Três áreas são importantes para formar um entendimento de como o setor público inova, de acordo com Bloch e Bugge (2013): a natureza dos serviços públicos, o contexto no qual as organizações públicas operam e as interfaces com outros atores dentro e além do setor público. Essas áreas também são importantes para auxiliar na exploração do que Osborne e Brown (2013) denominam das três falhas que limitam o 
entendimento da inovação no setor público: um entendimento falho sobre a natureza da inovação, o posicionamento da inovação como um bem normativo na política pública e resultante de políticas prescritivas, e a adoção de um modelo inapropriado de inovação da manufatura e não dos serviços. Bloch e Bugge (2013) se baseiam em três correntes para explorar os aspectos teóricos importantes para a inovação em serviços públicos: inovação em serviços, sistemas de inovação e adaptação de conceitos do setor privado para o público.

Nesta última corrente pode-se apresentar, inicialmente, o conceito presente no Manual de Oslo (OECD, 2005), onde a inovação é definida como a implementação de um produto, bem ou serviço, ou processo novo ou significativamente melhorado, um novo método de marketing, ou um novo método organizacional de práticas de negócio, organização do ambiente de trabalho ou de relações externas. Nesta definição, a inovação é a introdução de algo novo e útil, sendo as noções de "novo" e "útil" interpretadas como específicas ao contexto e às organizações, ao invés de serem universais. Percebe-se, adicionalmente, que neste contexto não apenas inovações radicais, aquelas que são novas para a sociedade, são consideradas, mas também o uso de práticas e tecnologias novas para uma organização específica, ou inovações incrementais. O Manual de Oslo (OECD, 2005) utiliza os conceitos de "novo para o mundo" e "novo para o mercado" para diferenciar estes níveis de novidade da inovação. Um conceito alternativo poderia ser "novo para o setor" onde a organização opera. No entanto, tanto os termos "mercado" quanto "setor" são difíceis de definir para muitas organizações públicas, visto que várias se percebem como operadores únicos dentro de sua área de atuação. De modo a evitar o problema de conceituação deste termo, Bloch (2011) utiliza os dois níveis de novidade em inovações, radical e incremental, sem um grupo de referência específico, sendo eles respectivamente: o primeiro a desenvolver e introduzir a inovação, e a inovação já introduzida por outros, mas nova para a organização. Como uma inovação pode ser radical ou incremental, em certos casos pode se tornar difícil distinguir entre inovação e reforma. De acordo com Windrum (2008) há uma miopia disciplinar entre os estudos de inovação e de ciências políticas, sendo os primeiros focados na inovação no setor privado, e os últimos percebendo a mudança no setor público como mudança política ou reforma, mas sem endereçar a inovação.

A definição da OECD (2005) pode servir para algumas partes do setor público, mas certos aspectos da definição podem ser mais problemáticos para outras partes. Por exemplo, a noção de melhoria pode ser elusiva em certos contextos do setor público, visto que a avaliação de melhoria pode ser contextual e depende da perspectiva das respectivas partes interessadas. Enquanto empresas no setor privado operam com um objetivo principal, organizações públicas contam com uma multiplicidade de objetivos, como aumentar qualidade, equidade e eficiência 
de seus serviços (Bugge et al., 2010). No entanto, da mesma forma que os estudos de inovação em serviços privados primeiramente utilizaram ferramentas e conceitos inicialmente gerados e baseados em estudos em empresas manufatureiras, é natural que o estudo da inovação no setor público se utilize de teorias e conceitos desenvolvidos em estudos de inovação do setor privado (Windrum, 2008). Neste ponto duas principais questões são apontadas por Bugge et al. (2010): quão diferente é a inovação no setor público da inovação no setor privado, e a inovação nos dois setores é comparável?

Os incentivos de gestão servem como um exemplo de como o setor privado e o público podem diferir. Gestores públicos, em geral, tem maior probabilidade de receber menos e menores benefícios baseados no desempenho, o que pode influenciar sua iniciativa em tomar riscos. Pode-se também considerar que o setor público, em um nível agregado, recruta menos empreendedores e tomadores de risco que o setor privado, devido a expectativas de recompensas ou penalidades da atividade empreendedora. A aversão ao risco no setor público também pode estar conectada a orçamentos limitadores e responsabilidade em relação aos contribuintes (Bugge et al., 2010).

Dentre estas motivações, uma diferença-chave que pode ser identificada é que organizações do setor público não operam em um modelo baseado no mercado e, assim, não são motivadas por objetivos relacionados a lucro ou competitividade. Por mais que isto seja, na maioria dos casos, verdade, pode-se argumentar, por um lado, que isto reflete uma visão muito simplista dos negócios privados, visto que suas estruturas de incentivo são formadas por muito mais do que a maximização de lucro. Por outro lado, enquanto organizações do setor público podem não procurar a maximização de lucro, elas são orientadas a objetivos, e há consequências negativas se esses objetivos não são atingidos (Bugge et al., 2010). Outras dissimilaridades de motivação para inovação entre os setores público e privado são apontadas por Halvorsen, Hauknes, Miles e Roste (2005), conforme apresentado no Quadro 1. 


\begin{tabular}{|c|c|}
\hline $\begin{array}{c}\text { Motivações para inovação no setor público } \\
\text { (Indivíduos) }\end{array}$ & $\begin{array}{c}\text { Motivações para inovação no setor privado } \\
\text { (Indivíduos) }\end{array}$ \\
\hline $\begin{array}{ll}\text { - } & \text { Prestígio } \\
\text { - } & \text { Autorrealização } \\
\text { - } & \text { Reconhecimento profissional } \\
\text { - } & \text { Potencial para criação de outros negócios a } \\
& \text { partir da inovação } \\
\text { - } & \text { Idealismo } \\
\text { - } & \text { Carreira } \\
\text { - } & \text { Poder } \\
\text { - } & \text { Dinheiro (salário) } \\
\end{array}$ & $\begin{array}{ll}\text { - } & \text { Prestígio } \\
\text { - } & \text { Autorrealização } \\
\text { - } & \text { Idealismo } \\
\text { - } & \text { Carreira } \\
\text { - } & \text { Poder } \\
\text { - } & \text { Dinheiro (salário, lucros, bônus) } \\
\text { - Segurança no emprego a partir de maior } & \text { competitividade e lucratividade da empresa } \\
\text { - } & \text { Requisito imposto }\end{array}$ \\
\hline $\begin{array}{c}\text { Motivações para inovação no setor público } \\
\text { (Organizações) }\end{array}$ & $\begin{array}{c}\text { Motivações para inovação no setor privado } \\
\text { (Organizações) }\end{array}$ \\
\hline $\begin{array}{ll}\text { - } & \text { Solução de problemas (para atingir objetivos) } \\
\text { - } & \text { Maior orçamento } \\
\text { - } & \text { Propagação de uma política, ideia ou } \\
& \text { racionalidade } \\
\text { - } & \text { Mais servidores } \\
\text { - } & \text { Relações públicas } \\
\end{array}$ & $\begin{array}{ll}\text { - } & \text { Solução de problemas (para atingir objetivos) } \\
\text { - } & \text { Lucros } \\
\text { - } & \text { Participação no mercado } \\
\text { - } & \text { Competitividade } \\
\text { - } & \text { Crescimento (em tamanho) } \\
\text { - } & \text { Relações públicas } \\
\end{array}$ \\
\hline
\end{tabular}

Quadro 1. Possíveis motivações para inovação nos setores público e privado

Fonte: Adaptado de Halvorsen et al. (2005) e Koch e Hauknes (2005)

Halvorsen et al. (2005) argumentam de modo similar que as diferenças da inovação nos setores público e privado são menos distintas e com mais nuances do que visões simplistas poderiam implicar. Isto é relevante para a comparação da inovação nos dois setores e para responder se ferramentas completamente diferentes são necessárias para a análise da inovação no setor público. O Quadro 2 apresenta as principais diferenças entre os setores privado e público que podem ser relevantes para a inovação.

\begin{tabular}{|c|c|c|}
\hline & Setor Privado & Setor Público \\
\hline $\begin{array}{c}\text { Princípios } \\
\text { Organizacionais }\end{array}$ & $\begin{array}{l}\text { Busca do lucro, da estabilidade ou do } \\
\text { crescimento de receitas }\end{array}$ & Execução de políticas públicas \\
\hline $\begin{array}{c}\text { Estruturas } \\
\text { Organizacionais }\end{array}$ & $\begin{array}{l}\text { Firmas de vários tamanhos, com opções } \\
\text { para novos entrantes }\end{array}$ & $\begin{array}{l}\text { Sistema complexo de organizações com } \\
\text { várias tarefas, às vezes conflitantes }\end{array}$ \\
\hline $\begin{array}{l}\text { Métricas de } \\
\text { Desempenho }\end{array}$ & Retorno sobre investimento & $\begin{array}{l}\text { Múltiplos indicadores e objetivos de } \\
\text { desempenho }\end{array}$ \\
\hline $\begin{array}{l}\text { Questões de } \\
\text { Gestão }\end{array}$ & $\begin{array}{l}\text { Alguns gestores têm autonomia } \\
\text { considerável, outros são restringidos por } \\
\text { acionistas, governança corporativa ou } \\
\text { dificuldades financeiras. Gestores de } \\
\text { sucesso são passíveis de recompensas com } \\
\text { benefícios materiais substanciais e } \\
\text { promoções }\end{array}$ & $\begin{array}{l}\text { Enquanto existem esforços de emular as } \\
\text { práticas de gestão do setor privado, os } \\
\text { gestores tipicamente estão sob altos níveis de } \\
\text { escrutínio político. Gestores de sucesso } \\
\text { normalmente recebem menos benefícios } \\
\text { materiais se comparados a gestores do setor } \\
\text { privado }\end{array}$ \\
\hline $\begin{array}{c}\text { Relações com } \\
\text { Usuários Finais }\end{array}$ & $\begin{array}{l}\text { Mercados podem ser consumidores ou } \\
\text { indústrias, e as firmas variam na intimidade } \\
\text { das conexões com os usuários finais de } \\
\text { seus produtos, mas normalmente o } \\
\text { feedback do mercado fornece o veredito da } \\
\text { inovação }\end{array}$ & $\begin{array}{l}\text { Os usuários finais são o público em geral, } \\
\text { tradicionalmente vistos como cidadãos, } \\
\text { apesar de recentemente ter havido esforços } \\
\text { para introduzir princípios de mercado e vê- } \\
\text { los como consumidores ou clientes }\end{array}$ \\
\hline $\begin{array}{l}\text { Relações com } \\
\text { Cadeias de } \\
\text { Suprimentos }\end{array}$ & $\begin{array}{l}\text { A maior parte das firmas são parte de uma } \\
\text { ou mais cadeias de suprimentos, com } \\
\text { grandes firmas tendendo a organizar essas } \\
\text { cadeias }\end{array}$ & $\begin{array}{l}\text { O setor público é tipicamente dependente de } \\
\text { fornecedores privados para a maior parte dos } \\
\text { seus equipamentos, e é um mercado muito } \\
\text { importante para diversas firmas }\end{array}$ \\
\hline
\end{tabular}




\begin{tabular}{|c|c|c|}
\hline $\begin{array}{l}\text { Relações com } \\
\text { Empregados }\end{array}$ & $\begin{array}{l}\text { A natureza da força de trabalho varia } \\
\text { consideravelmente, e as relações entre os } \\
\text { empregados e a gestão varia de harmoniosa } \\
\text { a conflitante. Esforços são tomados em } \\
\text { algumas firmas para gerar lealdade à } \\
\text { empresa e/ou uma abordagem centrada no } \\
\text { consumidor, mas as motivações dos } \\
\text { empregados são normalmente de cunho } \\
\text { econômico }\end{array}$ & $\begin{array}{l}\text { Os empregados do setor público são } \\
\text { tipicamente altamente sindicalizados. Muitos } \\
\text { são também trabalhadores profissionais } \\
\text { organizados através de associações } \\
\text { profissionais. Enquanto preocupações usuais } \\
\text { acerca de status e salários são aparentes, } \\
\text { muitos trabalhadores ingressam no serviço } \\
\text { público com motivações idealísticas }\end{array}$ \\
\hline $\begin{array}{l}\text { Relações com } \\
\text { Fontes de } \\
\text { Conhecimento }\end{array}$ & $\begin{array}{l}\text { As empresas têm flexibilidade } \\
\text { considerável para procurar informações } \\
\text { relacionadas à inovação de consultores, } \\
\text { associações de comércio e pesquisadores } \\
\text { do setor público, mas muitas firmas } \\
\text { menores têm recursos limitados para isso }\end{array}$ & $\begin{array}{l}\text { Apesar de muitos recursos, partes do setor } \\
\text { público podem ser restringidas de usar fontes } \\
\text { de conhecimento privado. As fontes de } \\
\text { conhecimento do setor público podem ser } \\
\text { altamente orientadas para outras partes do } \\
\text { setor público }\end{array}$ \\
\hline $\begin{array}{r}\text { Horiz } \\
\text { Te }\end{array}$ & $\begin{array}{l}\text { Curto prazo em vários setores, apesar de } \\
\text { serviços de utilidades e infraestrutura } \\
\text { podem ter horizontes de tempo longos }\end{array}$ & $\begin{array}{l}\text { Normalmente, longo prazo, apesar de muitas } \\
\text { decisões serem feitas para o curto prazo }\end{array}$ \\
\hline
\end{tabular}

Quadro 2. Características dos arquétipos dos setores público e privado e sua possível relação com a propensão e direção das inovações

Fonte: Adaptado de Halvorsen et al. (2005)

Quando analisando a questão sobre como a inovação no setor público se compara à inovação no setor privado, Bugge et al. (2010) sugerem recuperar discussões similares sobre a comparabilidade da manufatura aos serviços. Três principais abordagens acerca da inovação em serviços podem ser encontradas na literatura: assimilação, demarcação e integração (Coombs \& Miles, 2000; Djellal e Gallouj, 2000; Drejer, 2004; Bloch et al., 2008). Uma quarta abordagem, a de inversão, foi proposta por Gallouj (2010) e posteriormente recuperada para a discussão de inovação nos serviços públicos por Djellal et al. (2013).

A perspectiva de assimilação estuda a inovação em serviços como sendo essencialmente a mesma inovação estudada em indústrias manufatureiras, dando foco na relação da inovação com os sistemas tecnológicos. Essa ênfase permite considerar esta abordagem como sendo uma ótica tecnicista, onde a inovação nos serviços é fruto da adoção de sistemas tecnológicos inovadores (Djellal et al., 2013). Droege et al. (2009) consideram que as perspectivas de assimilação e tecnicista constituem abordagens diferentes, apontando que alguns autores utilizam a segmentação tecnicista-demarcação-integração (Gallouj, 1998; Sundbo, OrfilaSintes, \& Sorensen, 2007), enquanto outros utilizam a segmentação assimilação-demarcaçãointegração (Coombs \& Miles, 2000; Drejer, 2004; DeVries, 2006). No entanto, Djellal et al. (2013) demonstram que, independente do rótulo utilizado, essas perspectivas apresentam uma visão de subordinação dos serviços à tecnologia e, consequentemente, à inovação na manufatura. Bugge et al. (2013) ainda afirmam que a assimilação reflete uma visão passiva, e antiquada, das organizações de serviço como adotantes de tecnologias, e não fontes de novo conhecimento e tecnologia. 
A literatura acerca da introdução de novas tecnologias em organizações públicas reflete bem o quadro analítico da perspectiva assimiladora. A inserção de computadores no serviço público, por exemplo, objetivou um aumento de produtividade e eficiência por meio de mainframes que permitissem processar grandes quantidades de números e dados (Djellal et al., 2013). Uma questão importante na introdução de novas tecnologias e os serviços públicos é a divisão digital, que pode ser colocada como a ideia que um desequilíbrio social pode ser ampliado pelo diferente acesso a novas tecnologias em diferentes regiões, classes sociais e gerações. Isso pode afetar as missões específicas do setor público que pode estar preocupado acerca de acesso diferenciado a, por exemplo, serviços online, e pode procurar diminuir a divisão digital por meio da educação e instalações públicas. Neste último ponto é possível observar inovações sociais, como o acesso aberto a meios eletrônicos para a população (Djellal et al., 2013).

Uma outra aplicação da perspectiva assimiladora para análise da inovação nos serviços públicos é o modelo do ciclo reverso de Barras (1986, 1990). Essa abordagem foi construída envolvendo não somente serviços de mercado, mas também serviços públicos, em especial serviços de governos locais. Djellal et al. (2013) descrevem o processo de informatização do setor público sob esta ótica. A primeira onda de informatização, a introdução de mainframes, resultou em inovações incrementais de processos nas áreas de suporte, para aumentar eficiência e velocidade e, mais importante, para diminuir custos. A segunda onda, caracterizada pela adoção de microcomputadores, resultou em inovações mais radicais de processo, envolvendo as áreas-fim das administrações públicas. Essas inovações tinham o objetivo de aumentar a efetividade e qualidade dos serviços. Outras ondas de informatização que acompanharam o desenvolvimento tecnológico dos computadores foram utilizadas para gerar aprimoramentos, sendo talvez mais visível o uso de redes para e-mail, acesso à informação e serviços interativos. Apesar de útil para explicar certas inovações no setor público, a abordagem de Barras (1986, 1990) possui limitações que vão além do privilégio dado a inovações tecnológicas. Por exemplo, o estudo de Uchupalanan (2000) conclui que inovações tecnológicas em serviços podem seguir diversas trajetórias, sendo o ciclo reverso somente uma dessas trajetórias, e uma bastante incomum. Isso é especialmente relevante para serviços públicos, onde as inovações podem surgir de fatores diversos, como no caso da difusão do e-government ao redor do mundo, que foi causado mais por formuladores de políticas procurando imitar ou superar inovações realizadas em outros lugares do que por descobertas de novas tecnologias por parte da administração pública (Djellal et al., 2013). 
Os estudos de padrões setoriais de inovação tecnológica, baseados na taxonomia de Pavitt (1984), também representam uma abordagem assimiladora utilizada para o estudo de inovações no setor público. A maior parte das pesquisas, no entanto, foca somente no setor privado, como no caso de Hipp e Grupp (2005). Em outros, como Soete e Miozzo (1989), o setor público é encaixado em uma outra categoria, a guiada por fornecedores, sem diferenciação entre os setores. No entanto, devido às dissimilaridades entre os setores público e privado, conforme apontado, entre outros, por Halvorsen et al. (2005) e Koch e Hauknes (2005), tornase implausível ver os serviços públicos dentro de uma grande categoria de empresas guiadas por fornecedor. Ainda assim, não é claro se é necessário criar novos padrões para os serviços públicos nos sistemas de classificação, ou se é possível categorizar melhor os serviços públicos nas classificações já existentes.

A utilização da perspectiva assimiladora tem sido limitada e diminuída de diversas formas, principalmente nas pesquisas mais recentes. Djellal et al. (2013) elencam duas principais formas para isso. A primeira pode ser chamada de autonomização, nos quais as organizações de serviço são cada vez menos vistas como subordinadas de inovações industriais. Desse modo, algumas organizações de serviço, e nestas estão incluídas organizações que prestam serviços públicos, não são mais vistas apenas como adotantes passivos de tecnologias produzidas em outros lugares. Em alguns casos, elas podem produzir algumas dessas tecnologias por conta própria, mas, mais importante, podem reverter a relação de poder exercendo uma influência decisiva sobre fornecedores industriais e, efetivamente, direcionar as trajetórias de inovação tecnológica. A segunda forma de afrouxamento pode ser chamada de endogenização da inovação tecnológica, que tem, possivelmente, o maior efeito nas indústrias de serviço e nos serviços públicos. A introdução de tecnologias em todos os níveis das organizações de serviço está possibilitando a mudança na natureza dos produtos, sendo que os serviços e a inovação em serviços aparecem de forma crescente como categorias híbridas que combinam tecnologias tangíveis e intangíveis e engenharia organizacional, ou seja, o desenvolvimento de formas organizacionais, não trabalhando somente sob uma ótica de inovação tecnológicas, mas das inovações organizacionais que as acompanham.

De forma oposta à perspectiva de assimilação, a abordagem de demarcação, também denominada de diferenciação ou baseada em serviços, foca nas especificidades dos serviços, explorando as diferentes formas que a inovação pode tomar e a organização distinta dos processos de inovação nas indústrias de serviços (Djellal et al., 2013). Dada a ênfase nas características específicas dos serviços, a abordagem de demarcação tem dificuldade em reutilizar o conhecimento gerado nos estudos de inovação na manufatura (Droege et al., 2009), 
e é uma abordagem diretamente oposta à perspectiva de assimilação. Esta perspectiva pode ser relacionada às pesquisas autônomas de inovação em serviços (Djellal \& Gallouj, 2001; Drejer, 2004). Duas características são vistas como as que levam a essa diferenciação, sendo estas observadas tanto nos serviços privados quanto públicos (Djellal et al., 2013). A primeira se trata da intangibilidade. O produto do serviço não é um artefato tangível, mas um estado de mudança (Hill, 1977). Dada esta característica, torna-se difícil perceber a distinção clássica entre inovação de produto, inovação de processo e inovação organizacional. Também é difícil proteger inovações intangíveis utilizando mecanismos de propriedade intelectual como patentes, e vários tipos de serviço são facilmente imitados. Por fim, a intangibilidade torna mais difícil avaliar o impacto dos resultados de uma inovação, visto que as fronteiras de um serviço não são sempre bem definidas (Djellal et al., 2013). A segunda característica, a interatividade, significa que o consumidor ou usuário do serviço está envolvido na produção do serviço. Essa coprodução, como é chamado esse processo interativo, impacta as inovações possíveis de serem implementadas no serviço. Essas duas características se aplicam tanto a serviços públicos quanto privados, sendo possível ainda considerar que os serviços públicos possuem suas próprias singularidades, podendo-se aplicar uma dupla diferenciação. As características específicas dos serviços públicos apresentadas nos Quadros 1 e 2 demonstram parte dessas singularidades.

Entre tipologias recentes sobre inovação em serviços públicos, é possível perceber algumas formas específicas de inovação ligadas ao setor público. Halvorsen et al. (2005) lista as inovações administrativas, por exemplo, o uso de um novo instrumento político que pode ser resultado de uma mudança política; inovações de sistema, que são um novo sistema ou uma mudança fundamental de um sistema existente, por exemplo, pelo estabelecimento de novas organizações ou novos padrões de cooperação e interação; inovações conceituais, que são uma mudança na visão geral dos atores, acompanhadas de mudanças de conceitos de gestão ou do próprio serviço; e mudanças radicais de racionalidade, que envolvem mudanças de visão de mundo ou de matriz mental dos empregados de uma organização em mudança. Hartley (2005) cita inovações de posicionamento, envolvendo novos contextos, consumidores ou parceiros para os serviços; estratégia, como novos objetivos, propósitos ou valores; governança, por exemplo, novas instituições democráticas s formas de participação; e retórica, onde novas linguagens, conceitos e definições são aplicados.

A perspectiva de demarcação também pode ser observada em estudos acerca de indicadores de inovação nos serviços públicos. Indicadores desenvolvidos para subsetores dos serviços públicos, como o setor de saúde (Djellal \& Gallouj, 2005) podem ser distinguidos de 
indicadores gerais de inovação, como aqueles propostos pela OECD (2005). Djellal et al. (2013) descrevem que, em 2010, a Comissão Europeia anunciou sua intenção de formar um Placar de Inovação no Setor Público Europeu. Em uma pesquisa com mais de 4000 organizações do serviço público em toda a Europa, confirmou-se a existência de resultados significativos para a inovação no continente: (1) dois terços dos serviços públicos pesquisados introduziram ou aprimoraram significativamente o serviço durante os três anos considerados na pesquisa; (2) a probabilidade de inovação aumenta quanto maior o tamanho da instituição; (3) o maior instigador de inovação é a introdução de novas leis e regulamentos, seguido por novas prioridades políticas e iniciativas de e-government; e (4), o principal modo de inovação é de cima para baixo ao invés de baixo para cima.

A abordagem de inversão, inicialmente proposta por Gallouj (2010), representa um contraste aos estudos que retratam as indústrias de serviço como setores retardatários ou residuais, identificando certas indústrias de serviços como sendo fontes de inovação para toda uma economia. Esse papel pode ser ocupado por grandes empresas que mobilizam seus fornecedores, mas normalmente essa perspectiva enfatiza o papel ativo de Serviços Intensivos em Conhecimento (KIBS - Knowledge-Intensive Business Services) nas inovações de outros setores, tais como consultorias, empresas de engenharia, tecnologia da informação e pesquisa e desenvolvimento, que podem fornecer insumos importantes para a inovação dos seus clientes (Djellal et al., 2013). Ressalta-se que esta abordagem somente é utilizada nas classificações de Gallouj (2010) e Djellal et al. (2013), sendo que, pelas características apresentadas, é possível considerá-la como um subtipo da perspectiva de demarcação, podendo este ser um dos motivos pelo qual a abordagem de inversão não é apresentada em outras classificações. Nesta perspectiva, Djellal et al. (2013) apresentam quatro visões de como os serviços públicos afetam as inovações em outros atores econômicos:

- Serviços públicos apoiando a inovação em outras atividades econômicas;

- Serviços públicos como instigadores da inovação em outras atividades como consumidor e usuário desta inovação;

- Serviços públicos passivamente fornecendo informações relacionadas à inovação para o setor privado;

- Serviços como coprodutores de inovação com o setor privado.

Por fim, a perspectiva integradora, ou de síntese, busca desenvolver quadros analíticos que sejam úteis para o estudo da inovação tanto em serviços quanto na produção de bens, 
considerando tanto inovações tecnológicas quanto não-tecnológicas (Djellal et al., 2013). Droege et al. (2009) apontam que esta corrente surgiu, em parte, pela aceitação que os estudos em inovação em serviços, inicialmente abordados na perspectiva de demarcação, trazem atenção a elementos importantes que haviam sido negligenciados por estudos de inovação de produtos na manufatura (Drejer, 2004). Esta abordagem é vista, atualmente, como a mais promissora em termos de avanços teóricos, dado que as fronteiras entre bens e serviços se tornam cada vez mais turvas (Gallouj \& Savona, 2009). O modelo baseado em características (Gallouj \& Weinstein, 1997), considerado um dos mais expoentes e importantes em termos de contribuição para a construção de uma teoria de inovação em serviços na abordagem integradora, foi aprimorado ao longo dos anos, e, em alguns casos, com o objetivo explícito de melhor refletir os serviços públicos. Windrum e Garcia-Goni (2008), por exemplo, sugerem incluir o governo no modelo e desenvolver um modelo de múltiplos agentes. Este quadro analítico tem sido aplicado em vários serviços públicos, e nessa representação a inovação é vista em termos das mudanças geradas nas características dos serviços (Djellal et al., 2013). Bugge et al. (2010) consideram ainda que a terceira edição do Manual de Oslo (OECD, 2005) pode ser vista como uma perspectiva de síntese para classificar e mensurar a inovação na manufatura e em serviços, apesar do quadro analítico básico ainda ser visivelmente baseado em organizações manufatureiras.

Miles (2013) argumenta que a abordagem de demarcação pode parecer bastante adequada para estudar a inovação em serviços públicos, dado que ela ressalta características específicas da inovação em serviços e, caso se aplique uma dupla diferenciação, ressalta também as características do serviço público. No entanto, pelo menos algumas das características ressaltadas também se apresentam em firmas de manufatura. Neste ponto, Drejer (2004) argumenta que inovações não-tecnológicas também são importantes para firmas manufatureiras e, por mais que uma ampliação da cobertura dos conceitos seja necessária, esse é o caso para ambos os setores. Dessa forma, cria-se um argumento para a utilização da abordagem integradora para análise da inovação nos serviços públicos. Uma questão prática na comparação da manufatura aos serviços apontada por Bugge et al. (2010) refere-se à crescente dificuldade, se não impossibilidade, de separar esses dois setores. No caso da diferenciação dos setores público e privado, percebe-se que um pode ser melhor isolado do outro, apesar de isso depender de como o setor público é concebido. Por exemplo, o setor de governo é, em grande medida, distinto do setor de negócios, enquanto muitos tipos de serviços públicos incluem tanto empresas quanto organizações de propriedade pública (Mortensen, 2010). 
No entanto, mesmo sendo diferente do setor privado em várias formas, os processos de inovação que acontecem no setor público compartilham muitas características com o setor privado. Da mesma forma, em termos do entendimento de como as estruturas sistêmicas impactam o comportamento e a inovação, os setores público e privado tem muitos elementos em comum (Bugge et al., 2010). Considera-se, assim, que mesmo possuindo características distintas, é viável a utilização de ferramentas e conceitos de estudos da inovação no setor privado para aplicação no setor público, mas estes devem ser desenvolvidos de forma a representar essas características específicas dos serviços públicos.

\subsubsection{Tipologias de Inovação em Serviços Públicos}

Assim como para a inovação para o setor privado, os estudos sobre a inovação do setor público oferecem uma pletora de definições e tipologias acerca do fenômeno. Em uma corrente, a inovação no nível organização é entendida enquanto desenvolvimento e implementação de um novo produto, serviço, processo, tecnologia, política, estrutura ou sistema administrativo (Damanpour \& Schneider, 2006; Walker, 2007; Damanpour, Walker, \& Avallaneda, 2009). Este conceito ainda é ampliado pela conceituação da inovação como geração, que resulta em produtos, serviços e práticas que são novos, ou adoção de novas ideias, objetos ou práticas, que resulta no uso de produtos, serviços ou práticas novas para o adotante (Walker, Damanpour, \& Devece, 2010). Sob uma perspectiva de disseminação, Farah (2008) apresenta um entendimento diferente sobre inovação. Nesta visão, a inovação é um arranjo particular novo e bem-sucedido de certos componentes, podendo este arranjo ser potencialmente útil em outros contextos e/ou localidades como solução para um problema específico.

Um outro conceito foi desenvolvido por Bloch (2011), como adaptação da definição do Manual de Oslo (OECD, 2005) para o contexto específico dos serviços públicos, onde inovação é definida como a implementação de uma mudança significativa no modo de uma organização operar ou nos produtos que ela fornece. Inovações compreendem mudanças novas ou significativas em serviços e bens, processos operacionais, métodos organizacionais, ou na forma que uma organização se comunica com seus usuários. As inovações devem ser novas para a organização, apesar de poderem ser desenvolvidas por outrem. Elas podem ser resultantes de decisões tomadas internamente à organização ou em resposta a novas regulações ou medidas políticas. 
Os conceitos de inovação são comumente acompanhados de uma operacionalização por meio da distinção de tipos de inovação. Em uma revisão da literatura acerca da inovação no setor público, Brandão e Bruno-Faria (2012) identificam tipologias de inovação no setor público, e analisam o nível de distinção em relação a tipologias de inovação no setor privado. Por exemplo, Walker (2006) apresenta inovações de produto no setor público como novos bens ou serviços, convergindo à proposta de inovações de produto colocada por Sundbo (2003) para o setor privado. Posteriormente, Walker (2007) investiga especificamente as inovações em serviços, novos serviços oferecidos por organizações do setor público para atender demandas do ambiente ou novos usuários externos. Neste tipo de inovação, Walker (2007) identifica três subcategorias de inovação: a) totais, que envolvem a oferta de novos serviços para novos usuários; b) expansionistas, que se referem à oferta de serviços já existentes para novos usuários; e c) evolucionárias, que incluem a oferta de novos serviços para usuários já atendidos pela organização.

Um diferente tipo de inovação estudado no contexto do setor público é a de processo, a inovação com foco interno à organização e que busca aumentar a eficiência e efetividade de processos organizacionais e, consequentemente, facilitando a produção e entrega de produtos ou serviços para os usuários (Damanpour, Walker, \& Avallaneda, 2009). Desta forma, inovações de processo não geram diretamente produtos ou serviços, mas podem afetar indiretamente sua introdução para os usuários (Walker, 2006, 2007). As definições de inovações de processo para o setor público são similares às definições deste mesmo tipo no contexto privado, como apresentado por Tidd, Bessant e Pavitt (1997) e Sundbo (2003).

Assim como para as inovações de produto, as inovações de processos possuem subcategorias: a) tecnológicas, definidas como novos elementos no sistema de produção da organização, como novas tecnologias (Walker, 2006, 2007; Damanpour, Walker, \& Avallaneda, 2009); b) organizacionais, também denominadas administrativas, referentes à novas abordagens e práticas que modificam as relações entre membros de uma organização e alteram regras, papéis, procedimentos, estruturas, comunicações e relações de transação com o ambiente externo à organização (Walker, 2006, 2007; Damanpour, Walker, \& Avallaneda, 2009); e c) orientada ao ambiente, que envolve a modificação de sistemas e procedimentos operacionais para aumentar a eficiência ou efetividade da produção e oferta de serviços aos usuários pela organização (Walker, 2007). Uma distinção com a definição de inovações de processo no setor privado é identificada, visto que inovações administrativas ou organizacionais são destacadas como um tipo diferente e independente de inovações de processo (Carayannis, Gonzales, \& Wetter, 2003; Birkinshaw, Hamel, \& Mol, 2008). 
Por fim, Bloch (2011) operacionaliza o conceito de inovação por meio da distinção de quatro tipos de inovações: de produto, de processo, organizacional e de comunicação. Esta tipologia, assim como a definição geral de inovação oferecida pelo autor, tem o objetivo de gerar dados comparáveis com o setor privado, sendo uma adaptação dos tipos definidos no Manual de Oslo (OECD, 2005) para representar o contexto do setor público. As duas tipologias, e os conceitos associados a cada tipo, são apresentadas no Quadro 3.

\begin{tabular}{|c|c|c|c|}
\hline \multicolumn{2}{|c|}{ Setor Privado - OECD (2005) } & \multicolumn{2}{|c|}{ Setor Público - Bloch (2011) } \\
\hline $\begin{array}{c}\text { Tipo de } \\
\text { Inovação }\end{array}$ & Definição & $\begin{array}{c}\text { Tipo de } \\
\text { Inovação }\end{array}$ & Definição \\
\hline Produto & $\begin{array}{l}\text { Introdução de um bem ou serviço } \\
\text { novo ou significativamente } \\
\text { melhorado no que se refere a suas } \\
\text { características ou usos previstos }\end{array}$ & Produto & $\begin{array}{l}\text { Introdução de um bem ou serviço } \\
\text { novo ou significativamente } \\
\text { melhorado comparado com os } \\
\text { serviços e bens já existentes na } \\
\text { organização }\end{array}$ \\
\hline Processo & $\begin{array}{l}\text { Implementação de um método de } \\
\text { produção ou distribuição novo ou } \\
\text { significativamente melhorado, } \\
\text { incluindo mudanças significativas } \\
\text { em técnicas, equipamentos e/ou } \\
\text { softwares }\end{array}$ & Processo & $\begin{array}{l}\text { Implementação de um método de } \\
\text { produção ou entrega de serviços ou } \\
\text { bens novo ou significativamente } \\
\text { melhorado comparado com os } \\
\text { processos já existentes na } \\
\text { organização }\end{array}$ \\
\hline Marketing & $\begin{array}{l}\text { Implementação de um novo método } \\
\text { de marketing com mudanças } \\
\text { significativas na concepção do } \\
\text { produto ou em sua embalagem, no } \\
\text { seu posicionamento, em sua } \\
\text { promoção ou na fixação de preços }\end{array}$ & Comunicação & $\begin{array}{l}\text { Implementação de um novo método } \\
\text { de promoção da organização ou de } \\
\text { seus serviços e bens, ou novos } \\
\text { métodos para influenciar o } \\
\text { comportamento de indivíduos ou } \\
\text { outras organizações }\end{array}$ \\
\hline Organizacional & $\begin{array}{l}\text { Implementação de um novo método } \\
\text { organizacional nas práticas de } \\
\text { negócios da empresa, na } \\
\text { organização do seu local de } \\
\text { trabalho ou em suas relações } \\
\text { externas }\end{array}$ & Organizacional & $\begin{array}{l}\text { Implementação de um novo método } \\
\text { organizacional ou gerencial que } \\
\text { difere significativamente } \\
\text { métodos jos já existentes na } \\
\text { organização }\end{array}$ \\
\hline
\end{tabular}

Quadro 3. Tipologias de inovação para os setores privado e público

Fonte: Adaptado de OECD (2005) e Bloch (2011)

Brandão e Bruno-Faria (2012) observam que Hughes, Moore e Kataria (2011) utilizaram tipologia similar para pesquisa com organizações públicas do Reino Unido, dando foco a inovações de serviços e processos organizacionais. Inovações de serviço são definidas como a expansão da oferta de serviços e aprimoramentos na velocidade da entrega, qualidade, acesso e avaliação dos usuários. Inovações de processos organizacionais, por outro lado, incluem mudanças na estratégia organizacional e técnicas avançadas de gestão, incluindo sistemas de gestão do conhecimento, investimento em pessoal e mudanças na estrutura organizacional.

O presente estudo irá adotar a tipologia de inovações em serviços públicos definida por Bloch (2011). Visto que os quatro tipos desta classificação são comparáveis aos quatro tipos do 
Manual de Oslo (OECD, 2005), a utilização desta tipologia permite comparações com resultados de demais pesquisas realizadas no setor privado. Adicionalmente, a tipologia de Bloch (2011) foi utilizada em sua versão original ou com adaptações por outras iniciativas de pesquisa acerca da inovação no setor público em outros países, tais como Reino Unido (Hughes et al., 2011) e Austrália (APSII, 2011), possibilitando uma possível comparação com resultados de pesquisas realizadas internacionalmente.

\subsection{Indutores de Inovação}

A inovação ocorre em um contexto sistêmico ao invés de um caminho linear (Agolla \& Van Lill, 2013). Pode-se argumentar que a inovação deve ser considerada um produto de diversos fatores como mecanismos e relações interativas entre unidades sistêmicas que influenciam o processo de inovação (Roste, 2004; Koch et al., 2006). Dessa forma, há a necessidade de estudar todo o sistema de instituições e elementos e processos organizacionais de modo a entender o fenômeno da inovação no setor público (Nystrom, 1990), dentre os quais se destacam os indutores de inovação (Agolla \& Van Lill, 2013).

Para Tidd, Bessant e Pavitt (2008), indutores são influências que são mobilizadas para gerar inovação, e representam ferramentas que podem ser utilizadas para a gestão da inovação por uma organização. Luke, Verreynne e Kearins (2010) definem indutores como elementos que influenciam o desenvolvimento de atividades inovadoras, sendo os indutores diferentes dos facilitadores, definidos como aqueles atributos que apoiam as atividades inovadoras, mas que não são considerados centrais ou fundamentais para o desenvolvimento da inovação. De modo complementar, Bloch (2011) conceitua indutores enquanto fatores-chave que conduzem o processo de inovação, entre os quais pode-se citar pessoas, organizações ou outros fatores que incentivam o desenvolvimento de inovações.

Para o contexto específico do setor público, Borins (2001) identifica as seguintes categorias de condições que levam a inovações: iniciativas oriundas do sistema político; novas lideranças; crises; problemas internos; e novas oportunidades criadas por tecnologias. Ainda sobre indutores da inovação para serviços públicos, Halvorsen et al. (2005) identificam: a) a realização de eleições em intervalos fixos no caso de países democráticos; b) a opinião popular; c) os acordos internacionais, leis e novos regulamentos; d) os desenvolvimentos tecnológicos e científicos; e) outros desenvolvimentos e pressões sociais como crescimento populacional, 
movimentos migratórios e crises econômicas; e f) a frustração dos cidadãos com a falta de habilidade de organizações públicas para oferecer serviços dentro da qualidade esperada. De modo complementar, Mulgan (2007) identifica seis elementos capazes de promover a inovação em organizações públicas: capacidade das lideranças em estabelecer uma cultura de inovação; gatilhos políticos; criatividade e capacidade de recombinação; estímulo a protótipos e pilotos; capacidade para mobilizar implementação em larga escala e disseminação da inovação; e existência de um sistema sofisticado de gestão de riscos. Agolla e Lill (2013) definem o ambiente externo como fator de influência para inovação em organizações do serviço público, sendo identificados seis tipos de ambiente: político, econômico, social, tecnológico, ambiental e legal.

Ainda com foco em organizações do setor público, Koch e Hauknes (2005) identificam oito fatores, entre indutores e facilitadores, que servem para combater barreiras à inovação e criam pressões e suporte para o desenvolvimento e disseminação de inovações em serviços públicos, sendo eles: orientados a problema, não orientados a problema, impulso político, fatores tecnológicos, competição, crescimento de cultura de revisão, mecanismos de suporte à inovação e aptidão para a inovação. Considerando a diferenciação feita por Luke et al. (2010) acerca de indutores e facilitadores, pode-se destacar como indutores na tipologia de Koch e Hauknes (2005) apenas os cinco primeiros elementos. Dentre estes, deve-se considerar a aplicabilidade da competição enquanto indutor, visto que, em geral, organizações do setor público não operam em um modelo baseado no mercado e, assim não são motivadas por objetivos relacionados a lucro ou competitividade (Halvorsen et al., 2005). Desta forma, quatro categorias de indutores presentes na classificação de Koch e Hauknes (2005) podem ser consideradas: orientado a problema, não orientado a problema, impulso político e fatores tecnológicos.

Os indutores selecionados da categorização de Koch e Hauknes (2005) compreendem indutores apresentados por outros autores. Borins (2001) identifica uma crise, definida como um problema ou falha visível atual ou antecipada publicamente, e problemas internos da organização como condições para o desenvolvimento de inovações. Esses dois indutores estão alinhados ao conceito de um indutor orientado a problema de Koch e Hauknes (2005). Ainda para esta categoria, Halvorsen et al. (2005) citam pressões sociais como crescimento populacional, movimentos migratórios e crises econômicas, assim como a frustração dos cidadãos com a falta de habilidade de organizações públicas para oferecer serviços dentro da qualidade esperada. Três ambientes de indução de inovação apontados por Agolla e Lill (2013) também podem ser considerados indutores orientados a problema: a) o ambiente econômico, 
que provoca pressões para o aumento de eficiência e conformidade pelas organizações públicas; b) o ambiente social, que inclui pressões do público em relação a características demográficas e culturais; e c) o ambiente ecológico, que requisita uma posição proativa de organizações públicas para tratar dos impactos ecológicos gerados por atividades humanas. Como indutores não orientados a problema, pode-se destacar dois elementos citados por Mulgan (2007): o estímulo a protótipos e pilotos, e a existência de um sistema sofisticado de gestão de riscos, que pode apontar a necessidade de melhorias antes da aparição de um problema.

No que se refere ao indutor impulso político (Koch e Hauknes, 2005), duas condições citadas por Borins (2001) podem ser identificadas: as iniciativas oriundas do sistema político e as novas lideranças políticas. Halvorsen et al. (2005), por sua vez, identificam a realização de eleições em intervalos fixos em países democráticos pode fomentar a criatividade e inovação para revitalizar políticas públicas, assim como a opinião popular, em especial sobre assuntos considerados relevantes pela mídia e pela esfera política, podendo estes serem considerados indutores de impulso político. Mulgan (2007) cita gatilhos políticos como possíveis indutores, e Agolla e Lill (2013) identificam o ambiente político como um dos ambientes externos às organizações públicas que podem incentivar o desenvolvimento de inovações. O quarto indutor de Koch e Hauknes (2005), fatores tecnológicos, também é identificado por Borins (2001) como novas oportunidades criadas por tecnologias. Halvorsen et al. (2005) também citam os desenvolvimentos tecnológicos e científicos como um dos principais indutores da inovação no setor público, assim como Agolla e Lill (2013) que apresentam o ambiente tecnológico como ambiente indutor de inovações.

Uma categoria de indutores, no entanto, foi identificada nos trabalhos de Halvorsen et al. (2005) e Agolla e Lill (2013), mas não na classificação de Koch e Hauknes (2005). Halvorsen et al. (2005) colocam acordos internacionais, leis e novos regulamentos como um dos indutores da inovação no setor público. Para Agolla e Lill (2013) este indutor está representado no ambiente legal, visto que organizações do setor público são fundadas por meio de legislação e, dessa forma, sua operação deve acontecer dentro dos parâmetros definidos por esta legislação. Neste ponto, Porter e Stern (2002) afirmam que as atividades de inovação das organizações de um país são fortemente influenciadas pela política nacional, sendo esta influência ainda maior para organizações do setor público. Este quinto indutor, denominado imposição legal e definido como a criação de regulação, lei, decreto, emenda constitucional ou ação governamental que induzem inovação, será adicionada às quatro categorias de indutores selecionadas de Koch e Hauknes (2005) para compor a lista de categorias de indutores utilizada 
pelo presente estudo. Os cinco tipos de indutores e suas definições podem ser observados no Quadro 4.

\begin{tabular}{|c|l|}
\hline Indutor & \multicolumn{1}{c|}{ Definição } \\
\hline $\begin{array}{c}\text { Orientado a } \\
\text { problema }\end{array}$ & $\begin{array}{l}\text { Introdução de inovações para responder a um ou mais problemas específicos, tais como } \\
\text { fatores demográficos, envelhecimento da população, obesidade infantil, entre outros }\end{array}$ \\
\hline $\begin{array}{c}\text { Não orientado } \\
\text { a problema }\end{array}$ & $\begin{array}{l}\text { Necessidade de melhorias em relação a uma situação anterior em vez do tratamento de um } \\
\text { problema específico }\end{array}$ \\
\hline $\begin{array}{c}\text { Impulso } \\
\text { político }\end{array}$ & $\begin{array}{l}\text { Mudanças estratégicas no serviço público que requerem decisões fortes do topo par a base. } \\
\text { Pode ser baseada em ideologia ou em resposta a eventos críticos e pressões e também pode } \\
\text { se refletir através da imposição de metas de desempenho }\end{array}$ \\
\hline $\begin{array}{c}\text { Fatores } \\
\text { tecnológicos }\end{array}$ & $\begin{array}{l}\text { Surgimento ou disponibilidade de novas tecnologias que proporcionam oportunidades de } \\
\text { inovação }\end{array}$ \\
\hline $\begin{array}{c}\text { Imposição } \\
\text { legal }\end{array}$ & $\begin{array}{l}\text { Criação de regulação, lei, decreto, emenda constitucional ou ação governamental que } \\
\text { induzem inovação }\end{array}$ \\
\hline
\end{tabular}

Quadro 4. Indutores de inovação

Fonte: Adaptado de Halvorsen et al. (2005), Koch e Hauknes (2005) e Agolla e Lill (2013)

\subsection{Capacidades de Inovação}

Os termos inovação, capacidade de inovação e aptidão para inovação são muitas vezes utilizados na literatura de forma indistinta (Hogan, Soutar, McColl-Kennedy, \& Sweeney, 2011). Lawson e Samson (2001) argumentam que a inovação e as capacidades para inovação ocorrem em etapas diferentes do processo de inovação, sendo que a capacidade para inovação é um elemento crítico para o desenvolvimento e, consequentemente, resultados da inovação. Ainda assim, percebe-se uma lacuna no entendimento, e mensuração, das capacidades de inovação em organizações, em especial as organizações de serviço (Adams, Bessant, \& Phelps, 2006; Hogan et al., 2011). Como no caso da inovação, a literatura acerca das capacidades de inovação oferece uma variedade de conceitos e tipologias.

Lawson e Samson (2001) definem a capacidade de inovação de uma organização como fruto das habilidades e aptidões que permitem a aplicação de recursos, e reflete uma habilidade de transferir continuamente conhecimentos e ideias em novos produtos, processos e sistemas para o benefício da organização e de suas partes interessadas. Num conceito similar, Romijin e Aldabejo (2002) referem-se à capacidade de inovação como as habilidades e conhecimentos necessários para efetivamente absorver, dominar e aprimorar tecnologias existentes e criar novas tecnologias, enquanto Xu, Lin e Lin (2008) definem a capacidade de inovação como a capacidade de ganhar acesso a, desenvolver e implementar tecnologias inovadoras para projetos e manufatura. Na mesma corrente, Koc (2007) considera a capacidade de inovação como a 
melhoria contínua das capacidades e recursos gerais que uma organização possui para explorar e explotar oportunidades para desenvolvimento de novos produtos, enquanto Chen (2009) define capacidades de inovação como as capacidades de uma organização, baseadas em processos, sistemas e estrutura organizacional, que podem ser aplicadas para atividades de inovação de produtos ou processos.

As definições apresentadas enfatizam as capacidades para desenvolvimento de novas tecnologias, produtos e processos. Uma definição mais compreensiva é colocada por Ngo e O'Cass (2009), que se referem à capacidade de inovação como o processo integrativo de aplicação dos conhecimentos, habilidades e recursos coletivos da organização para executar atividades de inovação referentes a inovações técnicas - produtos ou serviços e tecnologia de processos de produção - e não-técnicas - gerenciais, de mercado e de marketing. A teoria de capacidades presume que há um diferencial de capacidade que permite a uma organização alcançar vantagem competitiva sustentável através de uma variedade de capacidades distintivas (Weerawardena \& McColl-Kennedy, 2002), sendo este conceito mais amplo aplicável para as capacidades de inovação (Hogan et al., 2011).

Em um esforço para verificar as capacidades de inovações que possuem congruência em diversas tipologias disponíveis na literatura, Valladares et al. (2014) identificaram modelos que reúnem um conjunto de capacidades, entre os quais estão: o modelo de inovação baseado em processos (Chiesa, Coughlan, \& Voss, 1996); o modelo de inovações em organizações (Tang, 1998); o modelo de capacidade de inovação (Lawson \& Samson, 2001); e o modelo de inovação (Smith et al., 2008).

O modelo de Chiesa et al. (1996) se baseia no processo de inovação que é determinado pela liderança e é afetado pela disponibilização de recursos e pelos instrumentos e sistemas de gestão de uma organização. Neste modelo, a inserção da inovação no planejamento da organização é de responsabilidade da liderança, sendo o conhecimento do usuário e do ambiente da organização parte do processo de geração do conceito de novos produtos, uma das fases do processo de inovação. Percebe-se um destaque para a visão sistêmica e o relacionamento com o meio externo da organização. Em se tratando do papel da liderança enquanto capacidade de inovação, outros autores apresentam visões distintas. Para Avolio, Bass e Jung (1999), o mais importante é o perfil transformador do líder, ponto suportado por Carless, Wering e Mann (2000). Por outro lado, Elenkov, Judge e Wright (2005) apontam que o consenso entre os membros da direção da organização é crucial.

No referente ao relacionamento ao meio externo da organização percebe-se também uma diferença de foco entre autores distintos. Read (2000), por exemplo, destaca como objeto 
o foco no cliente e no mercado, enquanto para Lawson e Samson (2001) o objeto do relacionamento com o meio externo deve abranger todo o setor de atuação da organização, sendo este fator denominado inteligência organizacional. O modelo de capacidade de inovação de Lawson e Samson (2001) ainda aponta como capacidades de inovação visão e estratégia, aproveitamento da competência base da organização, gestão da criatividade e ideias, estrutura organizacional e sistemas, cultura e clima, e gestão da tecnologia.

O modelo de inovação proposto por Smith et al. (2008) compreende o processo de inovação como uma atividade realizada por pessoas, sendo apoiado pela gestão do conhecimento, estilo gerencial e liderança, recursos, estrutura organizacional, estratégia corporativa e tecnologia. Os elementos deste modelo incluem processos, pessoas e recursos. A consideração de gestão de pessoas como uma capacidade de inovação é suportada por outros autores, como Read (2000), Adams, Bessant e Phelps (2006) e Metz, Terziovski e Samson (2007). Crossan e Apaydin (2010), por outro lado, consideram a gestão de pessoas como uma subcategoria dentro da capacidade cultura organizacional.

Os diversos modelos e as capacidades relatadas neles foram analisados e organizados por Valladares et al. (2014) de modo a se obter uma síntese das capacidades de inovação identificadas na literatura. A definição adotada pelos autores, e que serviu como um dos critérios para a seleção das capacidades, foi a de Peng, Schroeder e Shah (2008), onde a "capacidade de inovação é força ou a proficiência de um conjunto de práticas organizacionais para o desenvolvimento de novos produtos/processos" (p. 735). Esta abordagem baseada nas práticas ou rotinas organizacionais determinou o foco dado às capacidades capazes de serem expressadas em processos organizacionais, motivo pelo qual certas capacidades como recursos, cultura organizacional e aprendizagem organizacional não foram consideradas. Como resultado da análise, Valladares et al. (2014) identificam e definem sete capacidades de inovação, apresentadas no Quadro 5. Esta tipologia, por representar um esforço de organização de diversos outros modelos de capacidades de inovação, será adotada no presente estudo. 


\begin{tabular}{|c|c|}
\hline Cap & Definição \\
\hline $\begin{array}{c}\text { Liderança } \\
\text { transformadora }\end{array}$ & $\begin{array}{l}\text { Aquela que torna seus seguidores mais conscientes da importância e do valor do trabalho, } \\
\text { ativa suas necessidades de ordem superior, e os induz a transcender seus interesses pessoais } \\
\text { em prol da organização }\end{array}$ \\
\hline $\begin{array}{l}\text { Intenção } \\
\text { estratégica de } \\
\text { inovar }\end{array}$ & $\begin{array}{l}\text { Grau que a organização está disposta a assumir riscos para favorecer a mudança, o } \\
\text { desenvolvimento tecnológico e a inovação, estabelecendo-os por meio de sua estratégia }\end{array}$ \\
\hline $\begin{array}{l}\text { Gestão de } \\
\text { pessoas para } \\
\text { inovação }\end{array}$ & $\begin{array}{l}\text { Orientação da gestão de pessoas para a inovação, provendo a concessão de liberdade ou } \\
\text { autonomia de atuação aos empregados, estabelecendo metas desafiadoras, permitindo que } \\
\text { decidam como alcança-las e favorecendo a autorrealização e o comprometimento com os } \\
\text { objetivos da organização }\end{array}$ \\
\hline $\begin{array}{l}\text { Conhecimento } \\
\text { do usuário e do } \\
\text { ambiente }\end{array}$ & $\begin{array}{l}\text { s, necessidades, expectativas, mudanças significativas e } \\
\text { tte }\end{array}$ \\
\hline $\begin{array}{l}\text { Gestão } \\
\text { estratégica da } \\
\text { tecnologia }\end{array}$ & $\begin{array}{l}\text { Gestão do processo de criação e desenvolvimento de tecnologias, visando à criação de valor. } \\
\text { O processo de gestão tecnológica compreende cinco etapas: identificação, seleção, aquisição, } \\
\text { exploração e proteção }\end{array}$ \\
\hline $\begin{array}{l}\text { Organicidade } \\
\text { da estrutura } \\
\text { organizacional }\end{array}$ & $\begin{array}{l}\text { Grau em que a estrutura é caracterizada pela concessão de autonomia, controles flexíveis, } \\
\text { comunicação horizontal desimpedida, valorização do conhecimento e da experiência e } \\
\text { informalidade nas relações pessoais. Estrutura ditas orgânicas permitem resposta mais rápida } \\
\text { às mudanças no ambiente externo do que as denominadas mecanicistas }\end{array}$ \\
\hline $\begin{array}{l}\text { Gestão de } \\
\text { projetos }\end{array}$ & $\begin{array}{l}\text { Planejamento, provisão dos recursos, execução e controle do processo de inovação. Inclui } \\
\text { cuidadosa avaliação dos projetos, análise e planejamento visando, principalmente, ganhar } \\
\text { compreensão, compromisso e apoio tanto corporativo quanto do pessoal que estará envolvido } \\
\text { no projeto }\end{array}$ \\
\hline
\end{tabular}

Quadro 5. Capacidades de inovação

Fonte: Adaptado de Valladares et al. (2014).

\subsection{Resultados de Inovação}

Existem dificuldades em estabelecer precisamente os resultados de inovações, seus impactos no desempenho da organização, em especial para organizações do setor público (Innovation Unit, 2009). Por conta desta dificuldade, nas últimas duas décadas o setor tem crescentemente importado valores do setor privado (Kattel et al., 2013), que possui foco em mensurações relativas a consumidores, saídas ao invés de entradas e desempenho mais efetivo e eficiente (Hoque, 2008). No âmbito dos serviços ofertados por organizações públicas existe uma variedade de elementos que podem ser mensurados (Kuhlmann, 2010; Packard, 2010; Sillanpää, 2013). Esta é uma das principais diferenças entre os possíveis resultados esperados de uma inovação no setor privado e no setor público: enquanto empresas possuam objetivos secundários, seu principal objetivo é obter retorno sobre investimento, enquanto os objetivos no setor público são muito mais difusos e multifacetados (Bugge, Mortensen, \& Bloch, 2011).

O estudo realizado por Hipp e Grupp (2005) com organizações do setor de serviços aponta quatro fatores do efeito de inovações em serviços: melhoria da qualidade do produto de serviço, melhorias internas da organização, aprimoramento do desempenho ou produtividade 
do consumidor e conformidade com padrões ambientais e requisitos de segurança. Os autores identificam que o único fator que possui diferenças significativas entre setores, especificamente entre serviços intensivos e não intensivos em conhecimento, é o de conformidade com padrões ambientais e requisitos de segurança, sendo os demais efeitos de inovação representativos em todos os setores de serviços. Os dois primeiros fatores colocados por Hipp e Grupp (2005), melhoria da qualidade do produto de serviços e melhorias internas da organização, também são comumente citados como efeitos da inovação realizada por organizações públicas.

Um dos principais resultados esperados da inovação no setor público é a melhoria na entrega e/ou qualidade dos serviços públicos (Bloch, 2011; Bugge et al., 2011). Este resultado de inovação também está presente em estudos focados em setores específicos de atividades dentro do setor público, como no setor de educação (Newcomer \& Allen, 2010). Para Hughes et al. (2011), este resultado inclui a avaliação dos usuários em relação ao serviço, incluindo, portanto, fatores como o aumento da satisfação do usuário e envolvimento dos cidadãos nos serviços (Carter \& Belanger, 2005; Bugge et al., 2011; Mustafid \& Grisma, 2013; De Vries, Bekkers, \& Tummers, 2014). Outro resultado de inovação constantemente apresentado em estudos no setor público é a melhoria da gestão organizacional, representada por ganhos de eficiência ou produtividade (Kim \& Lee, 2009; Bloch, 2011; Bugge et al., 2011;), podendo esta ser acompanhada em ganhos de desempenho ou efetividade (Newcomer \& Allen, 2010; Hughes et al., 2011; Mustafid \& Grisma, 2013; De Vries et al., 2014). Albury (2005) afirma que uma inovação exitosa deve aumentar a eficiência e efetividade da organização, sendo que estes termos são usualmente utilizados conjuntamente sem diferenciação (Micheli et al., 2012).

Apesar das melhorias na entrega de serviços e na gestão organizacional serem as mais comumente listadas em estudos sobre a inovação no setor público, dois outros tipos de melhoria merecem destaque. Primeiramente, a melhoria da imagem e relações institucionais da organização pública é vista como possível resultado de inovações. Este tipo de melhoria é composto por elementos tais como maior capacidade de endereçar desafios sociais e outras mudanças politicamente importantes (Bloch, 2011; Bugge et al., 2011), os impactos da inovação sobre a esfera social e outros aspectos intangíveis como confiança e legitimidade na organização pública (Mustafid \& Grisna, 2013), o aumento da ética, transparência e prestígio do serviço público (Newcomer \& Allen, 2010), assim como o envolvimento e melhorias no relacionamento com parceiros e outras organizações (De Vries et al., 2014). Por fim, a melhoria do clima organizacional deve ser considerada um resultado potencial de inovações em organizações públicas, envolvendo aspectos como a cultura organizacional para inovação e aumento da satisfação dos colaboradores (Mustafid \& Grisna, 2013) e a melhoria das condições 
de trabalho (Bloch, 2011; Bugge et al., 2011). Os quatro tipos de resultado de inovação, acompanhados de suas definições, são apresentados no Quadro 6.

\begin{tabular}{|c|c|c|}
\hline Resultado & Definição & Referências \\
\hline $\begin{array}{l}\text { Melhoria na } \\
\text { entrega e/ou } \\
\text { qualidade dos } \\
\text { serviços }\end{array}$ & $\begin{array}{l}\text { Impactos positivos sobre os } \\
\text { mecanismos de entrega de serviços e/ou } \\
\text { nos próprios serviços, incluindo } \\
\text { aumento da satisfação e do } \\
\text { envolvimento dos usuários }\end{array}$ & $\begin{array}{l}\text { Carter e Belanger (2005), Hipp e Grupp (2005), } \\
\text { Newcomer e Allen (2010), Bloch (2011), Bugge } \\
\text { et al. (2011), Hughes et al. (2011), Mustafid e } \\
\text { Grisma (2013), De Vries et al. (2014) }\end{array}$ \\
\hline $\begin{array}{l}\text { Melhoria da } \\
\text { gestão } \\
\text { organizacional }\end{array}$ & $\begin{array}{l}\text { Impactos positivos sobre a eficiência e } \\
\text { efetividade da organização, incluindo } \\
\text { ganhos de produtividade e melhores } \\
\text { resultados em indicadores de } \\
\text { desempenho }\end{array}$ & $\begin{array}{l}\text { Albury (2005), Hipp e Grupp (2005), Kim \& Lee } \\
\text { (2009), Newcomer e Allen (2010), Bloch (2011), } \\
\text { Bugge } \text { et al. (2011), Hughes et al. }(2011), \\
\text { Mustafid e Grisma (2013), De Vries } \text { et al. }(2014)\end{array}$ \\
\hline $\begin{array}{l}\text { Melhoria da } \\
\text { imagem e } \\
\text { relações } \\
\text { institucionais }\end{array}$ & $\begin{array}{l}\text { Impactos positivos sobre a imagem da } \\
\text { organização e no relacionamento com } \\
\text { outras organizações, incluindo melhoria } \\
\text { na capacidade de resolução de desafios } \\
\text { sociais, aumento do prestígio da } \\
\text { organização e envolvimento de } \\
\text { parceiros. }\end{array}$ & $\begin{array}{l}\text { Newcomer e Allen (2010), Bloch (2011), Bugge } \\
\text { et al. (2011), Mustafid e Grisma (2013), De Vries } \\
\text { et al. (2014) }\end{array}$ \\
\hline $\begin{array}{l}\text { Melhoria do } \\
\text { clima } \\
\text { organizacional }\end{array}$ & $\begin{array}{l}\text { Impactos positivos sobre o clima da } \\
\text { organização, incluindo melhorias nas } \\
\text { condições de trabalho, satisfação dos } \\
\text { colaboradores e aprimoramento da } \\
\text { cultura de inovação. }\end{array}$ & $\begin{array}{c}\text { Bloch (2011), Bugge et al. (2011), Mustafid e } \\
\text { Grisma (2013) }\end{array}$ \\
\hline
\end{tabular}

Quadro 6. Resultados de inovação

Fonte: Elaborado pelo autor.

\subsection{Articulação das Variáveis}

No intuito de representar a relação entre capacidades de inovação, indutores de inovação, tipos de inovação e resultados da inovação, em especial por organizações do setor público, pode-se considerar os modelos elaborados por projetos internacionais de mensuração da inovação em serviços públicos. Neste âmbito, destacam-se os modelos propostos pelo Índice de Inovação para o Setor Público do Innovation Unit e pelo programa de Índices de Inovação do NESTA - National Endowement for Science Technology and the Arts no Reino Unido, e pelo APSII - Australian Public Sector Innovation Indicators Project - na Austrália.

O índice de inovação para o setor público proposto pelo Innovation Unit (2009) é composto por três domínios: a) atividade de inovação, definida como a aplicação de ideias e conhecimento para criar valor; b) capacidade de inovação, que envolvem as capacidades fundamentais para gestão estratégica da inovação; e c) resultados de inovação, que são os 
impactos da inovação sobre o desempenho da organização. Os três domínios são apresentados na Figura 1.

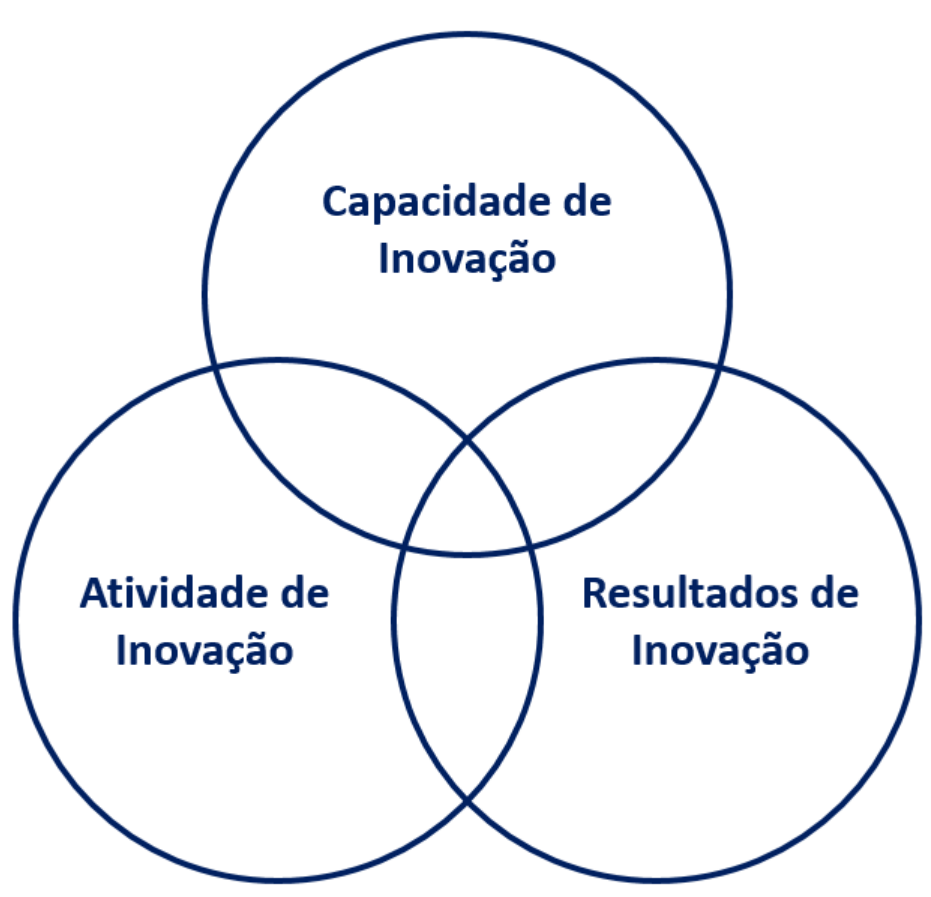

Figura 1. Domínios do índice de inovação para o setor público Fonte: Adaptado de Innovation Unit (2009, p. 8)

As relações identificadas pelo Innovation Unit (2009) são que as capacidades de inovação são fundamentais para a execução das atividades de inovação. As atividades, por sua vez, compreendem os processos de geração de uma inovação, e esta, quando exitosa, leva a resultados de inovação, que envolvem ganhos de desempenho para organização e adição de valor para outras esferas, como a social e ambiental.

De modo similar, o modelo do NESTA (Hughes et al., 2011) é composto por quatro áreas de avaliação da inovação: a) atividade de inovação, que descreve os meios de condução de ideias que fluem através de uma organização e a efetividade das atividades-chave associadas a inovação; b) capacidade de inovação, que se refere às principais capacidades-chave subjacentes que podem influenciar a atividade de inovação de forma sustentável; c) impacto no desempenho, que descreve o impacto da atividade de inovação no desempenho de uma organização em termos de impacto nos resultados, medidas de serviço e eficiências, assim como o contexto para mudança; e d) condições setoriais para inovação, que representam quão bem o sistema no qual a organização opera suporta ou atrapalha a inovação. A representação gráfica deste modelo pode ser vista na Figura 2. Nesta representação, as áreas coloridas demonstram o que está sob controle da organização - capacidades de inovação, atividade de inovação e 
impacto no desempenho. A área externa, condições setoriais para inovação está fora do controle da organização, mas dentro do controle de formuladores de políticas.

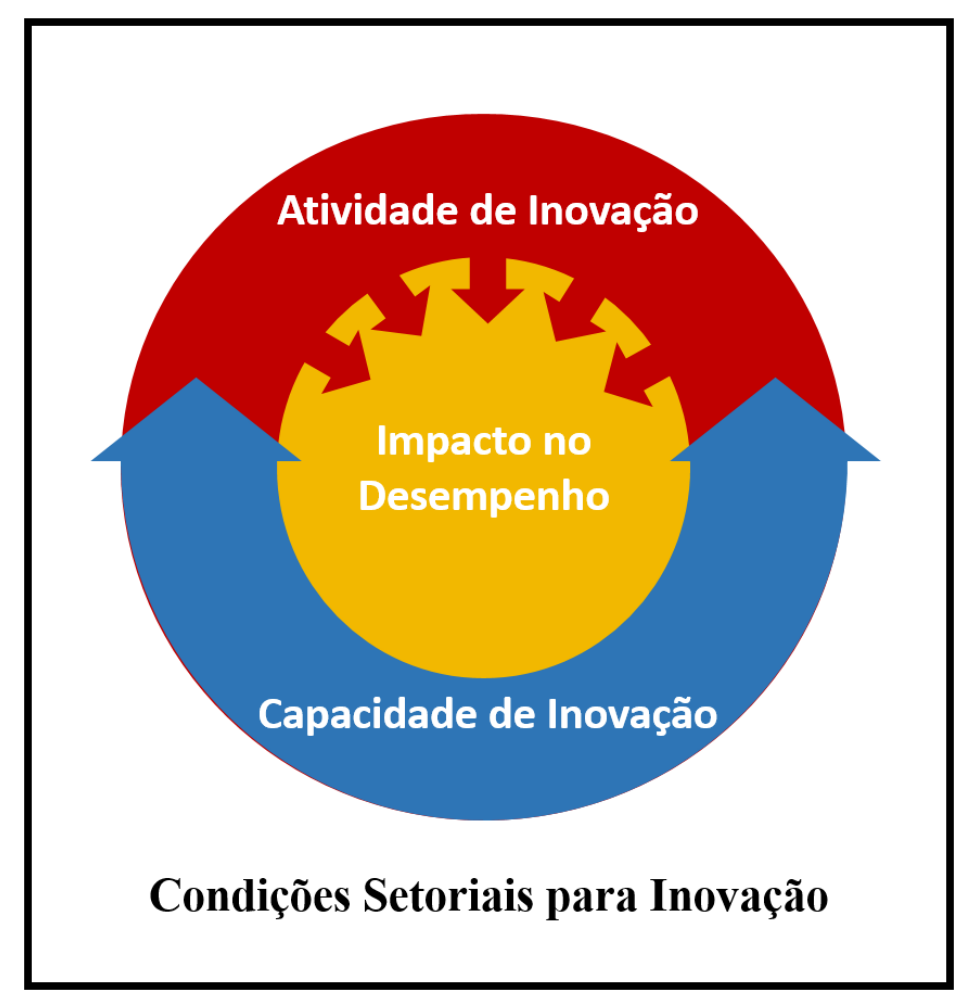

Figura 2. Modelo para inovação em organizações do setor público Fonte: Adaptado de Hughes et al. (2011, p. 47)

Próximo ao sugerido pelo Innovation Unit (2009), as relações identificadas no modelo do NESTA são que as capacidades de inovação influenciam diretamente as atividades de inovação da organização. As atividades de inovação, que incluem as etapas de acesso a novas ideias, seleção e desenvolvimento de ideias, implementação de ideias e difusão dos casos de sucesso (Hughes et al., 2011), geram as inovações, que podem ser classificadas, por exemplo, utilizando a tipologia de Bloch (2011). As inovações, por sua vez, causam impactos no desempenho da inovação, podendo estes serem considerados resultados de inovação. As condições setoriais para inovação possuem efeito sobre as atividades e capacidades de inovação da organização, mas estas condições estão sob o controle de formuladores de políticas e não da própria organização.

O modelo do APSII (2011) segue lógica próxima aos dois outros apresentados, mas adiciona indutores e barreiras como elementos-chave para o entendimento da inovação em organizações públicas. Quatro principais fatores compõem este modelo: a) desempenho de inovação, composto por atividades de inovação e impactos ou resultados de inovação; b) 
capacidades de inovação; c) indutores de inovação; e d) barreiras de inovação. A representação dos fatores e relações do modelo podem ser observadas na Figura 3.

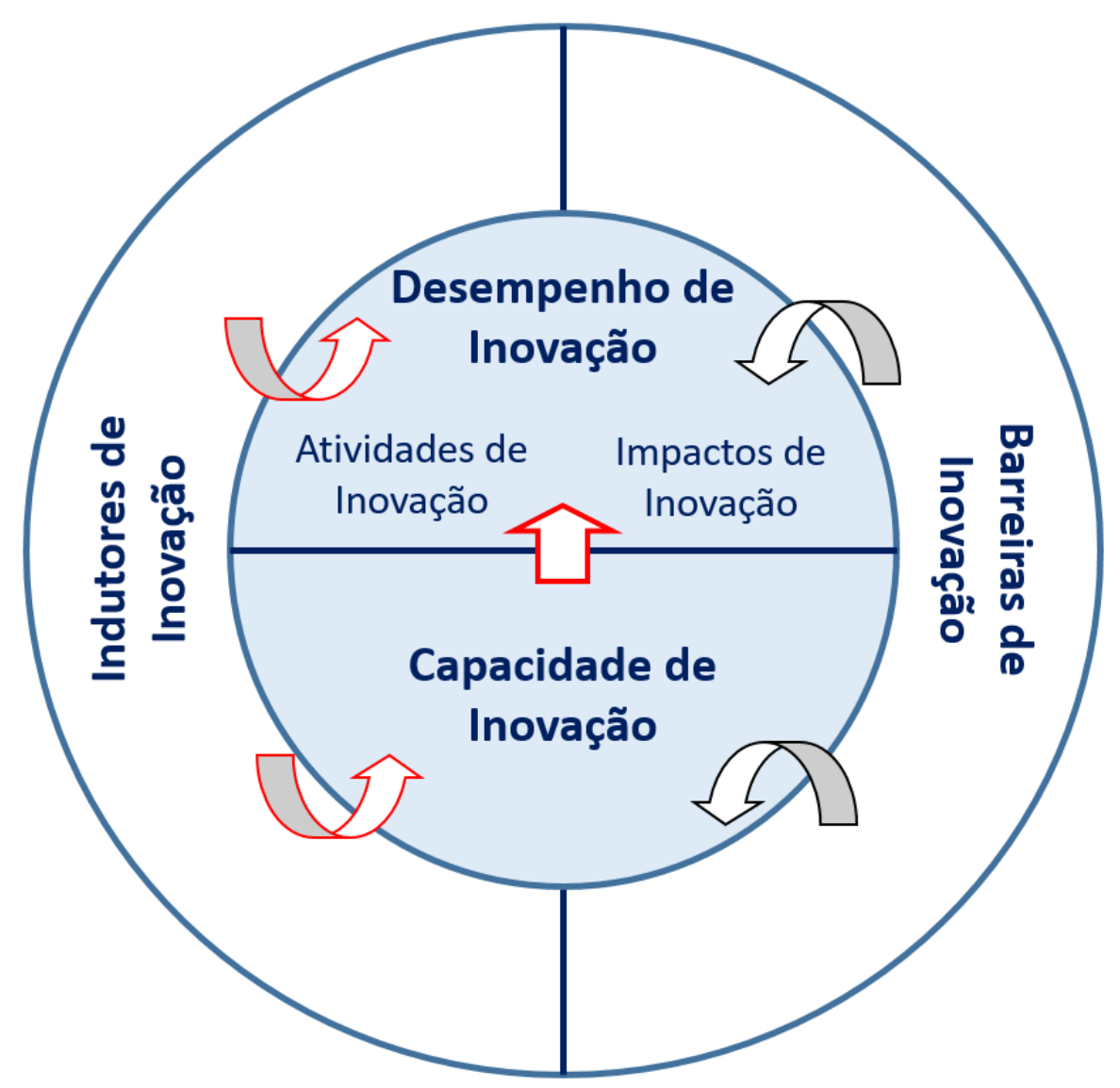

Figura 3. Modelo para análise da inovação em organizações do setor público Fonte: Adaptado de APSII (2011, p. 24)

O modelo utiliza uma variedade de setas para indicar as relações entre as áreas identificadas. Setas para cima e para baixo indicam os efeitos positivos e negativos de uma área na outra, respectivamente. Dessa forma, uma capacidade de inovação elevada teria um efeito positivo sobre o desempenho de inovação. Indutores fortes de inovação teriam efeito positivo sobre capacidades e, consequentemente, sobre desempenho de inovação. De forma oposta, barreiras fortes de inovação teriam efeito negativo sobre capacidades e sobre desempenho de inovação.

Observa-se que nestes três modelos o conceito de atividades de inovação é utilizado. Bloch (2011) define as atividades de inovação enquanto todas as atividades conduzidas internamente ou externamente, por meio de aquisições, que levam, ou pretendem levar, à implementação de inovações. O autor afirma, no entanto, que a identificação e mensuração de atividades de inovação é difícil para muitas organizações, visto que este tipo de informação não 
é comumente coletado. Outra questão relevante levantada é se atividades de inovação deveriam incluir quaisquer esforços de pesquisa e desenvolvimento (P\&D). Por exemplo, pesquisas básicas e, potencialmente, alguns tipos de pesquisa aplicada podem não se encaixar na definição de atividades de inovação, visto que não pretendem levar à implementação de inovações. De modo geral, os modelos apresentados utilizam as atividades de inovação para representar a execução e ocorrência da inovação. Para evitar possíveis barreiras e vieses relacionados ao uso do conceito de atividades de inovação, o presente estudo irá utilizar os tipos de inovação para detectar e caracterizar, assim como nos modelos, a execução e ocorrência da inovação.

Além das relações propostas nos modelos apresentados, outras proposições representam os efeitos entre os elementos componentes dos modelos de análise da inovação no setor público:

- O conceito de inovação pode ser operacionalizado por meio de tipologias de inovação (Bloch, 2011);

- As capacidades de inovação são críticas para o desenvolvimento de novos serviços que criam valor para a organização e para os usuários de seus serviços (Lawson \& Samson, 2001; Weerawardena \& O’Cass, 2004);

- A inovação deve ser considerada um produto de diversos fatores como mecanismos e relações interativas entre unidades sistêmicas que influenciam o processo de inovação (Roste, 2004; Koch et al., 2006), dentre os quais se destacam os indutores de inovação (Agolla \& Van Lill, 2013); e

- A inovação é importante para o aprimoramento na qualidade e eficiência dos serviços públicos e para responder a condições econômicas e sociais em mudança (NAO, 2009).

Com base nas relações e proposições apresentadas, o Quadro 7 apresenta as hipóteses levantadas para o presente estudo: 


\section{H1: A presença de capacidades de inovação aumenta a probabilidade de ocorrência de tipos de} inovação

H1a: A presença de capacidades de inovação aumenta a probabilidade de ocorrência de inovação de produto H1b: A presença de capacidades de inovação aumenta a probabilidade de ocorrência de inovação de processo H1c: A presença de capacidades de inovação aumenta a probabilidade de ocorrência de inovação de comunicação

H1d: A presença de capacidades de inovação aumenta a probabilidade de ocorrência de inovação organizacional

H2: A presença de indutores de inovação aumenta a probabilidade de ocorrência de tipos de inovação

H2a: A presença de indutores de inovação aumenta a probabilidade de ocorrência de inovação de produto

H2b: A presença de indutores de inovação aumenta a probabilidade de ocorrência de inovação de processo

H2c: A presença de indutores de inovação aumenta a probabilidade de ocorrência de inovação de comunicação

H2d: A presença de indutores de inovação aumenta a probabilidade de ocorrência de inovação organizacional

H3: A presença de capacidades e indutores de inovação aumenta a probabilidade de ocorrência de tipos de inovação

H3a: A presença de capacidades e indutores de inovação aumenta a probabilidade de ocorrência de inovação de produto

H3b: A presença de capacidades e indutores de inovação aumenta a probabilidade de ocorrência de inovação de processo

H3c: A presença de capacidades e indutores de inovação aumenta a probabilidade de ocorrência de inovação de comunicação

H3d: A presença de capacidades e indutores de inovação aumenta a probabilidade de ocorrência de inovação organizacional

H4: A presença de tipos de inovação aumenta a probabilidade de ocorrência de resultados de inovação

H4a: A presença de inovação de produto aumenta a probabilidade de ocorrência de resultados de inovação

H4b: A presença de inovação de processo aumenta a probabilidade de ocorrência de resultados de inovação

H4c: A presença de inovação de comunicação aumenta a probabilidade de ocorrência de resultados de inovação

H4d: A presença de inovação organizacional aumenta a probabilidade de ocorrência de resultados de inovação

H5: A presença de capacidades, indutores e tipos de inovação aumenta a probabilidade de ocorrência de resultados de inovação

H5a: A presença de capacidades, indutores e de inovação de produto aumenta a probabilidade de ocorrência de resultados de inovação

H5b: A presença de capacidades, indutores e de inovação de processo aumenta a probabilidade de ocorrência de resultados de inovação

H5c: A presença de capacidades, indutores e de inovação de comunicação aumenta a probabilidade de ocorrência de resultados de inovação

H5d: A presença de capacidades, indutores e de inovação organizacional aumenta a probabilidade de ocorrência de resultados de inovação

Quadro 7. Hipóteses do estudo

Fonte: Elaborado pelo autor 


\section{MÉTODO}

\subsection{Caracterização Geral da Pesquisa}

O presente estudo trata-se de uma pesquisa explicativa com o objetivo de analisar o efeito da presença de capacidades, indutores e tipos de inovação sobre a probabilidade de ocorrência de resultados de inovação em experiências inovadoras em gestão na Administração Pública Federal. Para Gil (2008), uma pesquisa explicativa é aquela que tem como principal preocupação identificar os fatores que determinam ou contribuem para a ocorrência dos fenômenos pesquisados, aprofundando o conhecimento da realidade por meio da explicação da razão. Em definição convergente, Vergara (2005) afirma que a pesquisa explicativa tem como objetivo tornar algo inteligível, justificando os motivos pelos quais um determinado fenômeno ocorre, esclarecendo os fatores que contribuem para a ocorrência do fenômeno.

Este trabalho também pode ser categorizado enquanto pesquisa documental, definida por Godoy (1995) como o exame de materiais e documentos de natureza diversa, que ainda não receberam tratamento analítico ou que podem ser reexaminados como objetivo de alcançar novas e/ou interpretações complementares. A presente pesquisa foi realizada a partir dos dados disponíveis nos relatos das experiências inovadoras no âmbito da administração pública federal relatadas e selecionadas pelo concurso de inovação da Escola Nacional de Administração Pública (ENAP).

A decisão de fazer uma pesquisa documental deve-se basear em dois aspectos: o pesquisador pode utilizar dados solicitados para o estudo ou pode utilizar documentos já existentes, que foram produzidos para outros fins (Flick, 2009). No caso desta pesquisa, os relatos das experiências não foram produzidos especificamente para os fins deste trabalho. Gil (2008) estabelece dois principais passos para o trabalho com documentos: a identificação das fontes e obtenção do material, e a leitura do material. Nesta segunda etapa, os seguintes objetivos são listados: identificar informações e dados constantes dos materiais, estabelecer relações entre as informações e dados com o problema proposto e analisar as consistências das informações e dados. Scott (1990) sugere quatro critérios para avaliar a qualidade dos documentos a serem utilizados em uma pesquisa:

- Autenticidade: relacionada à origem do documento

- Credibilidade: referente à acurácia da documentação, à confiabilidade do autor e à existência de erros e distorções; 
- Representatividade: se é um documento típico, ou seja, se contém as informações que um documento desse tipo geralmente traz; e

- Significado: ligado à clareza e compreensão pretendida pelo autor, à compreensão dos diferentes leitores e do significado social daquele documento.

Considera-se que os relatos das experiências do prêmio da ENAP passam pelos critérios propostos por Scott (1990). Em termos de autenticidade, os relatos são dispostos pelos próprios idealizadores e executores dos projetos de inovação, logo, a origem dos documentos pode ser considerada autêntica. Em relação à credibilidade, deve-se considerar que os relatos são avaliados por um comitê julgador composto por especialistas em gestão pública (Lemos, 2000; Pereira, 2013). Os relatos também possuem representatividade, pois apresentam todas as informações necessárias para descrever uma experiência de inovação, além de apresentarem as informações necessárias para esta pesquisa possuindo também, desta forma, significado, pois as informações são claras e permitem uma boa compreensão para a realização da pesquisa.

\subsection{Procedimento de Coleta de Dados}

Para o alcance do objetivo proposto para o presente estudo, foram coletados dados acerca das experiências finalistas e premiadas pela ENAP entre os anos de 1999 e 2014, num total de 287 casos. As edições consideradas na coleta de dados foram da quarta à décima nona. As primeiras três edições foram descartadas por apresentarem apenas um relato breve das experiências que não se encaixam no padrão de descrição adotado na quarta edição e em todas as edições seguintes, onde cada etapa da experiência é descrita em tópicos distintos, a saber: introdução, caracterização da situação anterior, descrição da experiência, objetivos propostos e resultados visados, ações realizadas, etapas da implementação, recursos utilizados, caracterização da situação atual e lições aprendidas. Essa é uma das limitações da análise de documentos, visto que os recursos disponíveis podem forçar o pesquisador a ser seletivo, ao invés de utilizar todos os documentos disponíveis (Flick, 2009). Duas fontes de informação foram utilizadas para a coleta dos dados: a) os relatos das experiências premiadas, disponíveis no sítio eletrônico da ENAP; e b) os relatos das experiências finalistas, coletados diretamente na ENAP. Ambos os documentos possuem os mesmos tipos de dados, que incluem as informações necessárias para identificar as variáveis de interesse do presente estudo. 
A obtenção de dados das experiências nos relatos se deu por meio de uma análise de conteúdo, definida como o exame minucioso da estrutura e dos elementos do conteúdo coletado para esclarecimento dos conceitos ali presentes (Laville \& Didone, 1999). Os relatos das experiências passaram pelas etapas da análise de conteúdo propostas por Bardin 2006). Inicialmente realizou-se a pré-análise, consistente da leitura flutuante dos documentos. Em seguida, fez-se a exploração do material, a fim de identificar as informações de interesse do estudo. Para Bardin (2006), a categorização das informações pode se basear em dois processos: o sistema de categorias fornecidas, ou ex ante, ou o sistema de categorias não fornecida, ou ex post. As categorias utilizadas no presente estudo foram fruto da revisão da literatura acerca das variáveis de interesse, portanto são categorias fornecidas. A última etapa trata-se do tratamento dos resultados, momento onde há a inferência e interpretação dos dados coletados.

Por meio da análise de conteúdo, identificou-se a ocorrência das categorias específicas das variáveis do modelo teórico proposto nos relatos das experiências a partir da leitura de cada caso e checagem com as variáveis integrantes do protocolo de codificação, disposto no Anexo A, e o preenchimento da tabela de codificação, disposta no Anexo B. As variáveis foram codificadas como variáveis dicotômicas binárias, sendo 1 a presença da categoria no relato da experiência, e 0 a ausência desta categoria. A escolha do formato binário foi baseada nas variáveis que não possuem categorias mutualmente exclusivas, tais como capacidades, indutores e resultados de inovação. Para essas variáveis, era possível identifica nenhuma, uma, ou mais de uma categoria no mesmo caso. Para a variável tipo de inovação, uma única categoria tinha de ser selecionada por experiência. Além das variáveis presentes no protocolo de codificação, foram também coletados dados referentes ao nível de atuação do governo, estruturas administrativas e áreas temáticas. Estes dados foram fornecidos nos relatos e não precisaram ser tratados pelo procedimento de codificação.

De modo a se obter maior nível de confiabilidade ao processo de coleta de dados, utilizou-se a técnica de triangulação de investigadores. De acordo com Denzin (1989), este é o tipo de triangulação onde diferentes pesquisadores são empregados para detectar ou minimizar vieses do pesquisador enquanto pessoa. Para o presente estudo, a codificação das variáveis foi realizada por um grupo de integrantes do Núcleo de Estudos e Pesquisa em Inovação e Estratégia (NINE), composto por pesquisadores com interesse em inovação, melhoria contínua, estratégia e desenvolvimento de modelos de gestão para os setores público e privado. Os pesquisadores realizaram a codificação de forma independente, e os dados foram comparados para obtenção dos dados finais utilizados nas análises. 


\subsubsection{Concurso de Inovação da Escola Nacional de Administração Pública}

No Brasil, a existência do Concurso Inovação na Gestão Pública Federal, promovido pela Escola Nacional de Administração Pública (ENAP), oferece uma preciosa fonte de dados para o estudo da inovação no setor público. A primeira edição deste concurso foi realizada no ano de 1996, tendo o objetivo de identificar, premiar e divulgar iniciativas bem-sucedidas de inovação na gestão pública brasileira, desenvolvidas por organizações do Poder Executivo Federal (Petrucci \& Rua, 1998). O concurso foi criado com o intuito de dar visibilidade às mudanças em curso na gestão pública (Coutinho, 2002). A partir de sua terceira edição, o concurso, na época chamado Concurso de Experiências Inovadoras de Gestão na Administração Pública Federal, passou a se chama Prêmio Hélio Beltrão, em homenagem ao ex-ministro da desburocratização. Nesta edição, deu-se destaque ao atendimento ao usuário, em especial aos serviços de unidade móvel que vão até o cidadão-usuário para melhor servi-lo (Petrucci \& Umbelino, 1999). A partir de 1999, estabeleceu-se o início de uma nova fase do concurso, onde seu objetivo principal passou a ser o reconhecimento de melhores práticas. Nesta edição as iniciativas passaram a ser julgadas pelo êxito obtido no alcance de resultados quantitativos e qualitativos medidos por indicadores de desempenho corretamente especificados. Até sua sétima edição, o conceito de inovação adotado pelo concurso não se relacionava a ineditismo, mas à superação da cultura burocrática e à adoção de princípios e instrumentos gerenciais. No entanto, o conceito de inovação enquanto a geração e introdução de novas práticas e de novos conhecimentos em gestão pública começou a ser utilizado a partir da $8^{\mathrm{a}}$ edição do concurso (Morais, 2005), fato acompanhado pela mudança do nome para Concurso Inovação na Gestão Pública Federal, utilizado até hoje (Paiva \& Araújo, 2004).

O concurso passou por diversos aperfeiçoamentos ao longo do tempo, sendo a revisão de 2007, que teve o objetivo de tornar mais precisas as informações enviadas pelos participantes, dar maior clareza aos critérios de seleção e oferecer melhores condições de avaliação ao Comitê Julgador, uma das mais amplas já realizadas. Dos esforços de revisão resultaram melhorias nos instrumentos, como manuais, fichas de inscrição e regulamento; maior clareza nos conceitos e definições utilizados; e a adição de uma nova fase de avaliação das experiências, representada por visitas in loco às 20 experiências finalistas pré-classificadas pelo Comitê Julgador (ENAP, 2008).

$\mathrm{O}$ atual processo de avaliação das iniciativas é composto por cinco etapas. Na primeira etapa, as inscrições passam por uma triagem interna, na qual são verificados os requisitos 
básicos constantes do regulamento, tais como tempo mínimo de implementação, não ter sido premiada em outra edição do concurso, pertencer ao Poder Executivo federal, entre outros. $\mathrm{O}$ segundo passo trata-se de uma avaliação inicial dos relatos pelo Comitê Julgador, onde são atribuídas notas para cada critério, com o objetivo de selecionar as 20 iniciativas que irão receber a visita do Comitê Técnico. Na terceira etapa, as 20 iniciativas selecionadas recebem a visita de uma dupla de integrantes do Comitê Técnico. Durante a visita in loco, os avaliadores técnicos têm o objetivo de averiguar e aprofundar as informações constantes do relato, assim como esclarecer quaisquer dúvidas dos membros do Comitê Julgador, que recebe e avaliar os relatórios das visitas técnicas na quarta etapa. A quinta etapa consiste em reunião do Comitê Julgador, com participação dos avaliadores técnicos, a fim de aprofundar o conhecimento sobre as iniciativas e embasar a escolha e classificação das dez inovações premiadas (Pereira, 2013).

\subsection{Procedimento de Análise dos Dados}

A primeira análise de dados realizada, de caráter descritivo, consistiu na consolidação das frequências de observação das categorias das variáveis e outras informações descritivas nos relatos das experiências selecionadas. Estas descrições fornecem um entendimento inicial da estrutura das inovações. As análises das relações entre variáveis foram feitas pela utilização de regressões logísticas. A escolha deste método se deu pela natureza da codificação das variáveis, visto que estas assumiram formato dicotômico e a saída das relações destas é a probabilidade de ocorrência ou não de um resultado que se constitui também em um dado binário. Field (2009) considera que um resultado dicotômico viola o princípio de linearidade na relação entre variáveis, o que torna inviável a utilização de qualquer tipo de regressão linear. A regressão logística transforma os dados utilizando uma equação logarítmica, tendo o efeito de criar o formato de relação linear mantendo a relação em si como não-linear. Dessa forma, este método expressa a equação de uma regressão linear múltipla em termos logarítmicos, superando o problema de violação do pressuposto de linearidade.

A execução dos testes de regressão logística foi realizada no método de eliminação para trás por razão de verossimilhança. Este método possui um risco menor de erro de Tipo II por trabalhar com uma maior probabilidade de eliminar preditores com efeitos supressores (Field, 2009). De modo a testar as diversas possibilidades de relação entre as variáveis, os seguintes modelos de regressão foram utilizados: 
- Capacidades (antecedente) e Tipo de inovação (resultante);

- Indutores (antecedente) e Tipo de inovação (resultante);

- Capacidades e Indutores (antecedentes) e Tipo de inovação (resultante);

- Tipo de inovação (antecedente) e Resultados de inovação (resultante);

- Capacidades, Indutores e Tipo de inovação (antecedentes) e Resultados de inovação (resultante).

Dada a natureza mutualmente exclusiva das categorias da variável Tipo de inovação, cada tipo específico compôs um modelo a ser testado. No caso das variáveis Capacidade e Indutores, que não são de natureza mutualmente exclusiva, os testes foram executados em dois passos: inicialmente com a inserção das categorias separadamente nos modelos e posteriormente com a inserção conjunta das categorias com coeficientes mais relevantes, de modo a averiguar a potencialização do efeito pela presença conjunta de diferentes categorias.

Além das regressões logísticas, foi executa um teste de Qui-quadrado de Pearson entre as variáveis de interesse do estudo e os períodos aos quais as experiências selecionadas pertenciam. Os dois períodos definidos foram dos anos 1999 a 2006, e 2007 a 2014 . A realização deste teste tornou-se necessária devido à mudança metodológica ocorrida no processo de análise e premiação do prêmio da ENAP em 2007. Neste ano foram implementadas visitas in loco às experiências finalistas. O teste Qui-quadrado de Pearson permite observar se há relação entre duas variáveis categóricas (Field, 2009). Dessa maneira, foi possível averiguar se as variáveis Capacidades, Indutores, Tipos e Resultados de inovação eram independentes do período. 


\section{RESULTADOS}

\subsection{Dados Descritivos das Experiências}

A análise descritiva das experiências é dividida em duas partes. A primeira verifica os dados característicos das experiências: nível de atuação do governo, estrutura administrativa e área temática. A segunda parte foca sob as variáveis de interesse: capacidades, indutores, tipos e resultados de inovação. Em relação aos dados característicos das experiências, a primeira característica analisada foi o nível de atuação do governo. Duas categorias são consideradas: governo centralizado, que é composto por organizações localizadas no Distrito Federal, e governo descentralizado, composta por organizações localizadas fora do Distrito Federal. Os resultados demonstram que as organizações do governo centralizado representam a maioria entre as experiências selecionadas. Algumas possíveis razões para este resultado são levantadas. Primeiro, a ENAP, instituição responsável pelo prêmio, é localizada no Distrito Federal, e a divulgação do prêmio pode ter maior poder de difusão em organizações próximas, significando que mais organizações do governo centralizado teriam conhecimento do prêmio e submeteriam suas experiências. Segundo, organizações do governo centralizado tendem a ser maiores em tamanho do que organizações de governo descentralizado e, devido ao seu tamanho, é possível que as mesmas instituições estejam submetendo muitas experiências, enquanto organizações menores estão focadas em menos iniciativas estratégicas de inovação. Terceiro, muitas ações tomadas pelo governo para incentivar a inovação no setor público, como é o caso do prêmio, se iniciam no nível central, e estas organizações tem acesso mais fácil a conhecimentos, sistemas e práticas que ajudam estabelecer suas próprias iniciativas. O Quadro 8 apresenta a distribuição de casos por nível de atuação do governo.

\begin{tabular}{|c|c|c|}
\hline Nível de Atuação & Número de casos & Percentual \\
\hline Governo Centralizado & 183 & 63,8 \\
\hline Governo Descentralizado & 104 & 36,2 \\
\hline TOTAL & 287 & 100,0 \\
\hline
\end{tabular}

Quadro 8. Frequência de casos por nível de atuação do governo Fonte: Elaborado pelo autor.

Em seguida observou-se a estrutura administrativa das organizações com experiências selecionadas. Duas categorias são observadas. Estrutura direta se refere aos serviços integrados à estrutura administrativa da Presidência e dos Ministérios. Estrutura indireta é composta de entidades com sua própria pessoa jurídica, tais como autarquias, empresas públicas e fundações 
públicas. Os percentuais obtidos são próximos àqueles observados no nível do governo. Visto que a maioria das organizações do governo centralizado são de estrutura direta, esse resultado é esperado. A diferença no número de casos se dá devido às organizações de estrutura indireta localizadas no Distrito Federal. Os resultados para estrutura administrativa são apresentados no Quadro 9.

\begin{tabular}{|c|c|c|}
\hline Estrutura Administrativa & Número de casos & Percentual \\
\hline Direta & 159 & 55,4 \\
\hline Indireta & 128 & 44,6 \\
\hline TOTAL & 287 & 100,0 \\
\hline
\end{tabular}

Quadro 9. Frequência de casos por estrutura administrativa Fonte: Elaborado pelo autor.

Para área temática foram consideradas cinco categorias. Essas áreas são definidas pelo prêmio e cada organização deve apontar o tema mais próximo à sua experiência no momento da submissão do caso. A categoria mais incidente foi otimização e melhoria de processos, que se refere ao estabelecimento de parâmetros de qualidade, análise e implementação de melhoria contínua, e simplificação e racionalização de procedimentos. A segunda categoria mais utilizada foi planejamento e gestão organizacional, relacionada a iniciativas que focam em planejamento estratégico, gestão estratégica, gestão orçamentária e financeira, gestão de custos, gestão do conhecimento, construção e aplicação de indicadores de gestão, e avaliação do desempenho e controle dos resultados institucionais. As categorias de caráter finalístico, política pública e prestação de serviços, que se referem, respectivamente, a experiências na criação e implementação de sistemas de monitoramento ou avaliação de políticas públicas e a processos que objetivam responder diretamente a cidadãos, ficaram em terceiro e quarto lugar. A categoria menos incidente foi gestão da informação, apontada em experiências sobre informatização da gestão e uso de tecnologias para redesenhar processos e abrir canais de comunicação com cidadãos. Apesar da pequena diferença em percentuais, percebe-se uma preferência por iniciativas focadas em melhorias back office, que podem, possivelmente, ter um efeito indireto sobre áreas finalísticas, como entrega de serviços e política pública. O Quadro 10 apresenta a distribuição de casos entre as áreas temáticas.

\begin{tabular}{|c|c|c|}
\hline Área Temática & Número de casos & Percentual \\
\hline Otimização e melhoria de processos & 66 & 23,0 \\
\hline Planejamento e gestão organizacional & 65 & 22,6 \\
\hline Política pública & 57 & 19,9 \\
\hline Prestação de serviços & 52 & 18,1 \\
\hline Gestão da informação & 47 & 16,4 \\
\hline TOTAL & 287 & 100,0 \\
\hline
\end{tabular}

Quadro 10. Frequência de casos por área temática Fonte: Elaborado pelo autor. 
Em relação às variáveis de interesse, a primeira análise refere-se aos tipos de inovação, de acordo com a tipologia de Bloch (2011). A maioria dos casos (61\%) ficaram concentrados em duas categorias, sendo o primeiro tipo inovações de processo e o segundo inovações de produto, com percentuais próximos de $31 \%$ e $30 \%$, respectivamente. Este resultado demonstra uma dualidade, entre os relatos selecionados, em relação à introdução de novos processos e de novos produtos ou serviços. Esta dualidade diz respeito ao foco das inovações, sendo as inovações de processo comumente relacionadas a melhorias internas da organização e as inovações de produto ou serviço com foco externo e em melhorias na entrega de serviços para os usuários. Com percentual de 27,2\% estão as inovações organizacionais, sendo este um valor também próximo às inovações de processo e de produto ou serviço, demonstrando a existência de iniciativas que também focam na introdução de novos métodos organizacionais aplicados em suas respectivas organizações. Na última posição encontram-se as inovações de comunicação, representando $11,8 \%$ dos casos selecionados. O baixo número de inovações de comunicação frente aos demais tipos pode se dar devido ao foco dado pelos relatos aos novos métodos de entrega de serviços, em especial em casos com potencialidade para introdução de novos métodos de comunicação com usuários finais, o que levaria a inovação a ser classificada como inovação de produto ou serviço e não como inovação de comunicação. Os resultados acerca do número de casos por tipo de inovação podem ser observados no Quadro 11.

Quadro 11. Frequência de casos por tipo de inovação

\begin{tabular}{|c|c|c|}
\hline Tipos de Inovação & Número de casos & Percentual \\
\hline Inovação de processo & 89 & 31,0 \\
\hline Inovação de produto & 86 & 30,0 \\
\hline Inovação organizacional & 78 & 27,2 \\
\hline Inovação de comunicação & 34 & 11,8 \\
\hline TOTAL & 287 & 100,0 \\
\hline
\end{tabular}

Fonte: Elaborado pelo autor.

Em seguida foram verificadas as capacidades de inovação. Como o mesmo caso pode ter nenhuma, uma, ou mais de uma capacidade relatada ao mesmo tempo, o número total de capacidades computado pode excedeu o número de casos selecionados, totalizado 1098 capacidades. A média de capacidades por relato foi de 3,82, demonstrando que, em média, cada caso apresentava várias capacidades de inovação ao mesmo tempo. Entre as capacidades relatadas com maior frequência encontram-se gestão de pessoas para inovação e gestão de projetos, contidas em $75,3 \%$ e $71,1 \%$ dos casos, respectivamente. As práticas de gestão que demonstram a presença destas capacidades são amplas em variedade, o que facilita seu relato e posterior identificação. Estas práticas também são usualmente citadas em processos de gestão 
de inovações (Tidd et al., 1997; Pavitt, 2004; Tidd e Hull, 2006), o que poderia tornar seu relato mais comum entre praticantes com conhecimento em gestão de inovação. Em seguida encontram-se as capacidades gestão estratégica da tecnologia (59,6\%), capacidade relatada em especial nos casos que envolvem inovações relacionadas à aquisição ou desenvolvimento de uma nova tecnologia da informação; liderança transformadora $(57,1 \%)$, que acompanha muitas práticas de gestão de pessoas para inovação; organicidade da estrutura organizacional (53,7\%; e conhecimento do usuário e do ambiente (47\%), sendo em diversos casos a existência de práticas de coprodução com usuários e parceiros também presente, o que pode representar uma prática desta capacidade. Em última posição está a capacidade intenção estratégica de inovar, relata em 18,8\% dos casos. Percebe-se nos relatos que, em sua maioria, não se destaca a existência de um planejamento estratégico com foco em inovação. Muitas vezes também se encontram relatos que focam na liderança transformadora como papel representante de uma intenção de cima para baixo de inovar, mas não se destaca a existência de uma prática de gestão que poderia demonstrar a presença de intenção estratégica de inovar. Os resultados referentes às frequências das capacidades de inovação podem ser observados no Quadro 12.

\begin{tabular}{|c|c|c|c|}
\hline Capacidades de Inovação & Número de casos & \% (de 287) & \% (de 1098) \\
\hline Gestão de pessoas para inovação & 216 & 75,3 & 19,7 \\
\hline Gestão de projetos & 204 & 71,1 & 18,6 \\
\hline Gestão estratégica da tecnologia & 171 & 59,6 & 15,6 \\
\hline Liderança transformadora & 164 & 57,1 & 14,9 \\
\hline Organicidade da estrutura organizacional & 154 & 53,7 & 14,0 \\
\hline Conhecimento do usuário e do ambiente & 135 & 47,0 & 12,3 \\
\hline Intenção estratégica de inovar & 54 & 18,8 & 4,9 \\
\hline TOTAL & 1098 & 382,6 & 100,0 \\
\hline
\end{tabular}

Quadro 12. Frequência de casos por capacidade de inovação Fonte: Elaborado pelo autor.

Assim como para as capacidades, o mesmo caso pode relatar nenhum, um, ou mais de um indutor de inovação ao mesmo tempo, sendo o número total de indutores computado maior que o número de casos selecionados, totalizando 313 indutores relatados. A média de indutores relatados por caso é de 1,09, portanto, a maior parte das experiências relata apenas um indutor. Os indutores mais frequentes são o não orientado a problema (47\%) e orientado a problema $(37,3 \%)$. Estes indutores representam focos opostos para início de um processo de desenvolvimento de introdução de inovações. $O$ indutor não orientado a problema foi relatado em 135 casos, número próximo à metade das experiências, o que representa que, de acordo com os relatos, cerca de uma a cada duas inovações desenvolvidas surgem de oportunidades de melhoria identificadas, e não para resolver um problema específico. Entre os demais indutores, imposição legal representa 10,8\% dos casos, impulso político foi relatado em 8,7\% dos casos, 
e fatores tecnológicos estão presentes em 5,2\% das experiências. Destaca-se aqui que estes três últimos indutores podem ser percebidos enquanto indutores não orientados ou orientados a problema, o que pode dificultar sua identificação e posterior codificação caso não haja sua clara especificação nos relatos. O Quadro 13 apresenta os resultados de frequência de indutores de inovação.

\begin{tabular}{|c|c|c|c|}
\hline Indutores de Inovação & Número de casos & \% (de 287) & \% (de 313) \\
\hline Não orientado a problema & 135 & 47,0 & 43,1 \\
\hline Orientado a problema & 107 & 37,3 & 34,2 \\
\hline Imposição legal & 31 & 10,8 & 9,9 \\
\hline Impulso político & 25 & 8,7 & 8,0 \\
\hline Fatores tecnológicos & 15 & 5,2 & 4,8 \\
\hline TOTAL & 313 & 109,1 & 100,0 \\
\hline
\end{tabular}

Quadro 13. Frequência de casos por indutor de inovação Fonte: Elaborado pelo autor.

Para os resultados de inovação também era possível o mesmo caso relatar nenhum, um ou mais de um resultado ao mesmo tempo, sendo o número total de resultados computado igual a 537. A média de resultados por caso é de 1,87, o que demonstra que uma grande parte das experiências relatam mais de uma melhoria como fruto da inovação desenvolvida e introduzida. Os resultados mais relatados foram melhoria da gestão organizacional, em 69,7\% dos casos, e melhoria na entrega e/ou qualidade dos serviços, em $69 \%$ das experiências. Estes resultados podem estar relacionados aos tipos mais frequentes de inovação relatados, inovações de processo e organizacionais para melhoria da gestão organizacional, e inovações de produto ou serviço para melhoria na entrega e/ou qualidade dos serviços. Esta influência entre tipos e resultados será mais aprofundada por meio das análises de regressão, que permitirão investigar se há de fato uma relação entre os tipos e resultados mais frequentes. A melhoria da imagem organizacional é relatada em $34,5 \%$ dos casos e a melhoria do clima organizacional em 13,9\% dos casos, sendo este último o resultado de inovação menos frequente. As melhorias de clima organizacional podem ser relatadas em formato que permita apenas a codificação como melhoria de gestão organizacional, o que poderia justificar o baixo percentual obtido. Os resultados referentes às frequências dos resultados de inovação podem ser vistos no Quadro 14.

\begin{tabular}{|c|c|c|c|}
\hline Resultados de Inovação & Número de casos & \% (de 287) & \% (de 537) \\
\hline Melhoria da gestão organizacional & 200 & 69,7 & 37,2 \\
\hline Melhoria na entrega dos serviços & 198 & 69,0 & 36,9 \\
\hline Melhoria da imagem institucional & 99 & 34,5 & 18,4 \\
\hline Melhoria do clima organizacional & 40 & 13,9 & 7,4 \\
\hline TOTAL & 537 & 187,1 & 100,0 \\
\hline
\end{tabular}

Quadro 14. Frequência de casos por capacidade de inovação Fonte: Elaborado pelo autor. 


\subsection{Dependência em Relação ao Período de Submissão}

Devido à mudança metodológica ocorrida no processo de análise e premiação do prêmio da ENAP em 2007, foi necessário investigar a existência de dependência entre as variáveis de interesse do estudo e o período aos quais as experiências selecionadas pertenciam. Os resultados do teste de Qui-quadrado podem ser observados no Quadro 10.

\begin{tabular}{|l|c|c|}
\hline \multicolumn{1}{|c|}{ Tipos de Inovação } & Qui-quadrado de Pearson & Sig. (2 lados) \\
\hline Produto & 1,720 & 0,190 \\
\hline Processo & 0,173 & 0,678 \\
\hline Comunicação & 0,566 & 0,452 \\
\hline Organizacional & 2,146 & 0,143 \\
\hline \multicolumn{1}{|c|}{ Capacidades de Inovação } & Qui-quadrado de Pearson & Sig. (2 lados) \\
\hline Liderança transformadora & 5,284 & 0,022 \\
\hline Intenção estratégica de inovar & 23,981 & 0,000 \\
\hline Gestão de pessoas para inovação & 0,506 & 0,477 \\
\hline Conhecimento do usuário e do ambiente & 8,524 & 0,004 \\
\hline Gestão estratégica da tecnologia & 1,279 & 0,258 \\
\hline Organicidade da estrutura organizacional & 4,452 & 0,035 \\
\hline Gestão de projetos & 4,104 & 0,043 \\
\hline \multicolumn{1}{|c|}{ Indutores de Inovação } & 0,110 & Sig. (2 lados) \\
\hline Orientado a problema & 0,031 & 0,740 \\
\hline Não orientado a problema & 0,001 & 0,860 \\
\hline Impulso político & 1,984 & 0,979 \\
\hline Fatores tecnológicos & 6,616 & 0,159 \\
\hline Imposição legal & 0,010 & 0,010 \\
\hline \multicolumn{1}{|c|}{ Resultados de Inovação } & 2,021 & Sig. (2 lados) \\
\hline Melhoria na entrega e/ou qualidade dos serviços & 20,686 & 0,922 \\
\hline Melhoria da gestão organizacional & 17,814 & 0,155 \\
\hline Melhoria da imagem e relações institucionais & Qui-quadrado de Pearson & 0,000 \\
\hline Melhoria do clima organizacional & 0,000 \\
\hline
\end{tabular}

Quadro 10. Dependência das variáveis de interesse em relação ao período de submissão

Fonte: Elaborado pelo autor.

A existência de valores de significância $\mathrm{p}>0.05$ para todas as variáveis - tipos, capacidades, indutores e resultados de inovação - indica que as evidências são insuficientes para rejeitar a hipótese nula de que as variáveis são independentes. Conclui-se, portanto, que a alteração da metodologia de avaliação do prêmio ocorrida em 2007 não afeta o comportamento das variáveis, logo, as experiências dos períodos 1999 a 2006 e 2007 e 2014 podem ser testadas conjuntamente nos modelos de regressão. 


\subsection{Relações entre Capacidades e Tipos de Inovação}

O primeiro modelo de regressão logística explora a relação entre capacidades e tipos de inovação. A probabilidade de ocorrência de cada tipo de inovação foi avaliada em relação à presença das capacidades de inovação, sendo que as capacidades foram inseridas individualmente. A inserção de categorias de capacidades em conjunto não resultou em relações significativas com os tipos de inovação. As relações representadas a seguir são aquelas que apresentaram resultado significativo:

\begin{tabular}{|c|c|c|c|}
\hline \multicolumn{4}{|c|}{ RESULTANTE: Inovação de produto } \\
\hline Variáveis na equação & B & $\operatorname{Exp}(\mathbf{B})$ & Sig. \\
\hline Gestão de pessoas para inovação & 0,823 & 2,278 & 0,015 \\
\hline Constante & $-1,495$ & 0,224 & 0,000 \\
\hline \multicolumn{4}{|c|}{$\mathrm{R}^{2}=0,022($ Cox \& Snell) / 0,032 (Nagelkerke) $\mid$ Qui-quadrado $=6,526, \mathrm{p}=0,011$} \\
\hline \multicolumn{4}{|c|}{ RESULTANTE: Inovação de processo } \\
\hline Variáveis na equação & B & $\operatorname{Exp}(\mathbf{B})$ & Sig. \\
\hline Gestão de pessoas para inovação & $-0,666$ & 0,514 & 0,019 \\
\hline Constante & $-0,312$ & 0,732 & 0,194 \\
\hline $\mathrm{R}^{2}=0,019($ Cox \& Snell) $/ 0,026(\mathrm{I}$ & rke) $\mid \mathrm{Qu}$ & $o=5,386$ & 020 \\
\hline \multicolumn{4}{|c|}{ RESULTANTE: Inovação organizacional } \\
\hline Variáveis na equação & B & $\operatorname{Exp}(B)$ & Sig. \\
\hline Intenção estratégia de inovar & 1,054 & 2,868 & 0,002 \\
\hline Conhecimento do usuário e do ambiente & $-0,998$ & 0,369 & 0,001 \\
\hline Gestão estratégica da tecnologia & 0,703 & 2,020 & 0,018 \\
\hline Constante & $-1,234$ & 0,291 & 0,000 \\
\hline \multicolumn{4}{|c|}{$\mathrm{R}^{2}=0,079($ Cox \& Snell) / 0,087 (Nagelkerke) $\mid$ Qui-quadrado $=5,386, p=0,020$} \\
\hline \multicolumn{4}{|c|}{ RESULTANTE: Inovação de comunicação } \\
\hline Variáveis na equação & $\mathbf{B}$ & $\operatorname{Exp}(\mathbf{B})$ & Sig. \\
\hline Conhecimento do usuário e do ambiente & 1,138 & 3,120 & 0,005 \\
\hline Gestão estratégica da tecnologia & $-0,869$ & 0,419 & 0,021 \\
\hline Constante & $-2,214$ & 0,109 & 0,000 \\
\hline $\mathrm{R}^{2}=0,048($ Cox \& Snell) / 0,093 & ke) | Qui & $\mathrm{o}=14,13$ & 001 \\
\hline
\end{tabular}

Quadro 15. Relações significativas entre capacidades e tipos de inovação

Fonte: Elaborado pelo autor

Todos os modelos apresentados possuem Qui-quadrado significativo $(\mathrm{p}<0,05)$, o que indica que os modelos são ajustados aos dados. Para inovação de produto, percebe-se um aumento da probabilidade de ocorrência quando há presença de gestão de pessoas para inovação na iniciativa. Bloch (2011) afirma que uma equipe que possui parte do seu tempo destinado ao desenvolvimento de projetos de inovação, assim como incentivos para identificação de novas ideias, são um dos fatores importantes para a ocorrência de inovações no setor público, o que condiz com o resultado obtido. Por outro lado, a presença da capacidade gestão de pessoas para inovação diminui a probabilidade de ocorrência de inovação de processo para as experiências analisadas. Este resultado pode indicar uma orientação, nas experiências relatadas, da gestão de 
pessoas para a produção de produtos ou serviços novos ou aprimorados, mas não necessariamente para melhoria dos processos. Cabe apontar que em sua definiç̧ão de inovações de processo, Bloch (2011) sugere que aprimoramentos em funções de suporte, como tecnologia da informação, são parte deste tipo de inovação, o que poderia justificar uma relação de probabilidade negativa entre gestão de pessoas e inovações de processo.

Para inovações organizacionais, observa-se um aumento de probabilidade de ocorrência quando há presença das capacidades intenção estratégica de inovar e gestão estratégica da tecnologia. Inicialmente, cabe ressaltar a presença simultânea das duas capacidades, pois de acordo com Valladares et al. (2014) um dos aspectos que representa o domínio da intenção estratégica de inovar é a disposição, por parte da organização, em assumir riscos para o desenvolvimento tecnológico. A gestão da tecnologia por sua vez, pode levar a melhorias significativas dos sistemas de gestão, apontados por Bloch (2011) como parte de inovações organizacionais. Com efeito oposto, a presença da capacidade conhecimento do usuário e do ambiente diminui a probabilidade de ocorrência de inovações organizacionais. Esta relação negativa pode ser fruto da característica de foco externo da capacidade, visto que esta é definida enquanto habilidade para detectar eventos, necessidades, expectativas, mudanças e tendências externos à organização (Valladares et al., 2014), o que poderia mudar o foco de inovações organizacionais para outros tipos, como ocorreu para as inovações de comunicação. Para este tipo, a presença de conhecimento do usuário e do ambiente aumenta a probabilidade de ocorrência da inovação, sendo o maior efeito observado entre as capacidades $(\operatorname{Exp}(B)=3,120)$. A gestão estratégica da tecnologia diminui a probabilidade de ocorrência de inovações de comunicação, podendo este resultado também ser fruto de um foco diferente da capacidade, neste caso interno, e da inovação, neste caso externo.

Em relação à hipótese $\mathrm{H} 1$ - a presença de capacidades de inovação aumenta a probabilidade de ocorrência dos tipos de inovação - obteve-se evidências conflitantes. Para as inovações de produto relatadas, a presença da capacidade gestão de pessoas para inovação teve efeito positivo, o que permite suportar a hipótese $\mathrm{H} 1 \mathrm{a}$ - a presença de capacidades de inovação aumenta a probabilidade de inovação de produto. No entanto, esta mesma capacidade, quando presente no relato da experiência, diminuiu a probabilidade de inovações de processo serem relatadas, o que não dá suporte à hipótese $\mathrm{H} 1 \mathrm{~b}$ - a presença de capacidades de inovação aumenta a probabilidade de ocorrência de inovação de processo. Para inovações de comunicação e organizacionais, obteve-se tanto resultados positivos quanto negativos. A presença da capacidade conhecimento do usuário e do ambiente no relato aumentou a probabilidade de ocorrência de inovação de comunicação no mesmo relato, mas diminuiu a chance de presença 
de inovação organizacional. A capacidade gestão estratégica da tecnologia teve efeito contrário, aumentando a chance de relato de inovações organizacionais, mas diminuindo a probabilidade de ocorrência de inovações de comunicação. Deste modo, as hipóteses H1c - a presença de capacidades de inovação aumenta a probabilidade de ocorrência de inovação de comunicação e H1d - a presença de capacidades de inovação aumenta a probabilidade de ocorrência de inovação organizacional - são suportadas apenas parcialmente. A natureza mutualmente exclusiva dos tipos de inovação pode levar à uma exclusividade dos elementos antecessores nos modelos de regressão. Devido à impossibilidade de ocorrência de mais de um tipo de inovação na mesma experiência, se uma capacidade aumenta a chance de ocorrência de um tipo ela poderia, automaticamente, diminuir a chance dos três outros. Com base nos resultados obtidos, a hipótese $\mathrm{H} 1$ é suportada parcialmente. A representação gráfica das relações encontradas entre capacidades e tipos de inovação pode ser observada na Figura 5.

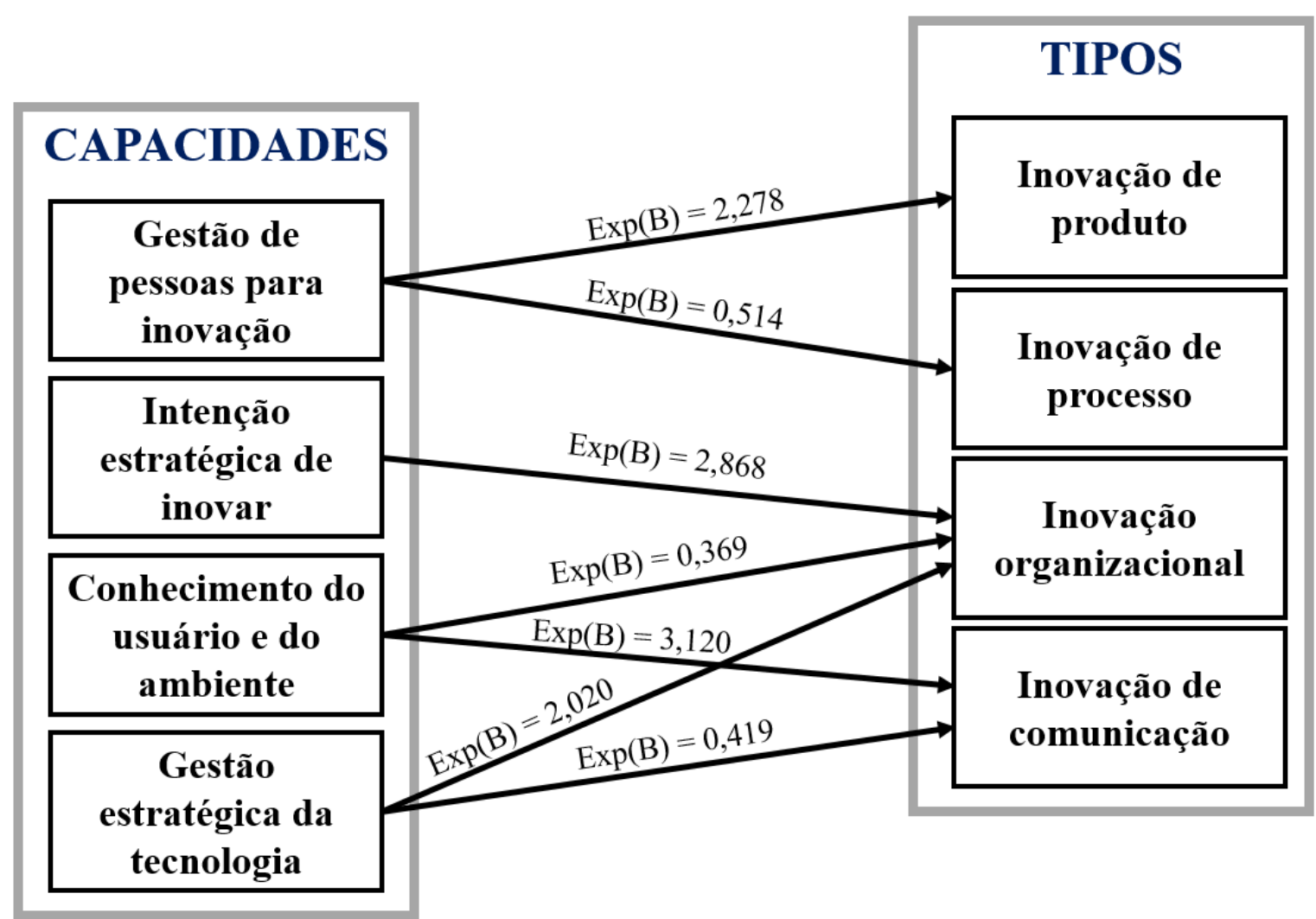

Figura 5. Relações significativas entre capacidades e tipos de inovação Fonte: Elaborado pelo autor. 


\subsection{Relações entre Indutores e Tipos de Inovação}

O segundo modelo de regressão logística explora a relação entre indutores e tipos de inovação. A probabilidade de ocorrência de cada tipo de inovação foi avaliada em relação à presença dos indutores de inovação, sendo que os indutores foram inseridos individualmente. A inserção de categorias de indutores em conjunto não resultou em relações significativas com os tipos de inovação. As relações representadas a seguir são aquelas que apresentaram resultado significativo:

\begin{tabular}{|c|c|c|c|}
\hline \multicolumn{4}{|c|}{ RESULTANTE: Inovação de processo } \\
\hline Variáveis na equação & $\mathbf{B}$ & $\mathbf{E x p}(\mathbf{B})$ & Sig. \\
\hline Orientado a problema & 2,024 & 7,569 & 0,001 \\
\hline Não orientado a problema & 1,766 & 5,849 & 0,002 \\
\hline Imposição legal & 1,349 & 3,853 & 0,010 \\
\hline Constante & $-2,605$ & 0,074 & 0,000 \\
\hline $\mathrm{R}^{\mathbf{2}}=$ 0,057 (Cox \& Snell) / 0,080 (Nagelkerke) $\mid$ Qui-quadrado $=16,871, \mathrm{p}=0,001$ \\
\hline RESULTANTE: Inovação de comunicação \\
\hline Variáveis na equação & $\mathbf{B}$ & $\mathbf{E x p}(\mathbf{B})$ & Sig. \\
\hline Impulso político & 1,219 & 3,385 & 0,013 \\
\hline Constante & $-2,164$ & 0,115 & 0,000 \\
\hline $\mathrm{R}^{2}=0,019$ (Cox \& Snell) / 0,036 (Nagelkerke) $\mid$ Qui-quadrado $=5,375, \mathrm{p}=0,020$ \\
\hline
\end{tabular}

Quadro 16. Relações significativas entre indutores e tipos de inovação Fonte: Elaborado pelo autor

Todos os modelos apresentados possuem Qui-quadrado significativo ( $\mathrm{p}<0,05)$, o que indica que os modelos são ajustados aos dados. Para inovação de processo, observa-se que a presença de três indutores aumenta a probabilidade de ocorrência deste tipo de inovação. A influência de imposição legal sobre inovações de processo converge com a afirmativa de Agolla e Lill (2013), que apontam que organizações de setor público são fundadas por meio de legislação e sua operação deve acontecer dentro dos parâmetros da legislação. Dessa forma, uma alteração ou nova imposição legal poderia alterar os requisitos de operação das organizações, incentivando o desenvolvimento de inovações de processo. As inovações de processo também aumentam em probabilidade de ocorrência na presença dos indutores não orientado a problema e orientado a problema. Inovações de processo não orientadas a problema podem se referir a iniciativas de melhoria contínua e modernização da gestão pública. Por outro lado, a orientação a problema representa o maior efeito observado na probabilidade de ocorrência das inovações de processo $(\operatorname{Exp}(B)=7,569)$, representando as melhorias implementadas em resposta a pressões específicas, podendo as próprias pressões legais representarem uma orientação a problema. Para inovações de comunicação, a presença do 
indutor impulso político aumenta a probabilidade de ocorrência da inovação. Considerando que impulso político pode refletir a necessidade de resposta a eventos críticos e pressões externas, sendo fruto de decisões estratégicas do topo para a base (Koch \& Hauknes, 2005), uma inovação nos métodos de comunicação para os usuários e outras partes interessadas da organização pública poderia suprir a necessidade que gerou o indutor.

Em relação à hipótese $\mathrm{H} 2$ - a presença de indutores de inovação aumenta a probabilidade de ocorrência dos tipos de inovação - não foram obtidas evidências para suporte completo da hipótese. Para as inovações de produto relatadas não foram encontradas relações significativas com nenhum indutor, não permitindo suporte à hipótese $\mathrm{H} 2 \mathrm{a}$ - a presença de indutores de inovação aumenta a probabilidade de ocorrência de inovação de produto. A hipótese $\mathrm{H} 2 \mathrm{~b}$ - a presença de indutores de inovação aumenta a probabilidade de ocorrência de inovação de processo - foi suportada, por outro lado, visto que a chance de presença deste tipo no relato era maior quando havia também o relato dos indutores orientado a problema, não orientado a problema ou imposição legal. Da mesma forma, a presença do indutor impulso político no relato da experiência aumentou a probabilidade de uma inovação de comunicação ser relatada no mesmo caso, o que permite suporte à hipótese $\mathrm{H} 2 \mathrm{c}$ - a presença de indutores de inovação aumenta a probabilidade de ocorrência de inovação de comunicação. Assim como para a hipótese $\mathrm{H} 2 \mathrm{a}$, a hipótese $\mathrm{H} 2 \mathrm{~d}$ - a presença de indutores de inovação aumenta a probabilidade de ocorrência de inovação organizacional - não foi suportada, pois nenhum indutor teve efeito positivo sobre a chance de ocorrência deste tipo nos relatos. Cabe ainda pontar que o indutor fatores tecnológicos não apresentou efeito significativo sobre nenhum tipo de inovação. Com base nestes resultados, a hipótese H2 é suportada parcialmente. A representação gráfica das relações encontradas entre indutores e tipos de inovação é apresentada na Figura 6. 


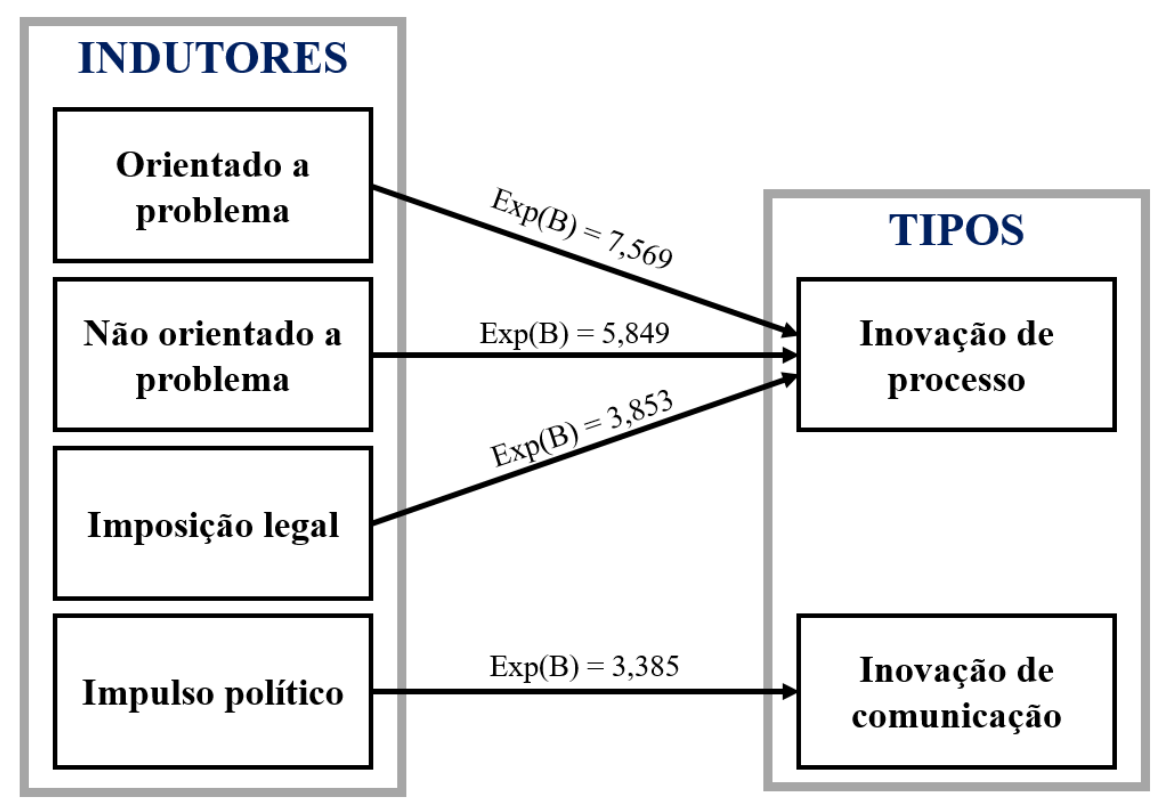

Figura 6. Relações significativas entre indutores e tipos de inovação Fonte: Elaborado pelo autor.

\subsection{Relações entre Capacidades, Indutores e Tipos de Inovação}

O terceiro modelo de regressão logística explora a relação entre capacidades, indutores e tipos de inovação. A probabilidade de ocorrência de cada tipo de inovação foi avaliada em relação à presença das capacidades e dos indutores de inovação, sendo que ambos capacidades e indutores foram inseridos individualmente. A inserção de categorias de capacidades e/ou indutores em conjunto não resultou em relações significativas com os tipos de inovação. As relações representadas a seguir são aquelas que apresentaram resultado significativo:

\begin{tabular}{|c|c|c|c|}
\hline \multicolumn{4}{|c|}{ RESULTANTE: Inovação de processo } \\
\hline Variáveis na equação & B & $\operatorname{Exp}(B)$ & Sig. \\
\hline Orientado a problema & 2,058 & 7,830 & 0,000 \\
\hline Não orientado a problema & 1,782 & 5,940 & 0,002 \\
\hline Imposição legal & 1,330 & 3,780 & 0,011 \\
\hline Gestão de pessoas para inovação & $-0,704$ & 0,495 & 0,017 \\
\hline Constante & $-2,108$ & 0,121 & 0,000 \\
\hline \multicolumn{4}{|c|}{$\mathrm{R}^{2}=0,075$ (Cox \& Snell) / 0,106 (Nagelkerke) $\mid$ Qui-quadrado $=22,483, \mathrm{p}=0,000$} \\
\hline \multicolumn{4}{|c|}{ RESULTANTE: Inovação de comunicação } \\
\hline Variáveis na equação & B & $\operatorname{Exp}(B)$ & Sig. \\
\hline Impulso político & 1,181 & 3,257 & 0,023 \\
\hline Conhecimento do usuário e do ambiente & 1,132 & 3,101 & 0,005 \\
\hline Gestão estratégica da tecnologia & $-0,810$ & 0,445 & 0,034 \\
\hline Constante & $-2,387$ & 0,92 & 0,000 \\
\hline \multicolumn{4}{|c|}{$\mathrm{R}^{2}=0,063($ Cox \& Snell) $/ 0,123$ (Nagelkerke) $\mid$ Qui-quadrado $=18,787, \mathrm{p}=0,000$} \\
\hline
\end{tabular}

Quadro 17. Relações significativas entre capacidades, indutores e tipos de inovação

Fonte: Elaborado pelo autor 
Todos os modelos apresentados possuem Qui-quadrado significativo ( $\mathrm{p}<0,05$ ), o que indica que os modelos são ajustados aos dados. Para as inovações de processo, os efeitos observados na presença de capacidades e indutores simultaneamente se repetem em relação aos testes realizados com essas variáveis de forma separada. A presença dos indutores orientado a problema, não orientado a problema e imposição legal nos relatos aumentam a probabilidade de ocorrência de uma inovação de processo no mesmo relato, enquanto a presença da capacidade gestão de pessoas para inovação diminui esta probabilidade. Nenhum novo indutor ou nova capacidade foram acrescentados ao modelo, o que demonstra que os efeitos das variáveis não presentes na equação não passaram a ser significativos quando os demais indutores e/ou capacidades foram adicionados ao teste. A partir dos resultados obtidos, a hipótese $\mathrm{H} 3 \mathrm{~b}$ - a presença de capacidades e indutores de inovação aumenta a probabilidade de ocorrência de inovação de produto - apresentou evidências para suporte apenas parcial, visto que as capacidades identificadas aumentam a probabilidade, mas o indutor diminui. A representação das relações observadas entre capacidades, indutores e inovações de processo pode ser vista na Figura 7.

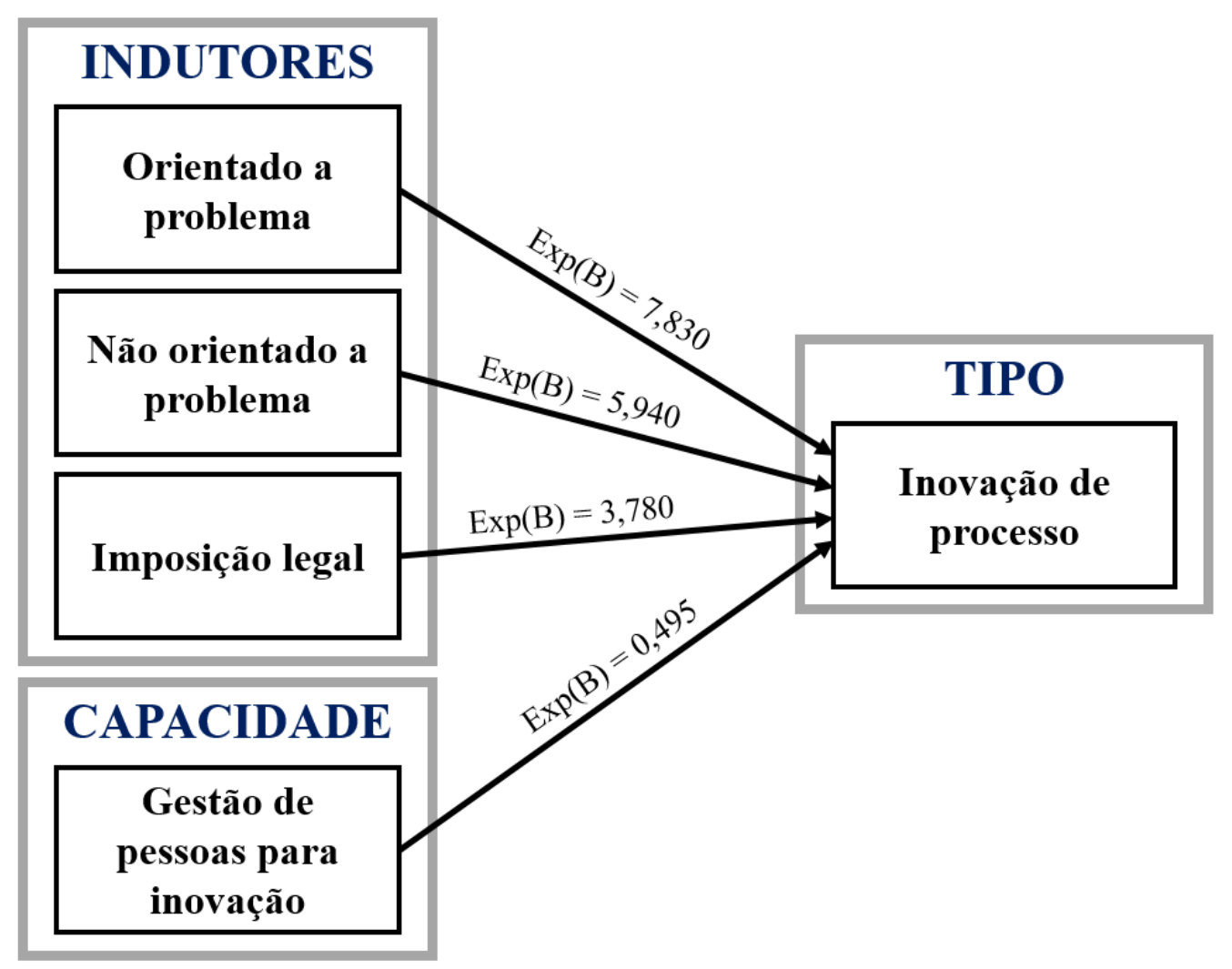

Figura 7. Relações significativas entre capacidades, indutores e inovação de processo Fonte: Elaborado pelo autor 
Em relação às inovações de comunicação, os resultados obtidos também se repetem em relação aos testes realizados com as capacidades e indutores de forma separada. A presença do indutor impulso político e da capacidade conhecimento do usuário e do ambiente no relato aumentam a probabilidade de ocorrência de uma inovação de comunicação no mesmo relato, enquanto a presença da capacidade gestão estratégica da tecnologia diminui esta probabilidade. Assim como para as inovações de processo, nenhum novo indutor ou nova capacidade foram acrescentados ao modelo, novamente demonstrando que os efeitos das variáveis não presentes na equação não passaram a ser significativos quando os demais indutores e/ou capacidades foram adicionados ao teste. Pelos resultados observados, a hipótese H3c - a presença de capacidades e indutores de inovação aumenta a probabilidade de ocorrência de inovação de comunicação - foi suportada parcialmente, visto que há relação negativa estabelecida entre a capacidade gestão estratégica e a chance de ocorrência de uma inovação de comunicação, não permitindo suporte completo à hipótese. A representação das relações observadas entre capacidades, indutores e inovações de comunicação é apresenta na Figura 8.

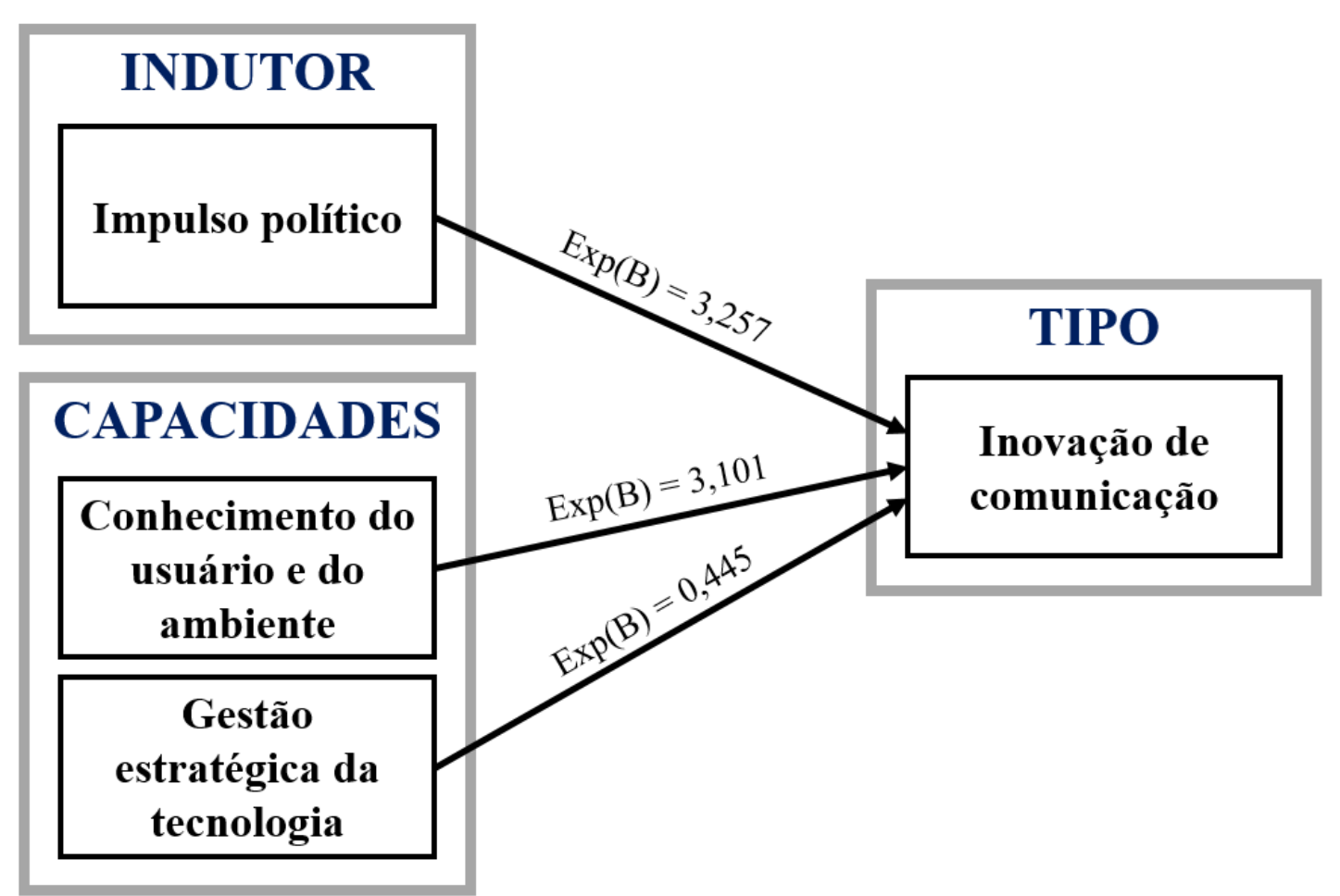

Figura 8. Relações significativas entre capacidades, indutores e inovação de comunicação Fonte: Elaborado pelo autor

Em relação às inovações de produto e organizacionais, não foram observadas relações significativas entre capacidades, indutores e estes tipos de inovação. Este resultado leva ao não suporte das hipóteses $\mathrm{H} 3 \mathrm{a}$ - a presença de capacidades e indutores de inovação aumenta a 
probabilidade de ocorrência de inovação de produto - e H3d - a presença de capacidades e indutores de inovação aumenta a probabilidade de ocorrência de inovação organizacional. Considerando estes resultados, a hipótese H3 - a presença de capacidades e indutores de inovação aumenta a probabilidade de ocorrência dos tipos de inovação - não foi suportada, visto que a presença de capacidades e indutores nos relatos não gerou somente aumento na chance de probabilidade de ocorrência de qualquer um dos tipos de inovação no mesmo relato.

\subsection{Relações entre Tipos e Resultados de Inovação}

O quarto modelo de regressão logística explora a relação entre tipos e resultados de inovação. A probabilidade de ocorrência de cada resultado de inovação foi avaliada em relação à presença dos tipos de inovação, sendo que os foram inseridos individualmente. Dado que as experiências possuem apenas um tipo de inovação cada, a inserção conjunta dos tipos de inovação não foi realizada. As relações representadas a seguir são aquelas que apresentaram resultado significativo:

\begin{tabular}{|c|c|c|c|}
\hline \multicolumn{4}{|c|}{ RESULTANTE: Melhoria na entrega e/ou qualidade dos serviços } \\
\hline Variáveis na equação & B & $\operatorname{Exp}(B)$ & Sig. \\
\hline Inovação organizacional & $-1,002$ & 0,367 & 0,000 \\
\hline Constante & 1,105 & 3,019 & 0,000 \\
\hline $\mathrm{R}^{2}=0,044($ Cox \& Snell $) /$ & ke) $\mid$ Qui & $=12,98$ & 000 \\
\hline \multicolumn{4}{|c|}{ RESULTANTE: Melhoria da gestão organizacional } \\
\hline Variáveis na equação & B & $\operatorname{Exp}(B)$ & Sig. \\
\hline Inovação organizacional & 1,839 & 6,290 & 0,000 \\
\hline Constante & 0,478 & 1,613 & 0,001 \\
\hline \multicolumn{4}{|c|}{$\mathrm{R}^{2}=0,089$ (Cox \& Snell) / 0,127 (Nagelkerke) $\mid$ Qui-quadrado $=26,905, \mathrm{p}=0,000$} \\
\hline \multicolumn{4}{|c|}{ RESULTANTE: Melhoria do clima organizacional } \\
\hline Variáveis na equação & B & $\operatorname{Exp}(B)$ & Sig. \\
\hline Inovação de produto & $-0,999$ & 0,368 & 0,031 \\
\hline Constante & $-1,592$ & 0,204 & 0,000 \\
\hline \multicolumn{4}{|c|}{$\mathrm{R}^{2}=0,019($ Cox \& Snell) / 0,035 (Nagelkerke) $\mid$ Qui-quadrado $=5,546, \mathrm{p}=0,019$} \\
\hline
\end{tabular}

Quadro 18. Relações significativas entre tipos e resultados de inovação Fonte: Elaborado pelo autor

Todos os modelos apresentados possuem Qui-quadrado significativo ( $\mathrm{p}<0,05)$, o que indica que os modelos são ajustados aos dados. Para melhoria na entrega e/ou qualidade dos serviços, a presença de inovação organizacional diminui a probabilidade de ocorrência desse resultado. Uma inovação organizacional é definida como a implementação de um novo método para organizar eu gerenciar o trabalho, tendo foco em melhorias internas na gestão da organização (Bloch, 2011). Esse foco interno pode justificar a diminuição de probabilidade de 
ocorrência de melhoria na entrega e/ou qualidade dos serviços, visto que este é um resultado focado nos usuários dos serviços, e não na própria organização. Este resultado, no entanto, demonstra que as experiências que possuem inovações organizacionais tendem a não relatar ganhos, mesmo que indiretos, na entrega dos serviços aos usuários finais. A presença de inovação organizacional, por outro lado, aumenta a probabilidade de ocorrência de melhoria da gestão organizacional. A própria definição de inovação organizacional se alinha a este tipo de resultado, sendo esta relação, então, esperada.

Para melhoria do clima organizacional, a presença de uma inovação de produto diminui a probabilidade de ocorrência deste resultado. A melhoria de clima é focada em aprimoramento de aspectos internos da organização e, em especial melhorias relacionadas às condições de trabalho e aos colaboradores da organização (Bugge et al., 2011; Mustafid \& Grisma, 2013), sendo a inovação de produto focada na introdução ou melhoria de um produto ou serviço pela organização, sendo um dos seus aspectos o foco no usuário final (Bloch, 2011). A diferença de foco destes dois fatores poderia justificar a relação negativa de probabilidade entre eles.

Em relação à hipótese H4 - a presença dos tipos de inovação aumenta a probabilidade de ocorrência de resultados de inovação - não há evidências suficientes para total suporte da hipótese. Por um lado, inovações organizacionais aumentam a probabilidade de ocorrência de melhorias da gestão organizacional, o que suporta a hipótese. No entanto, as inovações organizacionais também afetam a probabilidade de ocorrência de melhorias na entrega e/ou qualidade dos serviços, mas, neste caso, o efeito é negativo. Deste modo, a hipótese H4d - a presença de inovação organizacional aumenta a probabilidade de ocorrência de resultados de inovação - é suportada parcialmente. Adicionalmente, as inovações de produto diminuem a probabilidade de ocorrência de melhorias de clima organizacional, sendo a hipótese H4a - a presença de inovação de produto aumenta a probabilidade de ocorrência de resultados de inovação - não suportada. Da mesma forma, as hipóteses $\mathrm{H} 4 \mathrm{~b}$ - a presença de inovação de processo aumenta a probabilidade de ocorrência de resultados de inovação - e H4c - a presença de inovação de comunicação aumenta a probabilidade de ocorrência de resultados de inovação - não foram suportadas, visto que não foram observadas relações significativas entre estes tipos de inovação e a probabilidade de ocorrência de quaisquer resultados de inovação. Assim, o conjunto de resultados permite apenas suporte parcial à hipótese H4. A representação gráfica das relações encontradas entre tipos e resultados de inovação pode ser observada na Figura 9. 


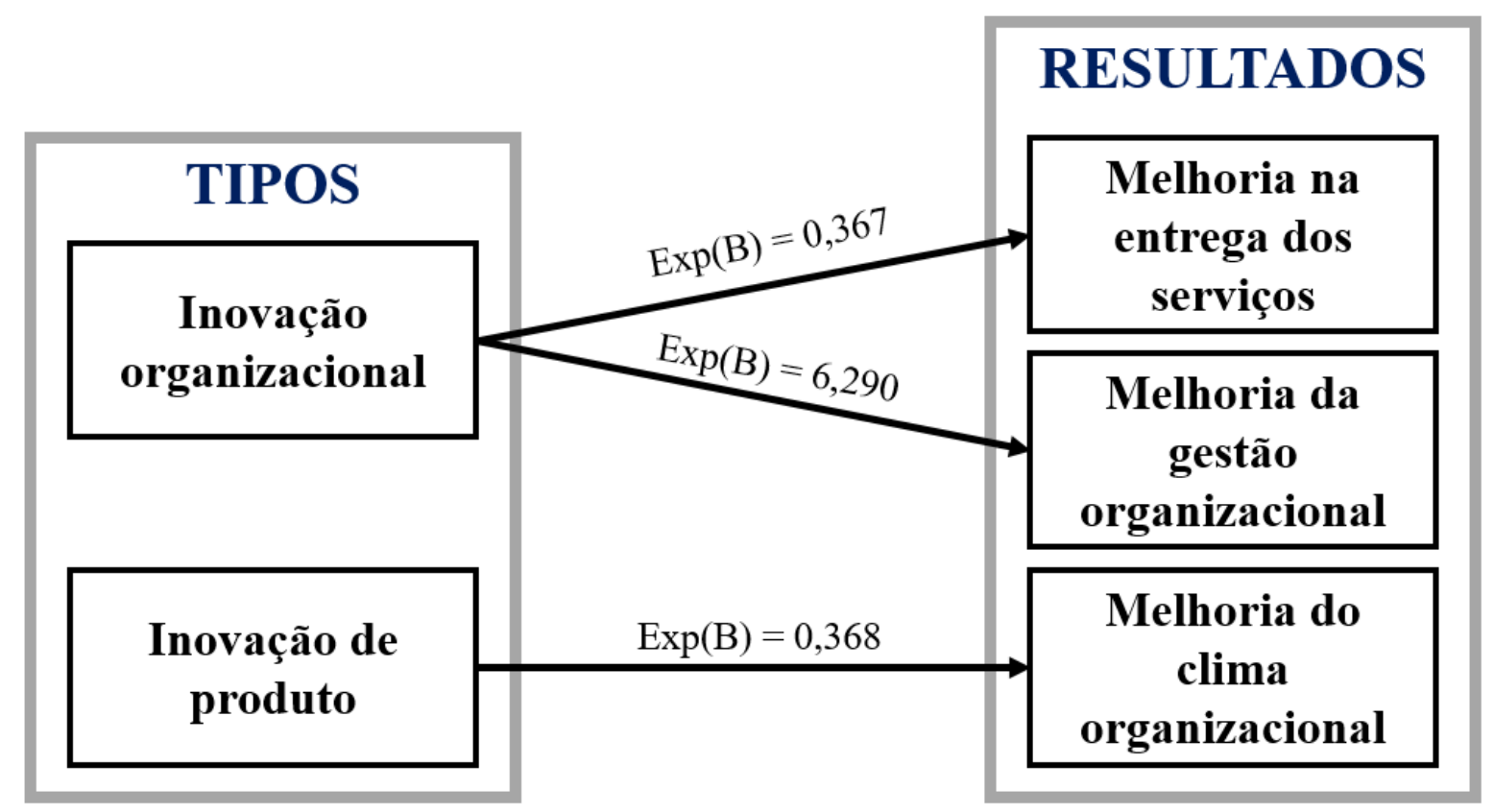

Figura 9. Relações significativas entre tipos e resultados de inovação Fonte: Elaborado pelo autor

\subsection{Relações entre Capacidades, Indutores, Tipos e Resultados de Inovação}

O quinto modelo de regressão logística explora a relação entre capacidades, indutores, tipos e resultados de inovação. A probabilidade de ocorrência de cada resultado de inovação foi avaliada em relação à presença das capacidades, indutores e tipos de inovação, sendo que todas as variáveis foram inseridas individualmente. A inserção de categorias de capacidades e/ou indutores em conjunto não resultou em relações significativas com os tipos de inovação. Visto que as experiências possuem apenas um tipo de inovação cada, a inserção conjunta de tipos de inovação não foi realizada. As relações representadas a seguir são aquelas que apresentaram resultado significativo: 


\begin{tabular}{|c|c|c|c|}
\hline \multicolumn{4}{|c|}{ RESULTANTE: Melhoria na entrega e/ou qualidade dos serviços } \\
\hline Variáveis na equação & B & $\operatorname{Exp}(\mathbf{B})$ & Sig. \\
\hline Impulso político & $-1,111$ & 0,329 & 0,011 \\
\hline Inovação de produto & 0,895 & 2,448 & 0,005 \\
\hline Constante & 0,672 & 1,958 & 0,000 \\
\hline \multicolumn{4}{|c|}{$\mathrm{R}^{2}=0,048($ Cox \& Snell) $/ 0,067$ (Nagelkerke) $\mid$ Qui-quadrado $=14,056, p=0,001$} \\
\hline \multicolumn{4}{|c|}{ RESULTANTE: Melhoria na entrega e/ou qualidade dos serviços } \\
\hline Variáveis na equação & $\mathbf{B}$ & $\operatorname{Exp}(\mathbf{B})$ & Sig. \\
\hline Não orientado a problema & $-0,566$ & 0,568 & 0,041 \\
\hline Impulso político & $-1,206$ & 0,299 & 0,008 \\
\hline Inovação organizacional & $-0,989$ & 0,372 & 0,000 \\
\hline Constante & 1,489 & 4,474 & 0,000 \\
\hline \multicolumn{4}{|c|}{$\mathrm{R}^{2}=0,074($ Cox \& Snell) $/ 0,105$ (Nagelkerke) $\mid$ Qui-quadrado $=22,981, p=0,000$} \\
\hline \multicolumn{4}{|c|}{ RESULTANTE: Melhoria da gestão organizacional } \\
\hline Variáveis na equação & B & $\operatorname{Exp}(\mathbf{B})$ & Sig. \\
\hline Gestão estratégica da tecnologia & 1,010 & 2,746 & 0,000 \\
\hline Gestão de projetos & $-0,685$ & 0,504 & 0,033 \\
\hline Orientado a problema & $-0,875$ & 0,417 & 0,002 \\
\hline Inovação de produto & $-0,594$ & 0,552 & 0,040 \\
\hline Constante & 1,325 & 3,763 & 0,000 \\
\hline \multicolumn{4}{|c|}{$\mathrm{R}^{2}=0,107$ (Cox \& Snell) / 0,151 (Nagelkerke) $\mid$ Qui-quadrado $=32,342, \mathrm{p}=0,000$} \\
\hline \multicolumn{4}{|c|}{ RESULTANTE: Melhoria da gestão organizacional } \\
\hline Variáveis na equação & B & $\operatorname{Exp}(\mathbf{B})$ & Sig. \\
\hline Gestão estratégica da tecnologia & 0,910 & 2,484 & 0,001 \\
\hline Gestão de projetos & $-0,644$ & 0,525 & 0,050 \\
\hline Orientado a problema & $-0,822$ & 0,440 & 0,004 \\
\hline Inovação organizacional & 1,713 & 5,546 & 0,000 \\
\hline Constante & 0,805 & 2,237 & 0,017 \\
\hline $\mathrm{R}^{2}=0,158($ Cox \& Snell $) / 0,22$ & ke) $\mid$ Qui & $0=49,40^{7}$ & 000 \\
\hline \multicolumn{4}{|c|}{ RESULTANTE: Melhoria do clima organizacional } \\
\hline Variáveis na equação & B & $\operatorname{Exp}(\mathbf{B})$ & Sig. \\
\hline Gestão estratégica da tecnologia & $-0,865$ & 0,421 & 0,014 \\
\hline Inovação de produto & $-1,066$ & 0,345 & 0,023 \\
\hline Constante & $-1,122$ & 0,326 & 0,000 \\
\hline $\mathrm{R}^{2}=0,040($ Cox \& Snell $) / 0,07$ & ke) $\mid$ Qui & $0=11,74$ & 003 \\
\hline
\end{tabular}

Quadro 19. Relações significativas entre capacidades, indutores, tipos e resultados de Inovação Fonte: Elaborado pelo autor

Todos os modelos apresentados possuem Qui-quadrado significativo ( $\mathrm{p}<0,05)$, o que indica que os modelos são ajustados aos dados. Devido à natureza mutualmente exclusiva dos tipos de inovação, cada combinação de resultado de inovação e tipos de inovação necessitou ser executada separadamente. Desta forma, a análise para melhoria na entrega e/ou qualidade dos serviços resultou em dois modelos de regressão, cada um com um tipo diferente de inovação. Primeiro, este resultado de inovação teve sua probabilidade de ocorrência aumentada pela presença de inovações de produto quando este tipo esteve acompanhado de impulso político que, por sua vez, diminuiu a probabilidade de ocorrência de melhoria na entrega e/ou qualidade dos serviços. A relação entre inovações de produto e melhoria na entrega de serviços pode ser baseada na natureza destes fatores, visto que inovações de produto focam na introdução ou aprimoramento de serviços oferecidos pela organização para seus usuários finais 
(Bloch, 2011). O indutor impulso político diminuiu a probabilidade deste resultado, no entanto, em análises anteriores, foi demonstrado que este indutor aumenta a probabilidade de ocorrência de inovações de comunicação, e não de produto. Dessa forma, este indutor pode favorecer outros tipos de melhoria, mas não uma melhoria ligada aos serviços ou métodos de entrega de serviço da organização. Este modelo está representado na Figura 10.

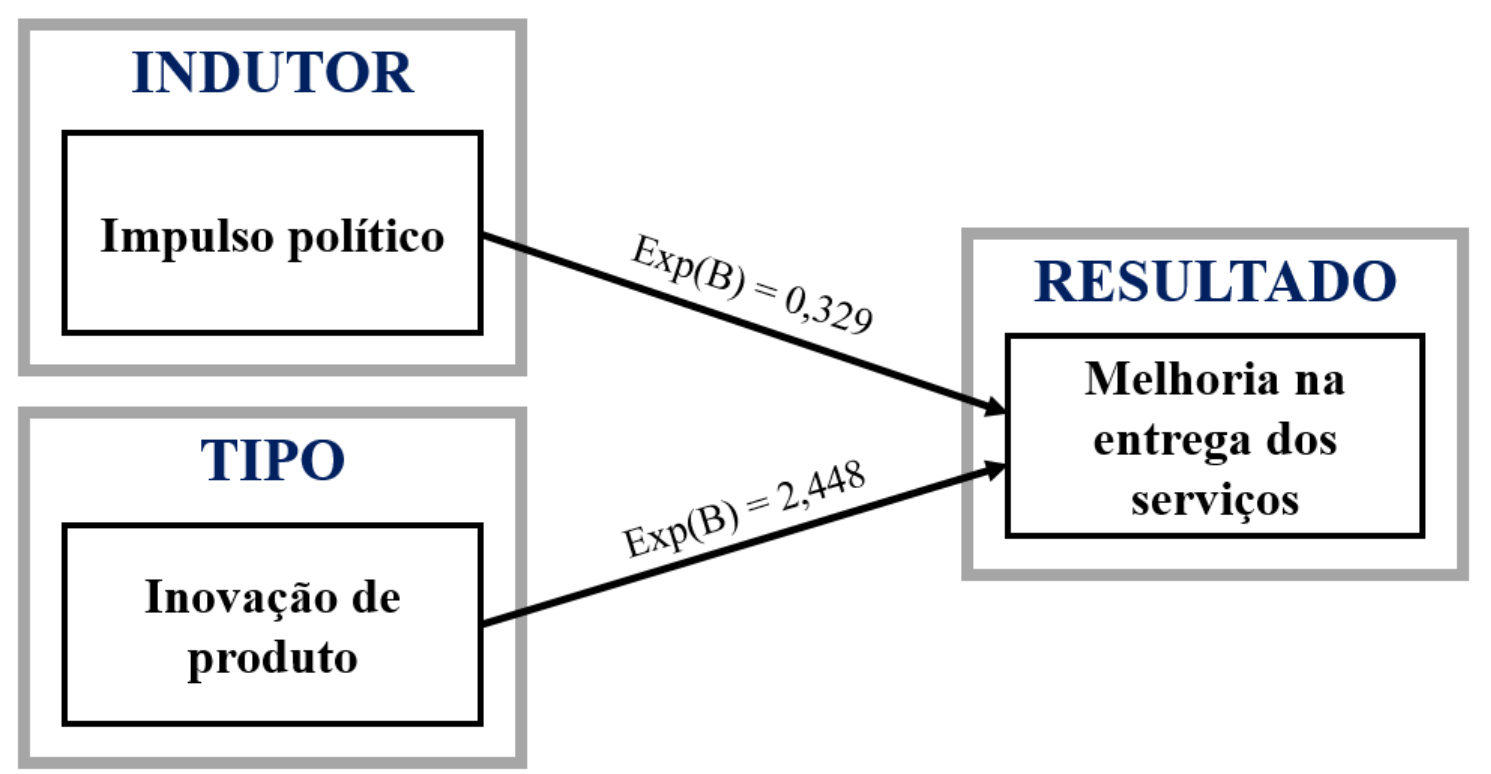

Figura 10. Relações significativas entre capacidades, indutores, inovação de produto e melhoria na entrega e/ou qualidade dos serviços

Fonte: Elaborado pelo autor

O segundo modelo para este resultado apresenta uma diminuição da probabilidade de ocorrência de melhoria na entrega e/ou qualidade dos serviços quando há presença de inovações organizacionais, indutores não orientados a problema e da capacidade gestão de projetos. A relação negativa entre inovação organizacional e este resultado de inovação já havia sido observada em testes anteriores. Para o indutor não orientado a problema, pode-se recuperar o resultado positivo encontrado com inovações de processos, que são ligadas a resultados distintos de melhoria na entrega dos serviços, o que poderia justificar a diminuição na chance de ocorrência desses resultados. A capacidade gestão de projetos, que não resultou em relações significativas em nenhum dos testes anteriores, também apresentou influência negativa para os resultados de entrega dos serviços. A representação deste modelo é apresentada na Figura 11. 


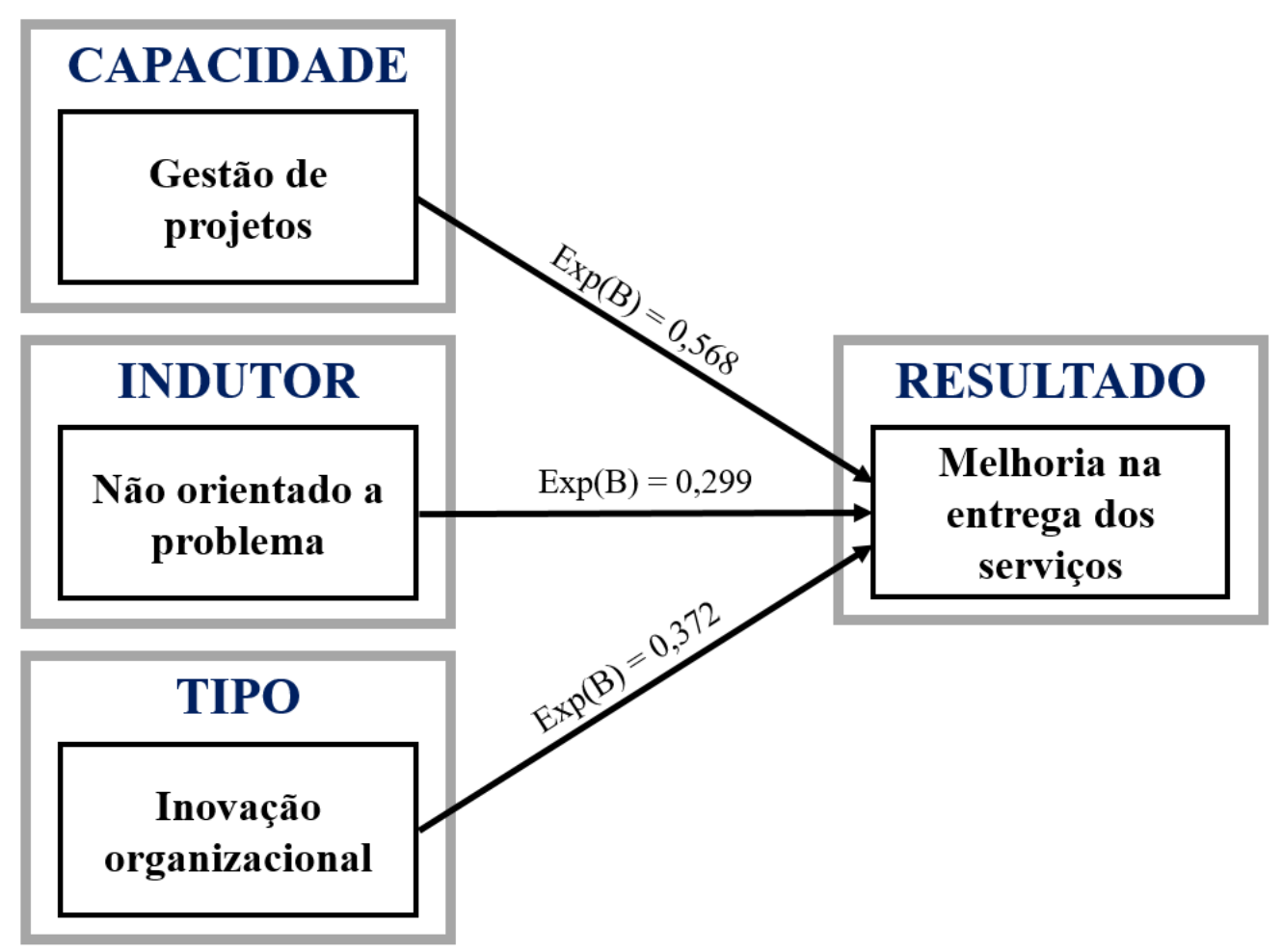

Figura 11. Relações significativas entre capacidades, indutores, inovação organizacional e melhoria na entrega e/ou qualidade dos serviços

Fonte: Elaborado pelo autor

A análise para melhoria da gestão organizacional também resultou em dois modelos. As mesmas capacidades, gestão estratégica da tecnologia e gestão de projetos, e o mesmo indutor, orientado a problema, foram obtidos para os dois modelos com os mesmos tipos de efeito sobre o resultado de inovação, sugerindo que o tipo de inovação não afeta a influência destes fatores sobre a melhoria na gestão organizacional. O efeito positivo da inovação organizacional sobre a melhoria de gestão organizacional já havia sido observado em testes anteriores, podendo ser justificado pelo alinhamento conceitual, de foco interno para a organização, dos dois elementos. Esta mesma questão conceitual poderia explicar o efeito negativo de inovações de produto sobre a melhoria da gestão organizacional, visto que essas inovações possuem foco na introdução ou aprimoramento de serviços pela organização para seus usuários finais, mas não necessariamente reflete modificações ou melhoramentos na gestão interna da organização. As representações dos dois modelos relacionados à melhoria da gestão organizacional podem ser vistas na Figura 12 e na Figura 13. 


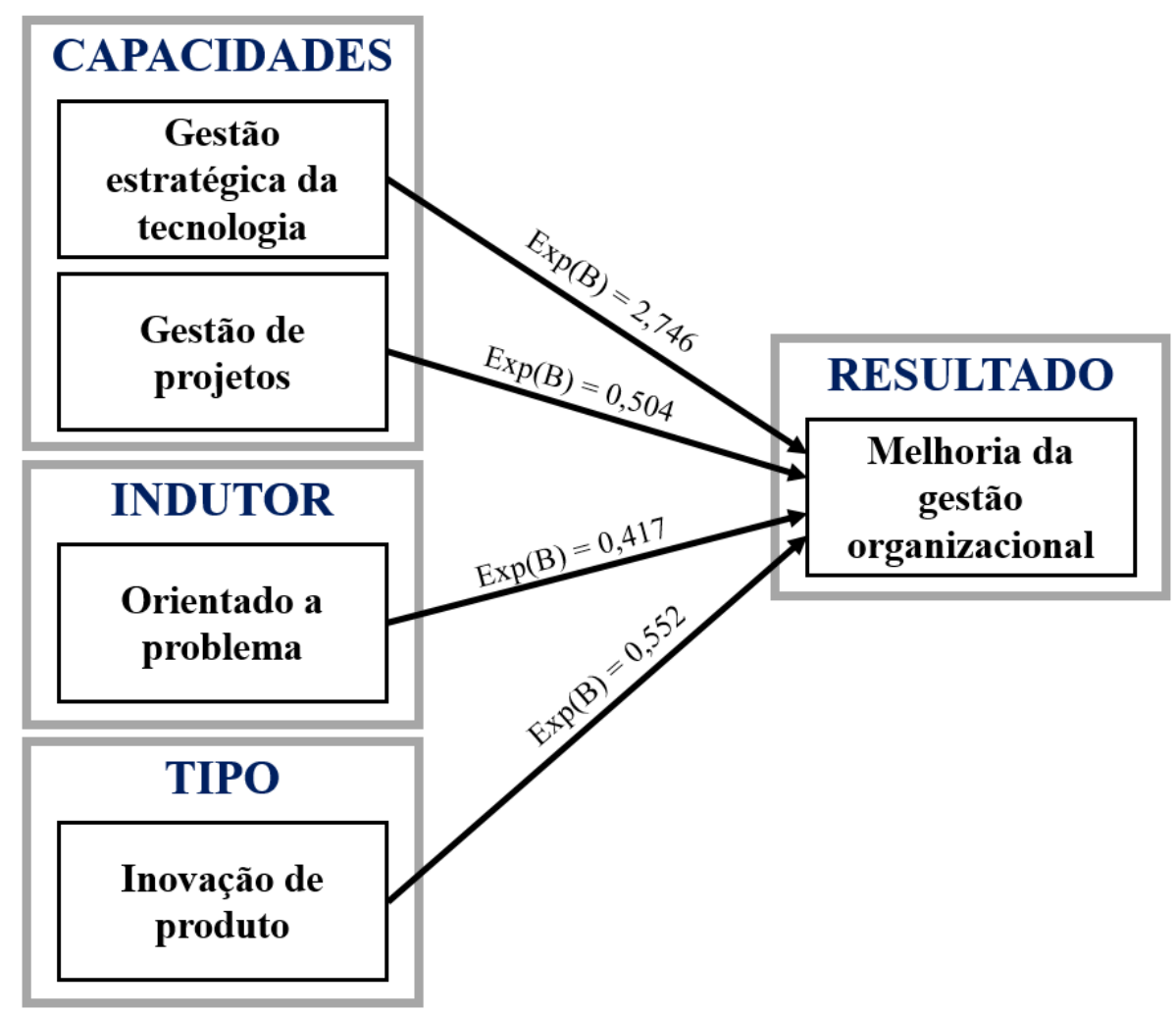

Figura 12. Relações significativas entre capacidades, indutores, inovação de produto e melhoria da gestão organizacional

Fonte: Elaborado pelo autor

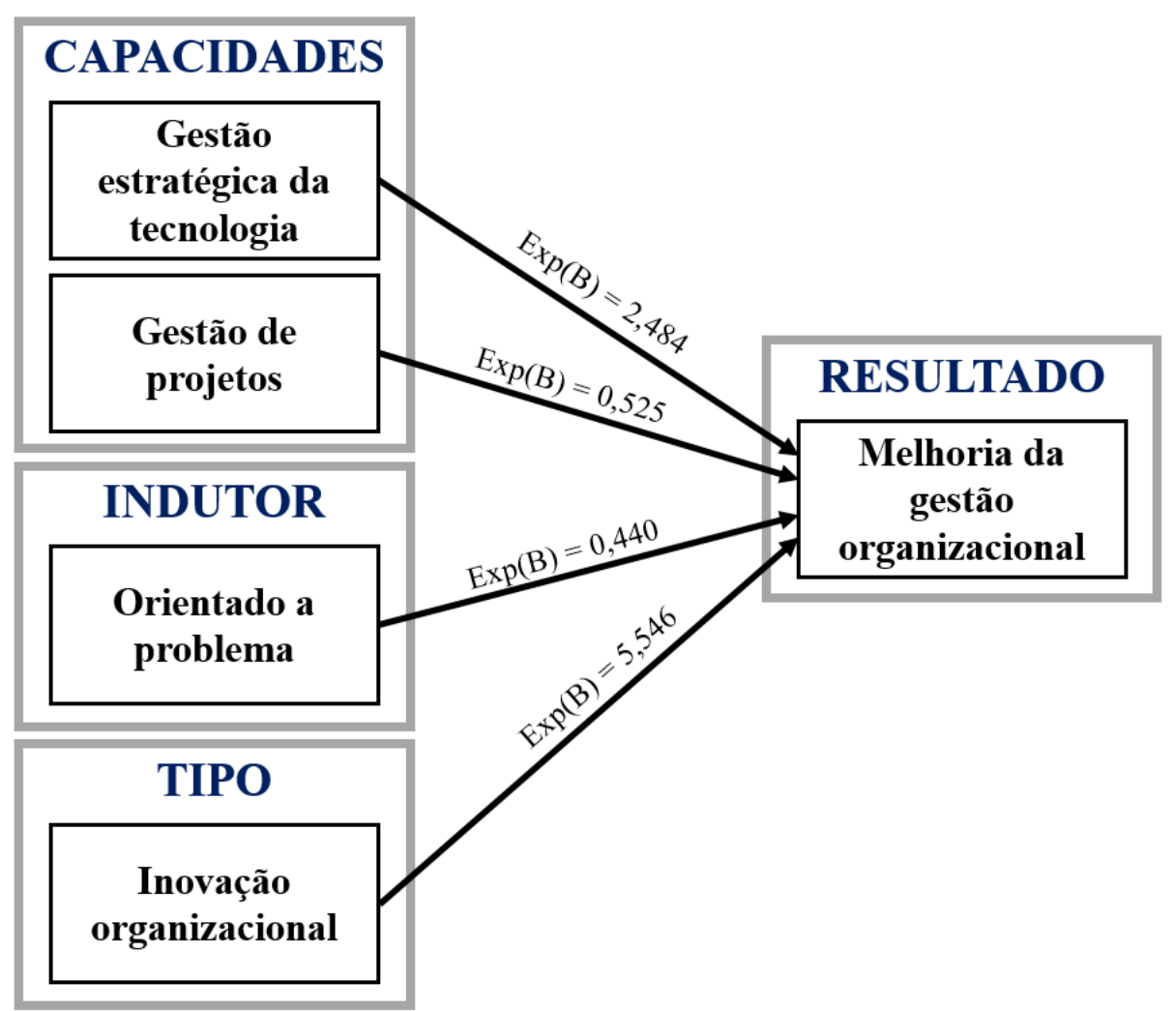

Figura 13. Relações significativas entre capacidades, indutores, inovação organizacional e melhoria da gestão organizacional

Fonte: Elaborado pelo autor 
Por fim, a análise para melhoria do clima organizacional resultou em um modelo, composto por inovação de produto e pela capacidade gestão estratégica da tecnologia. Nenhum indutor apresentou efeito significativo sobre este resultado de inovação. A relação negativa entre inovação de produto e melhoria do clima organizacional já havia sido observada em análises anteriores. A gestão estratégica da tecnologia também apresentou efeitos negativos sobre melhorias do clima organizacional. Esta capacidade é relacionada ao processo de gestão tecnológica da organização, que pode estar relacionada a aspectos da gestão interna da organização, como evidenciado em testes anteriores, mas não necessariamente para melhoramentos relacionados ao ambiente de trabalho e à satisfação dos colaboradores. A representação do modelo para melhoria do clima organizacional é apresentada na Figura 14.

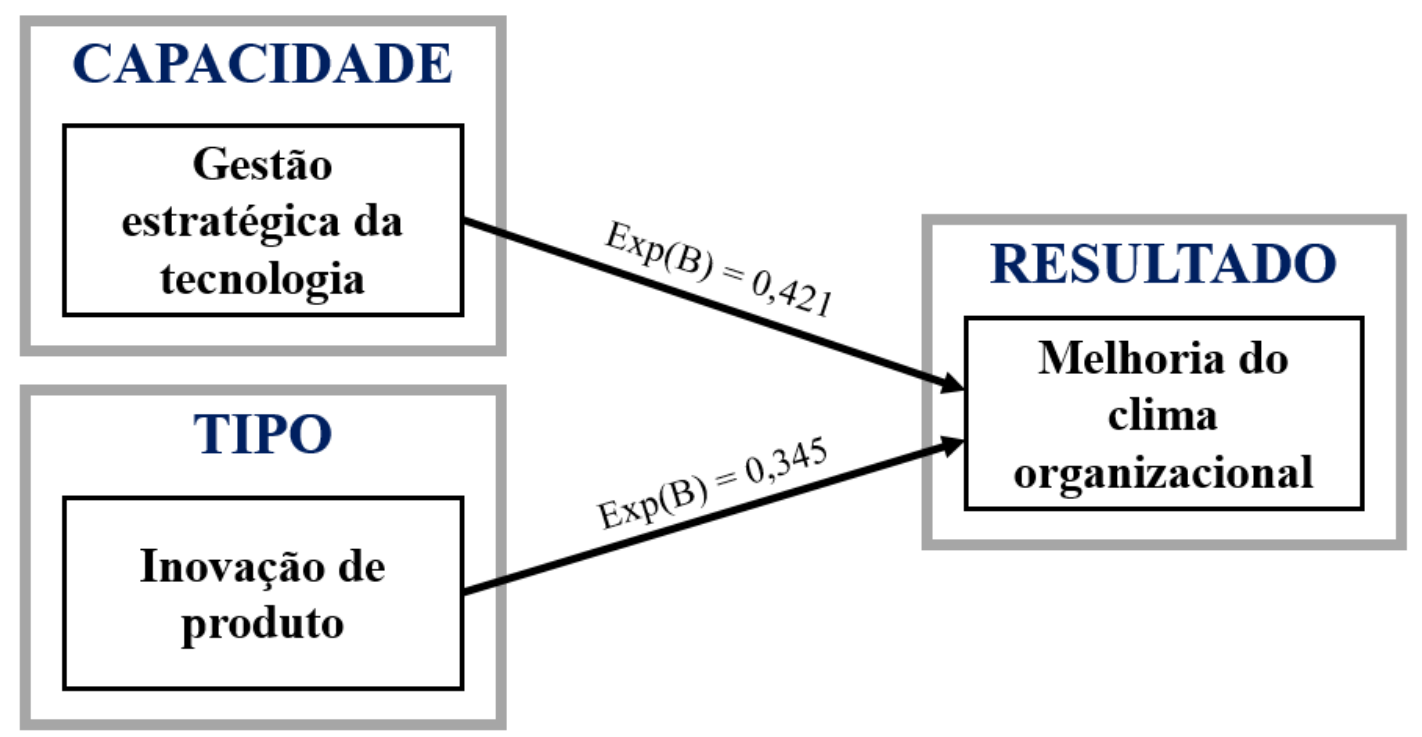

Figura 12. Relações significativas entre capacidades, indutores, inovação de produto e melhoria do clima organizacional

Fonte: Elaborado pelo autor

Em relação à hipótese H5 - a presença de capacidades, indutores e dos tipos de inovação aumenta a probabilidade de ocorrência de resultados de inovação - os resultados obtidos são insuficientes para suportar a hipótese totalmente. $\mathrm{O}$ único efeito positivo observado entre tipos e resultados de inovação que se repetiu da análise de tipos de modo separado para tipos junto a capacidades e indutores, foi e relação positiva entre inovações organizacionais e melhoria de gestão organizacional, sendo esta acompanhada por uma relação também positiva da capacidade gestão estratégica da tecnologia, mas por relações negativas da capacidade gestão de projetos e do indutor orientado a problema. No que se refere à melhoria na entrega e/ou qualidade dos serviços, a presença de inovação organizacional no relato diminuiu a 
probabilidade de ocorrência deste resultado no mesmo relato, sendo este efeito também negativo para a capacidade gestão de projetos e o indutor não orientado a problema. Estes dois resultados permitem apenas suporte parcial à hipótese $\mathrm{H} 5 \mathrm{~d}$ - a presença de capacidades, indutores e inovação organizacional aumenta a probabilidade de ocorrência de resultados de inovação.

De forma similar, a hipótese H5a - a presença de capacidades, indutores e inovação de produto aumenta a probabilidade de ocorrência de resultados de inovação - foi suportada apenas parcialmente. $\mathrm{O}$ único efeito positivo observado entre inovação de produto e um resultado de inovação foi em relação à melhoria na entrega e/ou qualidade dos serviços. Para este resultado, no entanto, a presença do indutor impulso político no relato diminuiu a chance de ocorrência de melhoria na entrega e/ou qualidade dos serviços no mesmo relato. Em relação à melhoria do clima organizacional e melhoria da gestão organizacional, a presença de inovação de produto no relato da experiência diminuiu a probabilidade de presença destes resultados de inovação. Estes efeitos foram acompanhados por uma relação também negativa da capacidade gestão estratégica da tecnologia, no caso da melhoria do clima organizacional, e de relações negativas da capacidade gestão de projetos e do indutor orientado a problema, mas relação positiva da capacidade gestão estratégica da tecnologia, no caso da melhoria da gestão organizacional. 


\section{CONCLUSÕES E RECOMENDAÇÕES}

O presente trabalho buscou analisar o efeito de capacidades, indutores e tipos de inovação sobres os resultados de inovação em experiências inovadoras em gestão na Administração Pública Federal. Para tal, foram analisados os relatos dos casos finalistas e premiados no Concurso de Inovação da ENAP entre os anos 1999 e 2014, somando um total de 287 experiências analisadas. Os relatos passaram por uma análise de conteúdo onde as variáveis de interesse do presente estudo - capacidades, indutores, tipos e resultados de inovação - foram codificadas como variáveis binárias representando a presença ou ausência daquela variável no relato. Esta análise de conteúdo se utilizou de uma triangulação de investigadores como ferramenta para aumento da confiabilidade das codificações obtidas. A partir disso, foi possível elaborar modelos de regressão logística para testar as relações entre as variáveis. As hipóteses levantadas por este estudo, e os seus resultados, podem ser vistas no Quadro 20.

\begin{tabular}{|c|c|}
\hline $\begin{array}{l}\text { H1: A presença de capacidades de inovação aumenta a probabilidade de ocorrência } \\
\text { dos tipos de inovação }\end{array}$ & $\begin{array}{c}\text { Suportada } \\
\text { parcialmente }\end{array}$ \\
\hline $\begin{array}{l}\text { H1a: A presença de capacidades de inovação aumenta a probabilidade de ocorrência de } \\
\text { inovação de produto }\end{array}$ & Suportada \\
\hline $\begin{array}{l}\text { H1b: A presença de capacidades de inovação aumenta a probabilidade de ocorrência de } \\
\text { inovação de processo }\end{array}$ & $\begin{array}{c}\text { Não } \\
\text { suportada }\end{array}$ \\
\hline $\begin{array}{l}\text { H1c: A presença de capacidades de inovação aumenta a probabilidade de ocorrência de } \\
\text { inovação de comunicação }\end{array}$ & \\
\hline $\begin{array}{l}\text { H1d: A presença de capacidades de inovação aumenta a probabilidade de ocorrência de } \\
\text { inovação organizacional }\end{array}$ & $\begin{array}{c}\text { Suportada } \\
\text { parcialmente }\end{array}$ \\
\hline $\begin{array}{l}\text { H2: A presença de indutores de inovação aumenta a probabilidade de ocorrência } \\
\text { dos tipos de inovação }\end{array}$ & $\begin{array}{c}\text { Suportada } \\
\text { parcialmente }\end{array}$ \\
\hline $\begin{array}{l}\text { indutores de inovação aumenta a probabilidade de ocorrência de } \\
\text { to }\end{array}$ & $\begin{array}{c}\text { Não } \\
\text { suportada }\end{array}$ \\
\hline $\begin{array}{l}\text { H2b: A presença de indutores de inovação aumenta a probabilidade de ocorrência de } \\
\text { inovação de processo }\end{array}$ & Suportada \\
\hline $\begin{array}{l}\text { H2c: A presença de indutores de inovação aumenta a probabilidade de ocorrência de } \\
\text { inovação de comunicação }\end{array}$ & $\mathrm{Su}_{\mathrm{r}}$ \\
\hline itores de inovação aumenta a probabilidade de ocorrência de & $\begin{array}{c}\text { Não } \\
\text { suportada }\end{array}$ \\
\hline $\begin{array}{l}\text { idades e indutores de inovação aumenta a probabilidade de } \\
\text { novação }\end{array}$ & $\begin{array}{c}\text { Suportada } \\
\text { parcialmente }\end{array}$ \\
\hline $\begin{array}{l}\text { H3a: A presença de capacidades e indutores de inovação aumenta a probabilidade de } \\
\text { ocorrência de inovação de produto }\end{array}$ & $\begin{array}{c}\text { Não } \\
\text { suportada } \\
\end{array}$ \\
\hline $\begin{array}{l}\text { H3b: A presença de capacidades e indutores de inovação aumenta a probabilidade de } \\
\text { ocorrência de inovação de processo }\end{array}$ & $\begin{array}{c}\text { Suportada } \\
\text { parcialmente }\end{array}$ \\
\hline $\begin{array}{l}\text { H3c: A presença de capacidades e indutores de inovação aumenta a probabilidade de } \\
\text { ocorrência de inovação de comunicação }\end{array}$ & $\begin{array}{c}\text { Suportada } \\
\text { parcialmente }\end{array}$ \\
\hline $\begin{array}{l}\text { H3d: A presença de capacidades e indutores de inovação aumenta a probabilidade de } \\
\text { ocorrência de inovação organizacional }\end{array}$ & $\begin{array}{c}\text { Não } \\
\text { suportada }\end{array}$ \\
\hline $\begin{array}{l}\text { H4: A presença dos tipos de inovação aumenta a probabilidade de ocorrência de } \\
\text { resultados de inovação }\end{array}$ & $\begin{array}{c}\text { Suportada } \\
\text { parcialmente }\end{array}$ \\
\hline $\begin{array}{l}\text { H4a: A presença de inovação de produto aumenta a probabilidade de ocorrência de } \\
\text { resultados de inovação }\end{array}$ & $\begin{array}{c}\text { Não } \\
\text { suportada }\end{array}$ \\
\hline
\end{tabular}




\begin{tabular}{|l|c|}
\hline $\begin{array}{l}\text { H4b: A presença de inovação de processo aumenta a probabilidade de ocorrência de } \\
\text { resultados de inovação }\end{array}$ & $\begin{array}{c}\text { Não } \\
\text { suportada }\end{array}$ \\
\hline $\begin{array}{l}\text { H4c: A presença de inovação de comunicação aumenta a probabilidade de ocorrência de } \\
\text { resultados de inovação }\end{array}$ & $\begin{array}{c}\text { Não } \\
\text { suportada }\end{array}$ \\
\hline $\begin{array}{l}\text { H4d: A presença de inovação organizacional aumenta a probabilidade de ocorrência de } \\
\text { resultados de inovação }\end{array}$ & $\begin{array}{c}\text { Suportada } \\
\text { parcialmente }\end{array}$ \\
\hline $\begin{array}{l}\text { H5: A presença de capacidades, indutores e dos tipos de inovação aumenta a } \text { a } \\
\text { probabilidade de ocorrência de resultados de inovação }\end{array}$ & $\begin{array}{c}\text { Suportada } \\
\text { parcialmente }\end{array}$ \\
\hline $\begin{array}{l}\text { H5a: A presença de capacidades, indutores e de inovação de produto aumenta a a } \\
\text { probabilidade de ocorrência de resultados de inovação }\end{array}$ & $\begin{array}{c}\text { Suportada } \\
\text { parcialmente }\end{array}$ \\
\hline $\begin{array}{l}\text { H5b: A presença de capacidades, indutores e de inovação de processo aumenta a } \\
\text { probabilidade de ocorrência de resultados de inovação }\end{array}$ & $\begin{array}{c}\text { Não } \\
\text { suportada }\end{array}$ \\
\hline $\begin{array}{l}\text { H5c: A presença de capacidades, indutores e de inovação de comunicação aumenta a } \\
\text { probabilidade de ocorrência de resultados de inovação }\end{array}$ & $\begin{array}{c}\text { Não } \\
\text { suportada }\end{array}$ \\
\hline $\begin{array}{l}\text { H5d: A presença de capacidades, indutores e de inovação organizacional aumenta a } \\
\text { probabilidade de ocorrência de resultados de inovação }\end{array}$ & $\begin{array}{c}\text { Suportada } \\
\text { parcialmente }\end{array}$ \\
\hline
\end{tabular}

Quadro 20. Hipóteses e resultados do estudo

Fonte: Elaborado pelo autor

A hipótese H1 foi suportada parcialmente, visto que a presença de capacidades em um relato aumentou, exclusivamente, a probabilidade de ocorrência de um tipo de inovação no mesmo relato para inovações de produto, sendo esta capacidade a gestão de pessoas para inovação. Para inovação de processo, esta mesma capacidade teve efeito negativo, diminuindo a probabilidade de presença deste tipo de inovação quando houve identificação de gestão de pessoas para inovação no mesmo caso. Para inovações organizacionais e inovações de comunicação os resultados foram ambivalentes, tendo a capacidade conhecimento do usuário e do ambiente efeito negativo em relação a inovações organizacionais, mas relação positiva com inovações de comunicação, e a capacidade gestão estratégica da tecnologia apresentando efeito oposto, positivo em relação às inovações organizacionais e negativo em relação às inovações de comunicação. A hipótese H2 também foi suportada parcialmente, pois tanto inovações de processo quanto de comunicação obtiveram maiores chance de presença em relatos que continham indutores orientado a problema, não orientado a problema e imposição legal, para o primeiro tipo de inovações, e do indutor impulso político, para o segundo. No entanto, as inovações de produto e organizacionais não demonstraram relação significativa com nenhum indutor.

De modo similar, a hipótese H3 foi suportada parcialmente. Para inovações de processo, os resultados obtidos nos testes das hipóteses H1 e H2 se repetiram, sendo os indutores orientado a problema, não orientado a problema e imposição legal positivamente relacionados à presença de inovações de processo nos relatos, e a capacidade gestão de pessoas para inovação negativamente relacionada. Para inovações de comunicação os mesmos resultados anteriores também foram obtidos, com a presença do indutor impulso político nos relatos aumentando a 
chance de presença destas inovações no mesmo relato, assim como para a capacidade conhecimento do usuário e do ambiente, mas a capacidade gestão estratégica da tecnologia tendo efeito negativo sobre a probabilidade de ocorrência de inovações de comunicação nos relatos.

A hipótese $\mathrm{H} 4$ foi suportada parcialmente, visto que a presença de inovações organizacionais nos relatos aumentou a chance de ocorrência de melhorias da gestão organizacional nos mesmos relatos, mas também diminuiu a probabilidade de ocorrência de melhoria na entrega e/ou qualidade dos serviços nestes mesmos relatos. A inovação de produto também apresentou efeito negativo em relação à chance de presença de melhorias do clima organizacional nos relatos. Tanto as inovações de processos quanto as inovações de comunicação não apresentaram relações significativas com os resultados de inovação. Por fim, a hipótese H5, que reúne todas as variáveis de interesse deste estudo, também foi suportada parcialmente. A presença de inovações de produto junto à presença do indutor impulso político nos relatos aumentou a chance de ocorrência de melhoria na entrega e/ou qualidade dos serviços nos mesmos relatos, sendo que o indutor teve efeito negativo sobre este resultado de inovação. No entanto, a presença de inovações de produto, junto a demais conjuntos variados de capacidades e indutores de inovações, diminuiu a probabilidade de presença de melhoria da gestão organizacional e melhoria do clima organizacional nos relatos. Resultado semelhante foi observado para inovações organizacionais. Quando testadas junto às capacidades gestão estratégica da tecnologia e gestão de projetos, e ao indutor orientado a problema, seu efeito sobre a probabilidade de ocorrência de melhoria da gestão organizacional foi positivo. No entanto, quando reunidas à capacidade gestão de projetos e ao indutor não orientado a problema, apresentaram efeito negativo sobre a chance de ocorrência de melhoria de entrega dos serviços nos relatos.

Os resultados obtidos apontam, com base nos relatos das experiências passadas analisadas, que o foco por parte de organizações públicas em apenas alguns indutores ou capacidades pode levar a uma maior probabilidade de ocorrência de inovações, mas não de todos os tipos. Desta forma, duas principais recomendações práticas são levantadas. Se uma organização pretende aumentar seu potencial de inovação, torna-se necessário o investimento no desenvolvimento e gestão de variadas capacidades e indutores. Visto que, por exemplo, uma única capacidade não aumenta a chance de mais de um tipo de inovação, o repertório de capacidades de inovação desenvolvidas pela organização deve ser variado, caso ela queira aumentar a chance de desenvolvimento de várias inovações de tipos diferentes. Isto, no entanto, gera uma falta de foco de investimento e, potencialmente, pode incorrer em maior gasto de 
recursos para gestão de portfólios de capacidades e indutores. Por outro lado, de modo a desenvolver iniciativas mais focadas, a organização poderia selecionar os tipos de inovação mais estratégicos para o momento da gestão, sendo esta decisão possivelmente baseada nos resultados mais prováveis de serem obtidos. A partir desta seleção, a organização poderia focar seus esforços para, por exemplo, desenvolver apenas as capacidades de inovação que potencializam o tipo de inovação de interesse. O lado negativo desta estratégia seria a possível diminuição da chance de ocorrência de outros tipos de inovação.

As limitações do presente trabalho incluem aspectos teóricos e metodológicos. Inicialmente, as variáveis selecionadas para este estudo não representam todos os elementos relacionados à inovação no setor público apresentados na literatura. Outros fatores como barreiras para inovação e coprodução de inovações, por exemplo, são colocados como variáveis importantes para o entendimento das iniciativas de inovação no setor público. As tipologias selecionadas para as variáveis também representam uma limitação, visto que outras classificações poderiam gerar codificações diferentes para as variáveis e, consequentemente, resultados distintos nas análises.

Do ponto de vista dos métodos empregados, a primeira limitação listada é em relação a amostra utilizada neste estudo, composta pelos casos finalistas e premiados pela ENAP entre 1999 e 2014. Este recorte não abrange todas as iniciativas implementadas pelo setor público no período, e a análise de projetos de inovação exitosos, mas não necessariamente premiados, poderia oferecer dados complementares em próximos estudos. A coleta de dados foi limitada pelos documentos utilizados, os relatos das experiências. Esses documentos não foram construídos para o presente trabalho, e certas informações de interesse podem não ter sido relatadas, o que poderia levar a não identificação de certas variáveis que podem ter estado presentes na iniciativa de inovação. Adicionalmente, as variáveis foram codificadas de modo binário, não permitindo uma avaliação escalar dos elementos estudados. Esta limitação levou à utilização da regressão logística como principal método inferencial, permitindo apenas a análise de aumento da probabilidade de uma variável na presença de outra, e outros métodos poderiam resultar em análises complementares às realizadas neste estudo.

Estudos futuros poderiam analisar iniciativas em organizações diferentes, utilizando outras bases de dados ou coletas primárias de dados para obter informações complementares às utilizadas no presente trabalho. A existência de outros prêmios de inovação na gestão pública pode configurar um possível campo de pesquisa. Recomenda-se também a análise de outros construtos relacionados à inovação, como coprodução, assim como mais variáveis relacionadas a inovação, como barreiras, ou tipologias diferentes das consideradas no presente estudo. A 
utilização de métodos diferentes para coleta de dados, codificação de variáveis e análise das relações também representam um potencial de pesquisa. Por exemplo, uma coleta primária de dados, utilização de variáveis escalares e aplicação de outros métodos de regressão ou outros testes paramétricos, poderiam oferecer resultados complementares aos obtidos neste estudo. Por fim, uma investigação qualitativa mais aprofundada das variáveis neste estudo poderia contribuir para um maior entendimento do fenômeno da inovação no setor público, como a exploração das rotinas gerenciais aplicadas pelas organizações para desenvolver suas capacidades de inovação. 


\section{REFERÊNCIAS}

Adams, R., Bessant, J., \& Phelps, R. (2006). Innovation management measurement: A review. International Journal of Management Reviews, 8(1), 21-47.

Agolla, J. E., \& Van Lill, J. B. (2013). Public Sector Innovation Drivers: A Process Model. Journal of Social Sciences, 34(2), 165-176.

Albury, D. (2005). Fostering Innovation in Public Services. Public Money \& Management, 25(1), 51-56.

Anggadwita, G., Dhewanto, W. (2013). Service Innovation in Public Sector: A case study on PT. Kereta Api Indonesia. Journal of Social and Development Sciences, 4, 308-315.

APSII (2011). Working Towards a Measurement Framework for Public Sector Innovation in Australia. Sydney: Department of Innovation Industry, Science and Research.

Avlonitis, G. J., Papastathopoulou, P. G., Gounaris, S. P. (2001). An empirically-based typology of product innovativeness for new financial services: success and failure scenarios. Journal of Product Innovation Management, 18, 324-342.

Avolio, B. J., Bass, B. M., \& Jung, D. I. (1999). Re-examining the components of transformational and transactional leadership using the multifactor leadership. Journal of Occupational and Organizational Psychology, 72(4), 441-462.

Bardin, L. (2006). Análise de conteúdo (L. de A. Rego \& A. Pinheiro, Trads.). Lisboa: Edições 70. (Obra original publicada em 1977).

Barras, R. (1986). Towards a theory of innovation in services. Research Policy, 15, 161-173.

Barras, R. (1990). Interactive innovation in financial and business services: the vanguard of the service revolution. Research Policy, 19, 215-237.

Birkinshaw, J., Hamel. G., \& Mol, M. J. (2008). Management innovation. Academy of Management Review, 33(4), 825-845.

Bitner, M. J., \& Brown, S. W. (2008). The service imperative. Business Horizons, 51(1), 3946.

Bloch, C. (2011). Measuring Public Innovation in the Nordic Countries: Copenhagen Manual. Copenhagen: MEPIN.

Bloch, C., Adalsteinsdóttir, E., Brehmer, P. O., Christensen, J. L., Drejer, I., Hydle, K., Jensen, M. B., Kuusisto, K., Kvalshaugen, R., \& Vinding, A. L. (2008). Service Innovation in the Nordic Countries: Key Factors for Policy Design, Final Report. Oslo: ServINNo project.

Bloch, C., \& Bugge, M. M. (2013). Public sector innovation - From theory to measurement. Structural Change and Economic Dynamics, 27, 133-145. 
Bloch, C., Jorgensen, L. L., Norn, M. T., \& Vad, T. B. (2009). Public Sector Innovation Index - A Diagnostic Tool for measuring innovative performance and capability in public sector organisations. Australia: NESTA.

Borins, S. (2001). Encouraging innovation in the public sector. Journal of Intellectual Capital, 2(3), 310-319.

Brandão, S. M., \& Bruno-Faria, M. F. (2012). Inovação no setor público: análise da produção científica em periódicos nacionais e internacionais da área de administração. Revista de Administração Pública, 47(1), 227-248.

Bugge, M. M., Hauknes, J., Bloch, C., \& Slipersaeter, S. (2010). The Public Sector in Innovation Systems: Module 1 - Conceptual Framework. Copenhagen: MEPIN.

Bugge, M. M., Mortensen, P. S., \& Bloch, C. (2011). Report of the Nordic Pilot studies Analyses of methodology and results. Conpenhagen: MEPIN.

Carayannis, E. G., Gonzales, E., \& Wetter, J. J. (2003). The nature and dynamics of discontinuous and disruptive innovations from a learning and knowledge management perspective. In: Shavinina, L. V. (Org.), The international handbook of innovation. Oxford: Elsevier Science, 115-138.

Carless, S. A., Wearing, A. J., \& Mann, L. (2000). A short measure of transformational leadership. Journal of Business and Psychology, 14(3), 389-405.

Carter, L., \& Belanger, F. (2005). The utilization of e-government services: Citizen trust, innovation and acceptance factors. Information Systems Journal, 15(1), 5-25.

Chen, C. J. (2009). Technology commercialization, incubator and venture capital, and new venture performance. Journal of Business Research, 62(1), 93-103.

Chiesa, V., Coughan, P., \& Voss, C. A. (1996). Development of a technical innovation audit. Journal of Product Innovation Management, 13(2), 105-136.

Coombs, R., \& Miles, I. (2000). Innovation, measurement and services. In: Metcalfe, J. S., \& Miles, I. (Eds.), Innovation Systems in the Service Economy: Measurement and Case Study Analysis. Boston: Kluwer Academic, 85-103.

Coutinho, G. A. (2002). Ações premiadas no $7^{\circ}$ Concurso de Inovação na Gestão Pública Federal - Prêmio Hélio Beltrão 2002. Brasília: ENAP.

Crossan, M. M., \& Apaydin, M. (2010). A multi-dimensional framework of organizational innovation a systematic review of the literature. Journal of Management Studies, 47(6), 1541191.

Damanpour, F., \& Schneider, M. (2006). Phases of the adoption of innovation in organizations: effects of environment, organization and top managers. British Journal of Management, 17, 215-236. 
Damanpour, F., \& Schneider, M. (2009). Characteristics of innovation and innovation adoption in public organizations: assessing the role of managers. Journal of Public Administration Research and Theory, 19(3), 495-522.

Damanpour, F., Walker, R. M., \& Avellaneda, C. N., (2009). Combinative effects of innovation types and organizational performance: a longitudinal study of service organizations. Journal of Management Studies, 46(4), 650-675.

Denzin, N. K. (1989). The Research Act. Englewood Cliffs: Prentice Hall.

DeVries, E. J. (2006). Innovation in services in networks of organizations and in the distribution of services. Research Policy, 35, 1037-1051.

De Vries, H. A., Bekkers, V. J. J. M., Tummers, L. G. (2014). Innovation in the Public Sector: A Systematic Review and Future Research Agenda. Rotterdam: LIPSE.

Djellal, F., \& Gallouj, F. (2000). Innovation surveys for service industries: A review. Paper presented at the DG Enterprise Conference on Innovation and Enterprise Creation: Statistics and Indicators.

Djellal, F., \& Gallouj, F. (2001). Patterns of innovation organization in service firms: portal survey results and theoretical models. Science and Public Policy, 28, 57-67.

Djellal, F., \& Gallouj, F. (2005). Mapping innovation dynamics in hospitals. Research Policy, $34,81-835$.

Djellal, F., \& Gallouj, F. (2007). Innovation in hospitals: a survey of the literature. European Journal of Health Economics, 8(3), 415-430.

Djellal, F., Gallouj, F., \& Miles, I. (2013). Two decades of research on innovation in services: Which place for public services? Structural Change and Economic Dynamics, 27, 98-117.

Drejer, I. (2004). Identifying innovation in surveys of services: a Schumpeterian perspective. Research Policy, 33, 551-562.

Droege, H., Hildebrand, D., \& Forcada, M. A. H. (2009). Innovation in services: present findings and future pathways. Journal of Service Management, 20(2), 131-155.

ENAP - Escola Nacional de Administração Pública. (2008). Ações Premiadas no $12^{\circ}$ Concurso de Inovação na Gestão Pública Federal 2007. Brasília: ENAP.

Farah, M. F. S. (2008). Disseminação de inovações e políticas públicas e espaço local. Revista Organizações \& Sociedade, 15(45), 10-126.

Field, A. (2009). Discovering statistics using SPSS. London: SAGE.

Flick, U. (2009). An Introduction to Qualitative Research. London: SAGE.

Gallouj, F. (1998). Innovating in reverse: services and the reverse product cycle. European Journal of Innovation Management, 1(3), 123-138. 
Gallouj, F. (2002). Innovation in services and the attendant old and new myths. Journal of Socio-Economics, 31, 137-154.

Gallouj, F. (2010). Services innovation: assimilation, differentiation, inversion and integration. In: Bidgoli, H. (Ed.), The Handbook of Technology Management. Hoboken: John Wiley ad Sons, 989-1000.

Gallouj, F., \& Savona, M. (2009). Innovation in services: a review of the debate and a research agenda. Journal of Evolutionary Economics, 19, 149-172.

Gallouj, F., \& Weinstein, O. (1997). Innovation in services. Research Policy, 26(4), 537-556.

Gallouj, F., \& Zanfei, A. (2013). Innovation in public services> Filling a gap in the literature. Structural Change and Economic Dynamics, 27, 89-97.

Gil, A. C. (2008). Métodos e Técnicas de Pesquisa Social. São Paulo: Atlas.

Godoy, A. (1995). Pesquisa Qualitativa: Tipos Fundamentais. Revista de Administração de Empresas, 35(3), 20-29.

Halvorsen, T., Hauknes, J., Miles, I., \& Roste, R. (2005). On the differences between public and private sector innovation. Oslo: NIFU STEP.

Hartley, J. (2005). Innovation in governance and public services: past and present. Public Money and Management, 25.

Hill, T. P. (1977). On goods and services. Review of Income and Wealth, 23, 315-338.

Hipp, C., \& Grupp, H. (2005). Innovation in the service sector: the demand for service-specific innovation measurement concepts and typologies. Research Policy, 34(4), 517-535.

Hogan, S. J., Soutar, G. N., McColl-Kennedy, J. R., \& Sweeney, J. C. (2011). Reconceptualizing professional service firm innovation capability: Scale development. Industrial Marketing Management, 40, 1264-1273.

Hoque, Z. (2008). Measuring and reporting public sector outputs/outcomes: exploratory evidence from Australia. International Journal of Public Sector Management, 21(5), 468-493.

Hughes, A., Moore, K., \& Kataria, N. (2011). Innovation in Public Sector Organisations: A pilot survey for measuring innovation across the public sector. London: NESTA.

Innovation Unit (2009). An innovation index for the public sector. Final draft report. London: The Innovation Unit.

Kattel, R., Cepilovs, A., Drechsler, W., Kalvet, T., Lember, V., \& Tonurist, P. (2013). Can we measure public sector innovation? A literature review. Rotterdam: LIPSE.

Kim, S. E., \& Lee, J. W. (2009). The impact of management capacity on government innovation in Korea: An empirical study. International Public Management Journal, 12(3), 345-369. 
Koc, T. (2007). Organizational determinants of innovation capacity in software companies. Computers and Industrial Engineering, 53, 373-385.

Koch, P., \& Hauknes, J. (2005). Innovation in the Public Sector. Publin Report No. D20. Oslo: NIFU STEP.

Koch, P., Cunningham, P., Schwabsky, N., \& Hauknes, J. (2006). Innovation in the Public Sector. Publin Report No. D24. Oslo: NIFU STEP.

Kuhlman, S. (2010). Performance Measurement in European local governments: a comparative analysis of reform experiences in Great Britain, France, Sweden and Germany. International Review of Administrative Sciences, 76(2), 331-345.

Lawson, B., \& Samson, D. (2001). Developing innovation capability in organisations: A dynamic capabilities approach. International Journal of Innovation Management, 5(3), 377400 .

Laville, C., \& Dionne, J. (1999). A construção do saber: manual de metodologia da pesquisa em ciências humanas. Porto Alegre: Artmed.

Lemos, C. F. (2000). Ações premiadas no $5^{\circ}$ Concurso de Inovação na Gestão Pública Federal - Prêmio Hélio Beltrão 2000. Brasília: ENAP.

Luke, B., Verreynne, M., \& Kearins, K. (2010). Innovative and entrepreneurial activity in the public sector: the changing face of public sector institutions. Innovation: Management, Policy \& Practice, 12(2).

Menor, I. J., \& Roth, A. V. (2008). New service development competence in retail banking: construct development and measurement validation. Journal of Operation Management, 25, 825-846.

Metz, I., Terziovsky, M., \& Samson, D. (2007). Development of an integrated innovation capability model. In: Terziovsky, M., Building innovation capability in organizations: an international cross-case perspective. London: Imperial College Press, 19-50.

Micheli, P., Schoeman, M., Baxter, D., \& Goffin, K. (2012). New business models for publicsector innovation successful technological innovation for government. Research-Technology Management, 55(5), 51-57.

Miles, I. (2013). Public service innovation: what message from the collision of innovation studies and services research? In: Osborne, S. P., \& Brown, L. (Eds.), Handbook of Innovation in Public Services. Cheltenham: Edward Elgar, 73-88.

Morais, J. G. (2005). Ações Premiadas no $9^{\circ}$ Concurso de Inovação na Gestão Pública Federal 2005. Brasília: ENAP.

Mortensen, P. S. (2010). M2 - Survey Methodology. Copenhagen: MEPIN.

Mulgan, G., \& Albury, D. (2003). Innovation in the public sector. Strategy unit, Cabinet Office. 
Mulgan, G. (2007). Ready or not? Taking innovation in the public sector seriously. London: NESTA.

Mustafid, Q. Y., \& Anggadwita, G. (2013). Determining Innovation Aspect in the Performance of Public Service Sector. Journal of Social and Development Sciences, 4(8), 361-368.

NAO - National Audit Office (2009). Innovation across central government. London: HMSO.

Newcomer, K. E., \& Allen, H. (2010). Public Service Education: Adding Value in the Public Interest. Journal of Public Affairs Education, 16(2), 207-229.

Ngo, L. V., \& O'Cass, A. (2009). Creating value offerings via resource-based capabilities. Industrial Marketing Management, 38, 45-59.

Nystrom, H. (1990). Organisational innovation. In: West, M. A., \& Farr, J. L. (Eds.), Innovation and Creativity at Work: Psychological and Organisational Strategies. Oxford: John Wiley \& Sons, 143-161.

OECD - Organisation for Economic Cooperation and Development (2005). Manual de Oslo. Rio de Janeiro: FINEP/OECD.

Osborne, S. P., \& Brown, L. (2013). Introduction: innovation in public services. In: Osborne, S. P., \& Brown, L. (Eds.), Handbook of Innovation in Public Services. Cheltenham: Edward Elgar, 1-14.

Packard, T. (2010). Staff perceptions of variables affecting performance in human service organizations. Nonprofit and Voluntary Sector Quarterly, 39(6), 971-990.

Paiva, A. B., \& Araújo, F. A. G. (2004). Ações premiadas no $8^{\circ}$ Concurso de Inovação na Gestão Pública Federal 2003. Brasília: ENAP.

Pavitt, K. (1984). Sectoral patterns of technical change: towards a taxonomy and a theory. Research Policy, 13, 343-374.

Pavitt, K. (2004). Innovation Processes. In: Fargerberg, J., Mowery, D. C., \& Nelson, R. R. (Eds.), The Oxford Handbook of Innovation. Oxford: Oxord University Press, 86-114.

Peng, D. X., Schroeder, R. G., \& Shah, R. (2008). Linking routines to operations capabilities: a new perspective. Journal of Operations Management, 26(6), 730-748.

Pereira, F. S. (2013). Ações premiadas no $18^{\circ}$ Concurso de Inovação na Gestão Pública Federal 2013. Brasília: ENAP.

Petrucci, V. L., \& Rua, M. (1998). Ações premiadas no $1^{o}$ Concurso de Experiências Inovadoras de Gestão na Administração Pública Federal. Brasília: ENAP.

Petrucci, V. L., \& Umbelino, L. M. (1999). Ações premiadas no $3^{\circ}$ Concurso de Experiências Inovadoras de Gestão na Administração Pública Federal. Brasília: ENAP. 
Porter, M. E., \& Stern, S. (2002). National Innovative Capacity. In: The Global Competitiveness Report 2001-2002. New York: Oxford University, 102-118.

Potts, J. (2009). The innovation deficit in public services: the curious problem of too much efficiency and not enough waste and failure. Innovation: Management, Policy \& Practice, 11, 34-43.

Read, A. (2000). Determinants of successful organizational innovation: a review of current research. Journal of Management Practice, 3(1), 95-119.

Resende-Junior, P. C., \& Guimarães, T. A. (2011). Inovação em Serviços: o estado da arte e uma proposta de agenda de pesquisa. Revista Brasileira de Gestão de Negócios, 14(44), 293 313.

Romijn, H., \& Albaladejo, M. (2002). Determinants of innovation capability in small electronics and software firms. Industrial and Corporate Change, 15(4), 653-682.

Rosenberg, N., \& Nelson, R. (1994). American Universities and technical advance in industry. Research Policy, 23(3), 323-348.

Roste, R. (2004). Studies of Innovation in the Public Sector, a Theoretical Framework. Publin Report No. D16. Oslo: NIFU STEP.

Scott, J. (1990). A Matter of Record: Documentary Sources in Social Research. Cambridge: Polity Press.

Silanpää, V. (2013). Measuring the impacts of welfare service innovations. International Journal of Productivity and Performance Management, 62(5), 474-489.

Soete, L., \& Miozzo, M. (1989). Trade and Development in Services: a Technological Perspective. Maastricht Economic Research Institute on Innovation and Technology (MERIT), Working paper 89-031.

Smith, M. K., Busi, M., Ball, P. D., \& Mer, R., van der (2008). Factors influencing an organisation's ability to manage innovation: a structured literature review and conceptual model. International Journal of Innovation Management, 12(4), 655-676.

Sundbo, J. (2003). Innovation and strategic reflexivity: an evolutionary approach applied to services. In: Shavinina, L. V. (Org.), The international handbook on innovation. Oxford: Elsevier Science, 97-114.

Sundbo, J., Orfila-Sintes, F., \& Sorensen, F. (2007). The innovative behaviour of tourism firms - comparative studies of Denmark and Spain. Research Policy, 36, 558-567.

Tang, H. K. (1998). An integrative model of innovation in organizations. Technovation, 18(5), 297-309.

Tidd, J., Bessant, J., \& Pavitt, K. (1997). Managing innovation: integrating technological, market and organizational change. West Sussex: John Wiley \& Sons. 
Tidd, J., \& Hull, F. M. (2006). Managing service innovation: the need for selectivity rather than 'best practice'. New Technology, Work and Employment, 21(2), 139-161.

Uchupalanan, K. (2000). Competition and IT-based innovation in banking services. International Journal of Innovation Management, 4, 455-459.

Valladares, P. S. D. de A., Vasconcellos, M. A. de, \& Di Serio, L. C. (2014). Capacidade de Inovação: Revisão Sistemática da Literatura. Revista de Administração Contemporânea, 18(5), 598-626.

Vergara, S. C. (2005). Métodos de pesquisa em administração. São Paulo: Atlas.

Viogda-Gadot, E., Shoham, A., Schwabsky, N., \& Ruvio, A. (2008). Public Sector Innovation for Europe: A Multinational Eight-Country Exploration of Citizens' Perspective. Public Administration, 86(2), 307-329.

Walker, R. M. (2006). An empirical evaluation of innovation types and diffusion: an empirical analysis of local government. Public Administration, 84(2), 311-335.

Walker, R. M. (2007). An empirical evaluation of innovation types and organizational and environmental characteristics: towards a configuration framework. Journal of Public Administration Research and Theory, 18(4), 591-615.

Walker, R. M., Damanpour, F., \& Devece, C. A. (2010). Management innovation and organizational performance: the mediating effect of performance management. Journal of Public Administration Research and Theory, doi:10.1093/jopart/muq043.

Weewardena, J., \& McColl-Kennedy, J. R. (2002). New service development and competitive advantage: A conceptual model. Australasian Marketing Journal, 10(1), 13-23.

Weerawardena, J., \& O'Cass, A. (2004). Exploring the characteristics of the market-driven firms and antecedents to sustained competitive advantage. Industrial Marketing Management, $33(5), 419-428$.

Windrum, P. (2008). Innovation and entrepreneurship in public services. In: Windrum, P., \& Koch, P. (Eds.), Innovation in Public Sector Services - Entrepreneurship, Creativity and Management. Cheltenham: Edward Elgar.

Windrum, P., \& Garcia-Goni, M. (2008). A neo-Schumpeterian model of health services innovation. Research Policy, 37, 649-672.

$\mathrm{Xu}, \mathrm{Z} ., \mathrm{Lin}, \mathrm{J} ., \quad \&$ Lin, D. (2008). Networking and innovation in SMEs: Evidence from Guagdong Province, China. Journal of Small Business and Enterprise Development, 15(4), 788-801.

Yen, H. R., Wang, W., Wei, C. P., Hsu, S. H. Y., \& Chiu, H. C. (2012). Service innovation readiness: Dimensions and performance outcome. Decision Support Systems, 53(4), 813-824. 


\section{ANEXOS}

\section{Anexo A - Protocolo para coleta e codificação de informações}

\begin{tabular}{|c|c|c|}
\hline \multicolumn{3}{|c|}{ TIPOS DE INOVAÇÃO } \\
\hline Categorias & Definição & Referência \\
\hline Produto & $\begin{array}{c}\text { Introdução de um bem ou serviço novo ou } \\
\text { significativamente melhorado comparado com os serviços } \\
\text { e bens já existentes na organização }\end{array}$ & Bloch (2011) \\
\hline Processo & $\begin{array}{l}\text { Implementação de um método de produção ou entrega de } \\
\text { serviços ou bens novo ou significativamente melhorado } \\
\text { comparado com os processos já existentes na organização }\end{array}$ & Bloch (2011) \\
\hline Comunicação & $\begin{array}{c}\text { Implementação de um novo método de promoção da } \\
\text { organização ou de seus serviços e bens, ou novos métodos } \\
\text { para influenciar o comportamento de indivíduos ou outras } \\
\text { organizações }\end{array}$ & Bloch (2011) \\
\hline Organizacional & $\begin{array}{c}\text { Implementação de um novo método organizacional ou } \\
\text { gerencial que difere significativamente dos métodos já } \\
\text { existentes na organização }\end{array}$ & Bloch (2011) \\
\hline \multicolumn{3}{|c|}{ CAPACIDADES DE INOVAÇÃO } \\
\hline Categoria & Definição & Referência \\
\hline $\begin{array}{l}\text { Liderança } \\
\text { transformadora }\end{array}$ & $\begin{array}{c}\text { Aquela que torna seus seguidores mais conscientes da } \\
\text { importância e do valor do trabalho, ativa suas necessidades } \\
\text { de ordem superior, e os induz a transcender seus interesses } \\
\text { pessoais em prol da organização }\end{array}$ & Valladares et al. (2014) \\
\hline $\begin{array}{l}\text { Intenção } \\
\text { estratégica de } \\
\text { inovar }\end{array}$ & $\begin{array}{l}\text { Grau que a organização está disposta a assumir riscos para } \\
\text { favorecer a mudança, o desenvolvimento tecnológico e a } \\
\text { inovação, estabelecendo-os por meio de sua estratégia }\end{array}$ & Valladares et al. (2014) \\
\hline $\begin{array}{l}\text { Gestão de pessoas } \\
\text { para inovação }\end{array}$ & $\begin{array}{l}\text { Orientação da gestão de pessoas para a inovação, provendo } \\
\text { a concessão de liberdade ou autonomia de atuação aos } \\
\text { empregados, estabelecendo metas desafiadoras, permitindo } \\
\text { que decidam como alcança-las e favorecendo a } \\
\text { autorrealização e o comprometimento com os objetivos da } \\
\text { organização }\end{array}$ & Valladares et al. (2014) \\
\hline $\begin{array}{l}\text { Conhecimento do } \\
\text { usuário e do } \\
\text { ambiente }\end{array}$ & $\begin{array}{l}\text { Habilidade para detectar os eventos, necessidades, } \\
\text { expectativas, mudanças significativas e tendências dos } \\
\text { usuários e do ambiente }\end{array}$ & Valladares et al. (2014) \\
\hline $\begin{array}{l}\text { Gestão estratégica } \\
\text { da tecnologia }\end{array}$ & $\begin{array}{l}\text { Gestão do processo de criação e desenvolvimento de } \\
\text { tecnologias, visando à criação de valor. O processo de } \\
\text { gestão tecnológica compreende cinco etapas: identificação, } \\
\text { seleção, aquisição, exploração e proteção }\end{array}$ & Valladares et al. (2014) \\
\hline $\begin{array}{l}\text { Organicidade da } \\
\text { estrutura } \\
\text { organizacional }\end{array}$ & $\begin{array}{l}\text { Grau em que a estrutura é caracterizada pela concessão de } \\
\text { autonomia, controles flexíveis, comunicação horizontal } \\
\text { desimpedida, valorização do conhecimento e da } \\
\text { experiência e informalidade nas relações pessoais. } \\
\text { Estrutura ditas orgânicas permitem resposta mais rápida às } \\
\text { mudanças no ambiente externo do que as denominadas } \\
\text { mecanicistas }\end{array}$ & Valladares et al. (2014) \\
\hline $\begin{array}{l}\text { Gestão de } \\
\text { projetos }\end{array}$ & $\begin{array}{c}\text { Planejamento, provisão dos recursos, execução e controle } \\
\text { do processo de inovação. Inclui cuidadosa avaliação dos } \\
\text { projetos, análise e planejamento visando, principalmente, } \\
\text { ganhar compreensão, compromisso e apoio tanto } \\
\text { corporativo quanto do pessoal que estará envolvido no } \\
\text { projeto } \\
\end{array}$ & Valladares et al. (2014) \\
\hline & INDUTORES DE INOVAÇÃO & \\
\hline
\end{tabular}




\begin{tabular}{|c|c|c|}
\hline Categoria & Definição & Referências \\
\hline $\begin{array}{l}\text { Orientado a } \\
\text { problema }\end{array}$ & $\begin{array}{c}\text { Introdução de inovações para responder a um ou mais } \\
\text { problemas específicos, tais como fatores demográficos, } \\
\text { envelhecimento da população, obesidade infantil, entre } \\
\text { outros }\end{array}$ & Koch e Hauknes (2005) \\
\hline $\begin{array}{l}\text { Não orientado a } \\
\text { problema }\end{array}$ & $\begin{array}{l}\text { Necessidade de melhorias em relação a uma situação } \\
\text { anterior em vez do tratamento de um problema específico }\end{array}$ & Koch e Hauknes (2005) \\
\hline Impulso político & $\begin{array}{l}\text { Mudanças estratégicas no serviço público que requerem } \\
\text { decisões fortes do topo par a base. Pode ser baseada em } \\
\text { ideologia ou em resposta a eventos críticos e pressões e } \\
\text { também pode se refletir através da imposição de metas de } \\
\text { desempenho }\end{array}$ & Koch e Hauknes (2005) \\
\hline Imposição legal & $\begin{array}{l}\text { Criação de regulação, lei, decreto, emenda constitucional } \\
\text { ou ação governamental que induzem inovação }\end{array}$ & $\begin{array}{l}\text { Halvorsen } \text { et al. (2005), } \\
\text { Agolla e Lill (2013) }\end{array}$ \\
\hline $\begin{array}{c}\text { Fatores } \\
\text { tecnológicos }\end{array}$ & $\begin{array}{l}\text { Surgimento ou disponibilidade de novas tecnologias que } \\
\text { proporcionam oportunidades de inovação }\end{array}$ & Koch e Hauknes (2005) \\
\hline \multicolumn{3}{|c|}{ RESULTADOS DE INOVAÇÃO } \\
\hline Categoria & Definição & Referência \\
\hline $\begin{array}{l}\text { Melhoria na } \\
\text { entrega e/ou } \\
\text { qualidade dos } \\
\text { serviços }\end{array}$ & $\begin{array}{l}\text { Impactos positivos sobre os mecanismos de entrega de } \\
\text { serviços e/ou nos próprios serviços, incluindo aumento da } \\
\text { satisfação e do envolvimento dos usuários }\end{array}$ & $\begin{array}{c}\text { Carter e Belanger (2005), } \\
\text { Hipp e Grupp (2005), } \\
\text { Newcomer e Allen } \\
\text { (2010), Bloch (2011), } \\
\text { Bugge et al. }(2011), \\
\text { Hughes } \text { et al. }(2011), \\
\text { Mustafid e Grisma } \\
\text { (2013), De Vries } \text { et al. } \\
\text { (2014) }\end{array}$ \\
\hline $\begin{array}{l}\text { Melhoria da } \\
\text { gestão } \\
\text { organizacional }\end{array}$ & $\begin{array}{l}\text { Impactos positivos sobre a eficiência e efetividade da } \\
\text { organização, incluindo ganhos de produtividade e } \\
\text { melhores resultados em indicadores de desempenho }\end{array}$ & $\begin{array}{c}\text { Albury (2005), Hipp e } \\
\text { Grupp (2005), Kim \& } \\
\text { Lee (2009), Newcomer e } \\
\text { Allen (2010), Bloch } \\
\text { (2011), Bugge et al. } \\
\text { (2011), Hughes } \text { et al. } \\
\text { (2011), Mustafid e } \\
\text { Grisma (2013), De Vries } \\
\text { et al. }(2014)\end{array}$ \\
\hline $\begin{array}{l}\text { Melhoria da } \\
\text { imagem e } \\
\text { relações } \\
\text { institucionais }\end{array}$ & $\begin{array}{l}\text { Impactos positivos sobre a imagem da organização e no } \\
\text { relacionamento com outras organizações, incluindo } \\
\text { melhoria na capacidade de resolução de desafios sociais, } \\
\text { aumento do prestígio da organização e envolvimento de } \\
\text { parceiros. }\end{array}$ & $\begin{array}{c}\text { Newcomer e Allen } \\
\text { (2010), Bloch (2011), } \\
\text { Bugge et al. }(2011), \\
\text { Mustafid e Grisma } \\
\text { (2013), De Vries } \text { et al. } \\
\text { (2014) }\end{array}$ \\
\hline $\begin{array}{l}\text { Melhoria do clima } \\
\text { organizacional }\end{array}$ & $\begin{array}{l}\text { Impactos positivos sobre o clima da organização, incluindo } \\
\text { melhorias nas condições de trabalho, satisfação dos } \\
\text { colaboradores e aprimoramento da cultura de inovação. }\end{array}$ & $\begin{array}{l}\text { Bloch (2011), Bugge et } \\
\text { al. (2011), Mustafid e } \\
\text { Grisma (2013) }\end{array}$ \\
\hline
\end{tabular}


Anexo B - Modelo de tabela para coleta e codificação de informações

\begin{tabular}{|c|c|c|c|}
\hline \multicolumn{4}{|c|}{ (NOME DA ORGANIZAÇÃO) } \\
\hline \multicolumn{4}{|c|}{ (MINISTÉRIO A QUAL ESTÁ VINCULADA) } \\
\hline \multicolumn{4}{|c|}{ (TÍTULO DA EXPERIÊNCIA) } \\
\hline $\begin{array}{l}\text { TIPOS DE } \\
\text { INOVAÇÃ }\end{array}$ & $\begin{array}{c}\text { IDENTIFICADO } \\
(\text { SIM/NÃO) }\end{array}$ & TRECHO DO RELATO & $\begin{array}{c}\text { TERMO DE } \\
\text { IDENTIFICAÇÃO }\end{array}$ \\
\hline \multicolumn{4}{|l|}{ Produto } \\
\hline \multicolumn{4}{|l|}{ Processo } \\
\hline \multicolumn{4}{|l|}{ Comunicação } \\
\hline \multicolumn{4}{|l|}{ Organizacional } \\
\hline $\begin{array}{l}\text { CAPACIDADES DE } \\
\text { INOVAÇÃO }\end{array}$ & $\begin{array}{c}\text { IDENTIFICADO } \\
\text { (SIM/NÃO) }\end{array}$ & TRECHO DO RELATO & $\begin{array}{c}\text { TERMO DE } \\
\text { IDENTIFICAÇÃO }\end{array}$ \\
\hline \multicolumn{4}{|l|}{$\begin{array}{c}\text { Liderança } \\
\text { transformadora }\end{array}$} \\
\hline \multicolumn{4}{|l|}{$\begin{array}{c}\text { Intenção estratégica de } \\
\text { inovar }\end{array}$} \\
\hline \multicolumn{4}{|l|}{$\begin{array}{c}\text { Gestão de pessoas para } \\
\text { inovação }\end{array}$} \\
\hline \multicolumn{4}{|l|}{$\begin{array}{c}\text { Conhecimento do } \\
\text { usuário e do ambiente }\end{array}$} \\
\hline \multicolumn{4}{|l|}{$\begin{array}{c}\text { Gestão estratégica da } \\
\text { tecnologia }\end{array}$} \\
\hline \multicolumn{4}{|l|}{$\begin{array}{c}\text { Organicidade da } \\
\text { estrutura organizacional }\end{array}$} \\
\hline \multicolumn{4}{|l|}{ Gestão de projetos } \\
\hline $\begin{array}{l}\text { INDUTORES DE } \\
\text { INOVAÇÃO }\end{array}$ & $\begin{array}{c}\begin{array}{l}\text { IDENTIFICADO } \\
\text { (SIM/NÃO) }\end{array} \\
\end{array}$ & TRECHO DO RELATO & $\begin{array}{c}\text { TERMO DE } \\
\text { IDENTIFICAÇÃO } \\
\end{array}$ \\
\hline \multicolumn{4}{|l|}{ Orientado a problema } \\
\hline \multicolumn{4}{|l|}{$\begin{array}{c}\text { Não orientado a } \\
\text { problema }\end{array}$} \\
\hline \multicolumn{4}{|l|}{ Impulso político } \\
\hline \multicolumn{4}{|l|}{ Imposição legal } \\
\hline \multicolumn{4}{|l|}{ Fatores tecnológicos } \\
\hline $\begin{array}{l}\text { RESULTADOS DE } \\
\text { COPRODUÇÃO }\end{array}$ & $\begin{array}{c}\begin{array}{l}\text { IDENTIFICADO } \\
\text { (SIM/NÃO) }\end{array} \\
\end{array}$ & TRECHO DO RELATO & $\begin{array}{c}\text { TERMO DE } \\
\text { IDENTIFICAÇÃO } \\
\end{array}$ \\
\hline \multicolumn{4}{|l|}{$\begin{array}{l}\text { Melhoria na entrega e/ou } \\
\text { qualidade dos serviços }\end{array}$} \\
\hline \multicolumn{4}{|l|}{$\begin{array}{c}\text { Melhoria da gestão } \\
\text { organizacional }\end{array}$} \\
\hline \multicolumn{4}{|l|}{$\begin{array}{l}\text { Melhoria da imagem e } \\
\text { relações institucionais }\end{array}$} \\
\hline $\begin{array}{c}\text { Melhoria do clima } \\
\text { organizacional }\end{array}$ & & & \\
\hline
\end{tabular}

